\title{
Nombres amerindios de las palmas (Palmae) de Colombia
}

\author{
Amerindian names of Colombian palms (Palmae)
}

\author{
Diana Marmolejo', María Emilia Montes ${ }^{1}$, Rodrigo Bernal $^{2}$
}

1 Departamento de Lingüística, Universidad Nacional de Colombia, Bogotá, Colombia. dmarmolejo@ unal.edu.co,memontesr@unal. du co

2 Instituto de Ciencias Naturales, Universidad Nacional de Colombia, Apartado 7495, Bogotá, Colombia. rgbernalg@unal.edu.co

\begin{abstract}
Trabajo presentado al Simposio Internacional "LAS PALMERAS EN EL MARCO DE LA INVESTIGACIÓN PARA EL DESARRollo EN AMÉRICA del SUR", del 07 al 09 de Noviembre 2007, Museo de Historia Natural, Universidad Nacional Mayor de San Marcos, Lima, Perú.
\end{abstract}

Publicado online: 29/11/2008

\section{Resumen}

Se presenta un glosario de 1276 nombres o variantes de nombres indígenas de palmas, correspondientes a por lo menos 121 especies, en 64 lenguas aborígenes de Colombia. Las especies con nombres en mayor número de lenguas son Bactris gasipaes, Oenocarpus bataua, Mauritia flexuosa, Euterpe precatoria y Astrocaryum chambira, cinco de las palmas más utilizadas en Suramérica. Las lenguas con mayor número de especies designadas son uitoto (48), tikuna (47), muinane (43), siona (34), sikuani (31) y miraña (30). Estas cifras reflejan los estudios detallados que se han hecho con estas etnias, además de la diversidad de palmas en sus territorios o su conocimiento de ellas. Los nombres se presentan ordenados de tres maneras diferentes: por especie, por lengua y una lista global de nombres, que incluye las referencias de cada registro.

Palabras clave: Colombia, fitónimos, lenguas amerindias, nombres amerindios, Arecaceae.

\section{Abstract}

A glossary of 1276 Amerindian names or name variants of palms is presented, representing at least 121 species in 64 aboriginal languages of Colombia. The species with documented names in the largest number of languages are Bactris gasipaes, Oenocarpus bataua, Mauritia flexuosa, Euterpe precatoria, and Astrocaryum chambira, which are five of the most used palms in South America. The languages with the largest number of named species are uitoto (48), tikuna (47), muinane (43), siona (34), sikuani (31) and miraña (30). These figures reflect the detailed studies carried out with these ethnic groups, besides the palm diversity of their territories and their knowledge about it. The names are presented in three separate lists -arranged by species, by language, and a global list of names that includes references for each individual record.

Keywords: Colombia, phytonyms, Amerindian languages, Amerindian names, Arecaceae.

\section{Introducción}

El estudio de los nombres comunes de las plantas es una poderosa herramienta para ayudar a entender las migraciones de los pueblos y de las especies vegetales asociadas (Al Azharia Jahn, 2005); para descubrir los usos antiguos de los ecosistemas y los procesos de domesticación de las especies (Bernal et al., 2007, Clement et al., en imprenta); e incluso para acercarse a la psicología cognitiva de los pueblos (Scarlat, 2004; Montes, 1983) y a la evolución misma de las lenguas (Montes, 1978). Pero a pesar de esta importancia, el estudio de los fitónimos ha recibido relativamente poca atención, y apenas si existen algunos trabajos de fitonimias comparadas entre lenguas (v. gr. Balée $\&$ Moore, 1991).

Las palmas son un grupo ideal para el estudio de fitonimias comparadas, pues son quizás las plantas más importantes para muchos de los pueblos indígenas americanos (Henderson et al., 1995), una importancia que viene, en muchos casos, desde hace más de 9000 ańos (Morcote $\&$ Bernal, 2001). Debido a su uso, muchas de las especies son bien conocidas en las regiones donde crecen, y reciben nombres comunes que a menudo son únicos y precisos.

Sin embargo, el estudio lingüístico-botánico de estos nombres se ha visto obstaculizado hasta ahora por la falta de una adecuada recopilación de la información, que se encuentra dispersa en la literatura botánica, etnográfica, histórica y lingüística, lo mismo que en los especímenes botánicos que se conservan en los herbarios. Los nombres de estas fuentes tienen dos grandes debilidades: por una parte, los que han sido tomados por botánicos, en general no transcriben de manera muy precisa la fonética de los vocablos, lo que a veces hace casi irreconocible el nombre documentado, dificultando su comparación; por otra parte, los nombres que han sido tomados por lingüistas, a menudo no están asociados a un nombre científico que permita establecer de manera inequívoca la identidad de la planta.
En Colombia se encuentran 230 especies de palmas (Bernal \& Galeano 2006; Bernal \& Galeano, datos inéditos) y entre 64 y 81 lenguas indígenas (Rodríguez de Montes, 1993; SIL International, 2008), dependiendo del criterio que se siga. Aunque algunas etnias, como los wayuu de la Guajira, habitan en zonas pobres en palmas, otras, como las de la costa del Pacífico y el piedemonte amazónico, habitan en unos de los ecosistemas más ricos en palmas en todo el planeta. En general, la mayoría de los pueblos indígenas de Colombia habita en áreas ricas en palmas. Así pues, la fitonimia indígena de las palmas colombianas es extensa.

El presente trabajo recopila los nombres indígenas de las palmas nativas de Colombia documentados en la literatura y en otras fuentes. Incluye, además, numerosos nombres tomados directamente por nosotros mediante entrevistas con hablantes de varias lenguas; en muchos casos, estos nombres, tomados simultáneamente con criterio lingüístico y botánico, han servido de base para interpretar algunos de los fitónimos encontrados en las fuentes consultadas.

Este artículo hace parte de una investigación a largo plazo sobre los nombres indígenas de las palmas en América, en el que hemos trabajado desde 2003 (Marmolejo et al., 2004). En la actualidad, nuestra base de datos cuenta con 5151 registros, que comprenden nombres en 215 lenguas y designan 292 especies, es decir, casi la mitad de las palmas que se conocen en América. La región mejor documentada hasta ahora en nuestra base de datos es Colombia, y por esa razón presentamos ahora esta lista.

\section{Materiales y métodos}

Se tomaron los nombres citados de floras y monografías botánicas, trabajos etnográficos y antropológicos, y gramáticas y diccionarios de lenguas indígenas colombianas. Así mismo, se incluyeron los nombres conservados en el Centro Colombiano para el Estudio de las Lenguas Aborígenes, CCELA, de 
la Universidad de Los Andes (la mayoría de ellos en listados inéditos) y en los especímenes del Herbario Nacional Colombiano (COL). Para el caso de etnias binacionales, se tomaron los nombres documentados en países vecinos, para etnias que también habitan en Colombia. Adicionalmente se obtuvieron nombres directamente mediante entrevistas, casi siempre en el campo, con hablantes de las lenguas cubeo, curripaco, desano, embera, kakua, piapoco, piratapuyo, puinave, sikuani, tariano, tikuna, tukano, tuyuca, wanano, waunana y yukuna.

La identificación de los nombres citados en las fuentes, cuando no había especímenes u otros elementos, se basó, cuando fue posible, en el nombre asociado en español, cuando éste estaba presente y se trataba de un nombre de aplicación inequívoca; en algunos casos recurrimos a otros registros de la misma lengua para corroborar las identificaciones.

Los nombres de las fuentes en algunos casos debieron ser reescritos por nosotros a partir de una ortografía ad hoc: una versión simplificada de una escritura mixta de tipo fonético y ortográfico. Otra opción habría sido conservar los datos como estaban en las fuentes y agregar cada vez notas explicativas; pero éstas habrían sido excesivas y el resultado no hubiese tenido los mismos efectos de comparabilidad. En los casos en los que hemos reescrito los nombres, conservamos también en nuestra base de datos la forma original que aparecía en la fuente, pero esas transcripciones originales no se presentan aquí, salvo en algunos pocos casos, en aras de la simplicidad. En vez de esto se da, para cada nombre, la referencia a la fuente de donde se tomó.

Dado que varias lenguas indígenas tienen ortografías normalizadas, acudimos a esos grafemas para las vocales y consonantes exclusivas de esas lenguas. Así pues, el material disponible es heterogéneo: escrituras fonéticas o fonológicas de lingüistas; propuestas ortográficas de materiales del ILV (Instituto Lingüístico de Verano/Summer Institute of Linguistics, SIL); y grafías propias de cada investigador biólogo o antropólogo (y por ello con sesgo de las lenguas nativas de los recolectores). Por otra parte, los autores no siempre explican satisfactoriamente sus convenciones. Por esta razón, consultamos en cada caso las obras disponibles para tomar algunas decisiones con base en la fonología de las lenguas, cuando sobre ello hay estudios; en algunos casos se hacen anotaciones sobre la transcripción.

El conocimiento certero de las estructuras y sonidos de todas las lenguas amerindias está lejos de ser un hecho cumplido. Sobre algunas lenguas hay buenos estudios y ortografías acordadas por los hablantes; sobre otras hay conocimientos parciales, debates en curso y propuestas ortográficas fluctuantes; muchas lenguas aún no se escriben.

De todas formas la plena confiabilidad de los datos requeriría una confrontación exhaustiva en todas las lenguas, con equipos en los que haya hablantes nativos, lingüistas y botánicos. Pero hay datos de lenguas recientemente desaparecidas (como el tinigua y el carijona) y datos históricos que no podrán ya ser verificados.

En la transcripción de los nombres, las letras o combinaciones de letras $a, b, c h, d, e, f, i, k, l, m, n, \tilde{n}, o, p, r, r r, s, t$, $u, w, y$, representan sonidos semejantes a los que representan en español. Para la transcripción de otros sonidos, usamos los siguientes símbolos:

\section{(') Tono bajo.}

(') Tono alto o acento (Varias lenguas amazónicas, especialmente en las familias Tukano y Makú, y otras lenguas como andoque, bora, miraña, muinane y tikuna, son lenguas tonales -como el chino- con dos o más tonos distintivos; sin embargo pocos transcriptores toman en cuenta esta complejidad prosódica que diferencia significados).

( ) Vocal nasal (puesto encima de la vocal, o a su derecha).

(ä) Vocal abierta, posterior, deslabializada (similar a la vocal de 'hot' en inglés); se encuentra en waunana.

(ë), (ö) Vocales abiertas similares a las vocales abiertas del portugués y del francés; se encuentran en kakua, (familia Makú). En piaroa los datos traen los símbolos ä, ö, ü’ para los cuales no logramos establecer un equivalente.

(i) Vocal central, deslabializada, cerrada (como la segunda vocal en la pronunciación de las palabras inglesas 'oxen' o 'table'); es la sexta vocal de las ortografías de lenguas de la familia Tukano y del uitoto, entre otras.

(ü) Vocal posterior deslabializada cerrada (se pronuncia como una 'u', con los labios planos); se postula como la sexta vocal en tikuna, y existe también en miraña, waunana, embera, sikuani y lenguas de la familia Makú. Algunos textos sikuani -y las fuentes aquí consultadas- aparentemente transcriben esta vocal como 'ẹ'.

(ə) Vocal central neutra (pronunciación similar a la vocal final en la palabra 'the' en inglés); presente en lenguas de la familia Makú, en ika (lengua de familia Chibcha de la Sierra Nevada de Santa Marta) y en carijona (familia Caribe).

$\left(\mathrm{a}^{\mathrm{h}}, \mathrm{o}^{\mathrm{h}}, \mathrm{u}^{\mathrm{h}} \ldots\right)$ Vocales post-aspiradas en desano, tukano, tuyuca y wanano (familia Tukano). Aunque se discute sobre el valor fonológico de esta post-aspiración vocálica, algunas grafías la conservan.

(a', e', o'...) Vocales interruptas (con final abrupto), como en nukak.

(c) En algunas lenguas los transcriptores usan esta letra para sonidos sin equivalente en espańol. En muinane parece haberse usado para un sonido retroflejo palatoalveolar oclusivo (un sonido producido reteniendo el paso del aire con la punta de la lengua vuelta hacia atrás, haciendo contacto un poco más atrás del área velar). Las ortografías del ILV para lenguas indígenas a menudo copian desacertadamente la ortografía castellana (ca, $\mathrm{co}, \mathrm{cu}$, que, qui) en este punto problemático. Los transcriptores hispanohablantes no lingüistas también recurren con frecuencia a la ortografía castellana en este punto.

(dy) Sonidos cercanos a la pronunciación francesa de 'g' en 'manger'.

(g) Oclusiva velar sonora (como la g en 'gato' o la combinación gu en 'guerra').

(h) Fricativa glotal sorda ( $\mathfrak{j}$ ' del español latinoamericano y 'h' del inglés').

(Il) Salvo en un dato del páez, este sonido no correspondería al sonido español de 'll' (lateral palatal); más bien parece una forma alterna usada por los transcriptores para consonantes sonoras palatales de diverso tipo, como la 'y' inicial o intervocálica del 
español; o quizá represente otros sonidos del área alveolopalatal (similares a la inicial de 'june' en algunos dialectos del inglés y a la inicial del francés en 'je' o 'jeune'). En muinane y sáliba la hemos conservado como está en la fuente, dada la dificultad de establecer la pronunciación precisa que el transcriptor pretende representar.

(sh) Sonido fricativo sordo igual al del inglés 'she’ o al del francés 'chanter'

$\left(\mathrm{t}^{\mathrm{y}}\right)_{\mathbf{O}}\left(\mathrm{t}^{\mathrm{j}}\right)$ Representa palatalización; aparece en los datos de muinane, bora y yujup.

(ts) La sucesión, en una sola articulación, de 't' y 's'

(v) Labiodental, fricativa (como en inglés o francés) o aproximante (es decir, mucho más suave que una fricativa, acercándose a una pronunciación vocálica); se presenta en koreguaje y cofán

(x) Velar fricativa sorda (como la 'j’ fuerte de algunos dialectos del español); aparece en guayabero y en kogui

(z) Representa diversos sonidos de tipo alveolar, sonoros o sordos, no siempre bien establecidos. Aparece en cofán, miraña, piapoco, puinave, uitoto y tinigua. En propuestas ortográficas de uno de los dialectos uitotos, ' $\mathrm{z}$ ' representa una consonante interdental sorda como la del español de España en 'zapato' o la 'th' del inglés en 'think'; es posible que sea también ése el sonido que representa en cofán. En otras lenguas aparentemente se usa para representar la fricativa sonora, la 'z' del francés y del inglés.

$\left(\mathrm{p}^{\mathrm{h}}, \mathrm{t}^{\mathrm{h}}, \mathrm{k}^{\mathrm{h}} \ldots\right)$ Consonantes post-aspiradas. Se pronuncian como las consonantes oclusivas sordas del inglés, cuando van seguidas de vocal ('pen', 'ten', 'car').

Para el tratamiento de las especies, hemos omitido las categorías infraespecíficas. Para la denominación de las lenguas, al igual que para su circunscripción, seguimos, con leves modificaciones, a Rodríguez de Montes (1993), quien reconoce 64 lenguas aborígenes en Colombia. En esa obra y en Ethnologue (SIL International 2008) se pueden encontrar las otras denominaciones que se han aplicado en el pasado a cada lengua.

\section{Resultados}

Se han recopilado en total 1276 nombres o variantes de nombres de palmas en 64 lenguas indígenas colombianas. Estos nombres designan 121 especies, es decir alrededor del $53 \%$ de todas las especies de palmas conocidas hasta ahora en el país. En la tabla 1 se presentan las especies para las cuales se han documentado nombres en más de 10 lenguas. En la tabla 2 se presentan las lenguas que tienen 20 o más especies de palmas identificadas, para las cuales se ha documentado nombre común.

En los apéndices 1 a 3 presentamos la información en tres listas separadas: el apéndice 1 presenta una lista alfabética de las especies de palmas, seguida de algunos de los nombres comunes con los que se conoce en español, y presentando a continuación los nombres indígenas que se conocen para esa especie, en orden alfabético de lenguas, y dentro de cada lengua. El apéndice 2 presenta una lista ordenada alfabéticamente por etnias, en la que se da para cada etnia una lista de los nombres documentados, seguido cada uno, entre paréntesis, por el nombre científico de la especie. Finalmente, el apéndice 3 presenta la lista global de todos los nombres, seguido cada uno del nombre científico de la palma, la lengua en la que se aplica y la fuente de donde hemos tomado la información. La presentación de la información en tres apéndices separados permite hacer uso de ella de una manera más fácil que si se presentara solo la lista global de nombres.

Muchas veces hay, en las tres listas, varias entradas diferentes para una misma especie en una misma lengua. Estas entradas corresponden a las diferentes variantes de transcripción que hemos encontrado en las fuentes, y las cuales hemos considerado prematuro unificar.

Para efectos del ordenamiento de los nombres no se han tomado en cuenta los signos diacríticos, como tampoco se han tenido en cuenta las marcas de nazalización, de tono o de acento; así, la letra ñ va intercalada con la n, y las vocales ä, ë, $\dot{\mathrm{t}}, \ddot{o}$, ü van intercaladas con a, e, i, o, u; las marcas de aspiración $\mathrm{a}^{\mathrm{h},} \mathrm{p}^{\mathrm{h},}$ etc., se han considerado como h; la combinación rr, aunque representa por sí sola un sonido, se toma como dos r; la vocal ə va al final del alfabeto, después de la z.

\section{Discusión}

Las especies registradas con mayor número de nombres hasta ahora (Tabla 1), son algunas de las palmas más utilizadas en América: el chontaduro (Bactris gasipaes) con nombre en 45 lenguas, el milpesos o seje (Oenocarpus bataua), en 43 lenguas, el moriche o canangucho (Mauritia flexuosa), en 39 lenguas, el asai (Euterpe precatoria), en 35 lenguas, y el cumare o chambira (Astrocaryum chambira), en 30 lenguas. Las evidencias arqueológicas muestran que algunas de estas especies, como Oenocarpus bataua, Mauritia flexuosa y Astrocaryum chambira, han sido utilizadas por los humanos desde hace más de 9000 años. Por otra parte, la mayoría de las palmas con nombres en muchas lenguas son especies de amplia distribución geográfica en el neotrópico o,

Tabla 1. Especies de palmas colombianas con nombre documentado en más de 10 lenguas aborígenes.

\begin{tabular}{lc}
\hline \multicolumn{1}{c}{ Especie } & $\begin{array}{c}\text { N. }{ }^{\circ} \text { de lenguas con nombre } \\
\text { documentado }\end{array}$ \\
\hline Bactris gasipaes & 45 \\
Oenocarpus bataua & 43 \\
Mauritia flexuosa & 39 \\
Euterpe precatoria & 35 \\
Astrocaryum chambira & 30 \\
Socratea exorrhiza & 29 \\
Iriartea deltoidea & 27 \\
Attalea maripa & 25 \\
Oenocarpus bacaba & 23 \\
Iriartella setigera & 21 \\
Mauritia carana & 16 \\
Astrocaryum jauari & 15 \\
Attalea butyracea & 15 \\
Manicaria saccifera & 15 \\
Lepidocaryum tenue & 14 \\
Cocos nucifera & 13 \\
Mauritiella armata & 13 \\
Oenocarpus minor & 13 \\
Attalea racemosa & 12 \\
Astrocaryum gynacanthum & 11
\end{tabular}


Tabla 2. Lenguas colombianas en las que se han documentado nombres comunes para 20 o más especies de palmas.

\begin{tabular}{ll}
\hline Lengua & N. ${ }^{\circ}$ de especies identificadas \\
\hline Uitoto & 48 \\
Tikuna & 47 \\
Muinane & 43 \\
Siona & 34 \\
Sikuani & 31 \\
Miraña & 30 \\
Embera & 28 \\
Cofán & 25 \\
Wanano & 25 \\
Curripaco & 20 \\
Tukano & 20 \\
Yukuna & 20 \\
\hline
\end{tabular}

si tienen distribución más restringida (v. gr. Mauritia carana), entonces crecen en áreas de alta diversidad lingüística.

Por su parte, las lenguas con mayor cantidad de especies designadas (Tabla 2) son uitoto (48 especies), tikuna (47), muinane (43), siona (34), sikuani (31) y miraña (30). La riqueza de nombres de estas lenguas refleja, por una parte, la gran diversidad de palmas que existe en el territorio que estas etnias ocupan; por otra parte refleja la mejor documentación que existe sobre ellas. En particular, la gran proliferación de nombres en estas lenguas refleja los estudios detallados de Galeano (1991; uitoto, muinane, miraña), Prado (2008; tikuna), Kronik et al. (1999; muinane) Balslev et al. (1997; siona) y Sánchez (1989; sikuani). Para muchas etnias que habitan en territorios ricos en palmas, la información disponible es todavía escasa. En muchos casos se tienen sólo listas de especies que no ha sido posible identificar, por falta de elementos asociados en la fuente original.

Pero incluso para las especies identificadas, en la mayoría de los casos no hay información que permita interpretar los nombres para conocer su significado o saber si se trata de nombres literales. Esta información es fundamental para estudios comparativos, y a menudo permite entender también los procesos de apropiación o transferencia de las especies o de sus nombres.

En varias de las lenguas estudiadas se encuentran clasificadores usados como sufijo, que llevan la connotación de 'palma'. En algunos casos el uso de estos clasificadores parece ser optativo, en tanto que en otros casos parece ser un componente integral del nombre. Los hemos identificado en tres familias lingüísticas: en la familia Arawak el clasificador es bai o pai en achagua (churúbai, kushibai, makúpai) , y $p^{h} i, p^{h} e$ o pi en tariano (eiñap ${ }^{h} i, k u m a l i p^{b} e$, mapanariphépi, maviphi, etc.); en las lenguas de la gran familia Tukano, como el siona (Tukano Occidental), cubeo (Tukano Central) y las Tukano Oriental (barasana, desano, wanano, piratapuyo, tanimuca, siriano, tatuyo, tuyuca) el clasificador, no obligatorio, toma las formas ño, $\tilde{n} u, \tilde{n} i$ (v. gr., pót táńo, boreyabeñu, bahiñi); estas variantes pueden ser diversos alomorfos o simplemente transcripciones diferentes); en la familia Guahibo (cuiba, jitnu, sikuani) el clasificador es bot o boto (v. gr., arákbot, kóchbot, ainawiboto, ataiboto, butsiboto, etc.).

La presente recopilación es sólo un punto de partida de un proyecto ambicioso (Marmolejo et al., 2004), y la exploración de los datos apenas ha comenzado (Bernal et al., 2007; Clement et al., en imprenta). Todavía se requiere de un extenso trabajo de campo de botánicos y lingüistas, antes de que podamos empezar a aprovechar todo el potencial de información de diverso tipo que encierran los nombres amerindios de las palmas.

\section{Agradecimientos}

Agradecemos a los numerosos hablantes de las diversas lenguas, que nos han brindado información sobre las palmas y sus nombres. En particular, agradecemos a Carlos Acosta, Zeneida Acosta, Paulina Aguía, Matilde Arango, María Paula Balcázar, Cristóbal Texeira Barbosa, Jhon Batista, Victorino Bautista, Milciades Borrero, Hermana Clarisa (Javareté, Brasil), Zaleth Cordero, Jaidonesama Domicó, Arbino Furia, Luis García, Eliana Garrido, Patricia Gómez, Avelino González, Bernardita González, Emilia González, William González, Francisco Guanga, Graciliano Lima, María Montoya, Domingo Muniz, Víctor Petrucci, Marta Prado, Jorge Eliécer Restrepo, Bernardo Rodríguez, Gaudencio Rodríguez, Norma Nelly Sabana, Luz Mila Santacruz, Gustavo Trinidad, María Noemí Uribe, Azulay Vásquez, José Yepes Matapí y Elí Yukuna; a Daniel Aguirre por permitirnos acceder a los archivos del CCELA y al ILV en Bogotá por brindarnos acceso a su biblioteca lingüística; a Consuelo Vengoechea por algunas precisiones sobre sonidos y ortografías muinane; a Ana María Ospina por algunas precisiones sobre grafías de yuhup; y a Luis Fernando Jaramillo y todo el personal de la CDA en Mitú, por su apoyo en el campo.

\section{Literatura citada}

Aguirre_L. D. 1993. Cuestionario lexical CCELA. Embera-chamí. CCELA, Universidad de Los Andes, Bogotá. Inédito.

Al Azharia Jahn S. 2005. How Plant Names Reveal Folk Botanical Classification, Trade, Traditional Uses and Routes of Dissemination (I). Asian Studies. International Journal for Asian Studies 6: 81-126.

Balée W. \& D. Moore. 1991. Similarity and variation in plant names in five Tupi-Guarani languages (Eastern Amazonia) . Bull. Florida Mus. Nat. Hist. Biol. Sci. 35 (4): 209-262.

Balick M. J. 1986a. Systematics and Economic Botany of the Oenocarpus-Jessenia (Palmae) complex. Advances in Economic Botany 3:1-55.

Balick M. J. 1986b. The indigenous palm flora of "Las Gaviotas", Colombia, including observations on local names and uses. Botanical Museum Leaflets 30: 1-34.

Balslev H., M. Rios, G. Quezada \& B. Nantipa. 1997. Palmas útiles en la Cordillera de Los Huacamayos. Colección Manuales de Aprovechamiento Sustentable del Bosque. PROBONA, Quito.

Benaissa T. 1991. Vocabulario Sáliba-Español, Español-Sáliba. Editorial Alberto Lleras Camargo, Lomalinda, Meta, Colombia.

Bernal R. \& G. Galeano. 1993. Las palmas del Andes Pacífico. In: I. P. Leyva (editor). Colombia Pacífico. Fondo para la protección del Medio Ambiente "José Celestino Mutis", Bogotá. Pp. 220-231

Bernal R. \& G. Galeano. 2006. Endangerment of Colombian Palms (Arecaceae): change over 18 years. Botanical Journal of the Linnean Society 151: 151-163. 
Bernal R., M. E. Montes \& D. Marmolejo. 2007. Eastern Tukanoan names of the palm Iriartea deltoidea: an evidence of its possible preagricultural use as a starch source. Journal of Ethnobiology 27(2): 174-181.

Binder R., P. L. Harms \& C. Peña Ismare. 1995. Vocabulario Ilustrado Wounmeu-Español-Epena pedee. Tomo 2. Asociación Instituto Lingüístico de Verano. Bogotá, Colombia.

Borchsenius F., H. B. Pedersen \& H. Balslev. 1998. Manual to the Palms of Ecuador. AAU Reports 37: 1-217.

Borrero Wanana M. \& M. Pérez Correa. 2004. Mãri jiti kiti. Vaupés: Mito y realidad. Ediciones Desde Abajo, Bogotá.

Bostrom P. K. 1998. Nominalizations and relative clauses in tatuyo: a prototype approach. MA Thesis, Department of Linguistics, University of Texas at Arlington.

Buenaventura_V. E. 1993. Observaciones preliminares acerca del Idioma Macaguán. Asociación Instituto Lingüístico de Verano. Bogotá, Colombia.

Cabrera G., C. Franky \& D. Mahecha. 1999. Los nikak: nómadas de la Amazonía colombiana. Editorial Unibiblos, Universidad Nacional de Colombia, Bogotá.

Calvache_D. R. 2000. Fonología y aproximación a la morfosintaxis del awa pit. In: M. S. González de Pérez \& M. L. Rodríguez de Montes (eds.), Lenguas Indígenas de Colombia. Una visión descriptiva. Instituto Caro y Cuervo, Bogotá. Pp. 97-114.

Carbonó de la Hoz E. 1987. Estudios Etnobotánicos entre los Coguis de la Sierra Nevada de Santa Marta. Tesis de Maestría. Departamento de Biología. Universidad Nacional de Colombia, Bogotá.

Cárdenas D. \& G. Politis. 2000. Territorio, movilidad, etnobotánica y manejo del bosque de los nukak orientales. Ediciones Uniandes, Universidad de Los Andes, Bogotá.

Cerón_M. C. E. 1995. Etnobiología de los Cofanes de Dureno. Publicaciones del Museo de Ciencias Naturales, Monografía No. 3, Quito, Ecuador.

Chaumeil J. P. 1998. Ver, Saber, Poder. El chamanismo de los Yagua de la Amazonía Peruana. Centro Amazónico de Antropología y Aplicación Práctica (CAAAP)- Instituto Francés de Estudios Andinos (IFEA)-Centro Argentino de Etnología Americana (CAEA-CONICET), Lima.

Clement C. R., R. Bernal, M. E. Montes \& D. Marmolejo. (en imprenta). Origin and Diffusion of Neotropical Crops: Interactions among Linguistics, Ethnobotany, Archaeology and Genetics. In: Denny Moore and Hein van der Voort (eds.) Linguistic Stocks of South America and their Prehistory. Univ. Texas Press, Austin.

Cook D., F. Gralow \& C. Muller de Young. 2001. Diccionario Bilingüe Koreguaje-Español, Español-Koreguaje. Editorial Alberto Lleras Camargo. Bogotá.

Duke J. A. 1972. Isthmian Ethnobotanical Dictionary. Scientific Publishers, Jodhpur, India

Galeano G. 1991. Las palmas de la región de Araracuara. TropenbosColombia, Bogotá.

Gallo C. 1972. Diccionario Tucano-Castellano. Prefectura Apostólica del Vaupés, Mitú.

García_F. G. \& J. R. Monguí S. 1975. Gramática Yebamasa. Lingüística Aplicada. Universidad Social Católica de La Salle. Departamento de Idiomas. Editorial Stella, Bogotá.

González de Pérez M. S. 2000. Bases para el estudio de la lengua Pisamira. In: M. S. González de Pérez \& M. L. Rodríguez de Montes (eds.). Lenguas Indígenas de Colombia. Una visión descriptiva. Instituto Caro y Cuervo. Bogotá. Pp. 373-393.

González_I. M. S. 1994. Flora utilizada por los Awa de Albi con énfasis en especies medicinales -estudio de Botánica Económica-. Tesis de Maestría. Departamento de Biología. Universidad Nacional de Colombia, Bogotá.
Guánchez F. J. \& G. A. Romero. 1998. Palms and amerindian fishing in Amazonas state, Venezuela. Principes 42(3): 125-135.

Henderson A. 1995. The Palms of the Amazon. Oxford University Press, New York.

Henderson A. 2000. Bactris (Palmae). Flora Neotropica 79: 1-186. Henderson A., G. Galeano \& R. Bernal. 1995. Field guide to the palms of the Americas. Princenton University Press, Princenton, New Jersey.

Howard L. 1972. Fonología del kamsá. Sistemas Fonológicos de Idiomas Colombianos Tomo I. Editorial Towsend, Bogotá.

Key M. R. (ed.). 2000. South American Indian Languages, Computer Database. Intercontinental Dictionary Series, Vol. 1. CDROM. University of California, Irvine.

Kronik J. et al. 1999. Fééjahisuu. Palmas de los Nietos de la Tierra y Montaña Verde del Centro. Centro de Investigación de Desarrollo, Copenhague.

Llerena_V. R. 1987. Relación y determinación en el predicado de la lengua kuna. Lenguas Aborígenes de Colombia. Descripciones 1. Colciencias-Universidad de Los Andes, Bogotá.

Llerena_V. R. 1993. Cuestionario lexical Epera del Alto Andágueda. CCELA, Universidad de Los Andes, Bogotá. Inédito.

Llerena_V. R. 1994. Cuestionario lexical Epera de Jaidukama. CCELA, Universidad de Los Andes, Bogotá. Inédito.

Marmolejo D., M.E. Montes \& R. Bernal. 2004. Los nombres de las palmas en las lenguas indígenas americanas. In: B.R. Ramírez-Padilla, D. Macías-P \& G. Varona-B (eds), Libro de Resúmenes Tercer Congreso Colombiano de Botánica. Universidad del Cauca, Popayán. P. 204

Meléndez_L., M. A. 1993. Achagua. Cuestionario lexical CCELA. Universidad de Los Andes, Bogotá. Inédito.

Meléndez L., M. A. 1998. La lengua achagua. Estudio gramatical. Lenguas Aborígenes de Colombia. Descripciones 11. Colciencias-Universidad de Los Andes, Bogotá.

Merchán_G., A. J. 1993. Kuiba-Maibén. Cuestionario lexical CCELA. Universidad de Los Andes, Bogotá. Inédito.

Metzger R. 2000. Diccionario de 1000 palabras. Carapana-Español. Editorial Alberto Lleras Camargo, Bogotá.

Mogollón_P. M. C. 1995. Barí. Cuestionario lexical CCELA. Universidad de Los Andes, Bogotá. Inédito.

Mogollón_P. M. C. 2000. Fonología de la lengua Barí. In: M. S. González de Pérez \& M. L. Rodríguez de Montes (eds.). Lenguas Indígenas de Colombia. Una visión descriptiva. Instituto Caro y Cuervo. Bogotá. Pp. 719-725.

Montes_G. J. J. 1978. Fitónimos de sustrato en el español del altiplano cundiboyacense y dialectos muiscas. Thesaurus 33: 41-54.

Montes_G. J. J. 1983. Motivación y creación léxica en el español de Colombia. Instituo Caro y Cuervo. Bogotá.

Montes_R. M. E. 1995. Ticuna. Cuestionario lexical CCELA. Universidad de Los Andes, Bogotá. Inédito.

Montes_R. M. E. 2004. Morfosintaxis de la lengua tikuna: Amazonía Colombiana. Descripciones 15. Ediciones Uniandes, Universidad de Los Andes, Bogotá

Morcote G. \& R. Bernal. 2001. Remains of palms (Palmae) at archaeological sites in the New World -A review. Botanical Review 67: 309-350.

Mugica C. 1969. Aprenda el guajiro. Gramática y vocabulario. Talleres de gráficas Mora-Escofet, Barranquilla.

Narváez A. \& F. Stauffer. 1999. Products derived from palms at the Puerto Ayacucho markets in Amazonas state, Venezuela. Palms 43: 122-129.

Ortiz_R. C. 1994. Kogui. Cuestionario lexical CCELA. Universidad de Los Andes, Bogotá. Inédito.

Ospina_B. A. M. 1999. Algunos aspectos de la fonología de la lengua yujup macú. Lenguas Aborígenes de Colombia. Memorias 6. Universidad de Los Andes, Bogotá. 
Patiño V. M. 1960. Historia colonial y nombres indígenas de la palma Pijibay (Guilielma gasipaes (HBK) Bailey). Revista Colombiana de Antropología 9: 23-72.

Pedersen H. B. \& H. Balslev. 1990. Ecuadorean Palms for Agroforestry. AAU Reports 23: 23-90.

Pérez van Leenden F. J. 1996. Wayuu. Cuestionario lexical CCELA, Universidad de Los Andes Inédito.

Pharris de Klumpp D. A. 1995. Vocabulario Piapoco-Español. Asociación Instituto Lingüístico de Verano. Bogotá, Colombia.

Prado M. L. \& J. Torres. 2004. Magütagü arü kua. Saberes ticunas. Plantas y animales I. Fundación Terra Nova, Bogotá.

Reichel Dolmatoff G. 1985. Los Kogi. Procultura, Bogotá.

Reinoso A. 1993. Piapoco. Cuestionario lexical CCELA. Universidad de Los Andes, Bogotá. Inédito.

Robayo C. 1993. Carijona. Cuestionario lexical CCELA. Universidad de Los Andes, Bogotá. Inédito.

Rodríguez de Montes M.L. (ed.). 1993. Estado Actual de la Clasificación de las Lenguas Indígenas de Colombia. Instituto Caro y Cuervo, Bogotá.

Rojas C. T. 1993. Páez. Cuestionario lexical CCELA. Universidad de Los Andes, Bogotá. Inédito.

Rojas S. F. A. 1997. Ciencias Naturales en la mitología curripaco. Programa Fondo Amazónico-Fundación Etnollano. Programa Coama. Guainía. Colombia.

Romayne H. E. 1997. Diccionario Bilingüe. Uw Cuwa (Tunebo)Español, Español-Uw Cuwa (Tunebo). Asociación Instituto Lingüístico de Verano. Bogotá.

Sánchez J. H. 1989. Pepabotonë peliwaisi (Las Palmas). Comité Guahibo de Educación Bilingüe Integral. Editorial Townsend, Bogotá

Sánchez_S. M. 1997. Catálogo comentado de la flora del Medio Caquetá. Tropenbos Colombia, Bogotá.

Sánchez M. \& O. Castro. 1977. Lenguas de Panamá. Tomo III. Una gramática pedagógica del waunana. Instituto Lingüístico de Verano. Instituto Nacional de Cultura. Dirección del Patrimonio Histórico. República de Panamá.

Scarlat C. 2004. Utile et dangereux dans quelques désignations de plantes dans le domaine daco-roumain. Géolinguistique 9: 81-116.

Schultes R. E. 1974. Palms and Religion in the Northwest Amazon. Principes 18: 3-21.

Seifart F. 2002. El sistema de clasificación nominal del miraña. Lenguas Aborígenes de Colombia. Descripciones 13. CCELA, Universidad de Los Andes, Bogotá.

SIL International. 2008. Ethnologue. http://www.ethnologue.com. Acceso 20/05/2008.

Smothermon J.R. \& J.H. Smothermon. 1993. Macuna-Español. Diccionario de 850 palabras. Editorial Alberto Lleras Camargo, Bogotá.

Smothermon J. R., J. H. Smothermon \& P. S. Frank. 1995. Bosquejo del Macuna. Aspectos de la cultura material de los macunas. Fonología. Gramática. Asociación Instituto Lingüístico de Verano. Bogotá.

Stephen B. 1977. The use of palms by the Barí Indians of the Maracaibo basin. Principes 21: 143-155.

Tamayo_L. C. 1998. Mi primer diccionario: español-tuyuca, tuyuca-español (primera edición). Ed. J. Barnes. Instituto Lingüístico de Verano. Bogotá.

Triana G. 1985. Los Puinaves del Inírida. Formas de subsistencia y mecanismos de adaptación. Biblioteca José Jerónimo Triana 8. Instituto de Ciencias Naturales, Universidad Nacional de Colombia, Bogotá.

Tobar N. 1993. Tinigua. Cuestionario lexical CCELA. Universidad de Los Andes, Bogotá. Inédito.

Tobar N. 1994. Guayabero. Cuestionario lexical CCELA. Universidad de Los Andes, Bogotá. Inédito.
Trujillo O., J. Delgaty, J. Carlson \& N. Morse. 1980. Vocabulario Siriano-Español. Editorial Townsend. Lomalinda, Meta.

Valencia S. 1994. Kubeo. Cuestionario lexical CCELA. Universidad de Los Andes, Bogotá. Inédito.

Vickers W. \& T. Plowman. 1984. Useful plants of the Siona and Secoya indians of eastern Ecuador. Fieldiana, Botany 15: 1-63.

Whisler D. \& J. Whisler. 1978. Buerique. Cartilla Tatuya. Instituto Lingüístico de Verano. Editorial Towsend, Lomalinda, Meta.

Zalabata R. 1995. Ika. Cuestionario lexical CCELA. Universidad de Los Andes, Bogotá. Inédito.

Apéndice 1. Lista de nombres amerindios de palmas colombianas ordenados por especie. En negritas se anota el nombre cientifico de la especie y el nombre comun en español, a continuación, con tipo regular los nombres amerindios.

1. Acrocomia aculeata (Jacq.) Lodd. ex Mart.

corozo, palma de corozo

shakána (damana), ñala (sáliba), yawalaboto (sikuani)

2. Aiphanes horrida (Jacq.) Burret

mararay

málibot (jitnu)

3. Aiphanes ulei (Dammer) Burret

chontaduro de nutria

pan si noha (cofán), ora mio (siona), himena ifué, ifue himena (uitoto)

4. Ammandra decasperma O.F. Cook

antá, cabecita, venita, yarina blanca

patisakó, patisako nume badishi, patisako numemba (cofán), opuahõ hopata (embera), ñumiñ̇ (koreguaje), túte sewa (siona), opúaho (waunana)

5. Asterogyne martiana (H. Wendl.) H. Wendl. ex Hemsl.

rabihorcado

kuriwa keddua (embera)

6. Astrocaryum acaule Mart

espina, corocito

kãhíka tsiambo (cubeo), udkám (puinave), matawakuliboto (sikuani), doká sarí (wanano)

7. Astrocaryum chambira Burret

cumare, palma de cumare

kumali (achagua), takone (andoque), dumestri (baniva), betaño (barasana), tuinfa (cofán), betoñì, hókłkł̇, mũiũúká, ñúkañi (cubeo), kumaria, wáketi (curripaco), ño ${ }^{\mathrm{h}} \mathrm{k}^{\mathrm{h}} \mathrm{p}^{\mathrm{h}}$ ora (desano), kaméla (guayabero), komtếgn (kakua), nühü'è̀húü'ò (miraña), matáigahiba, néhe (muinane), wamni, ut (nukak), kumàli (piapoco), yarí (piaroa), ñukáhpuño (piratapuyo), kumaki (puinave), kumaliñu (sáliba), kumari, kumaliboto (sikuani), beto, chambira, nyũkwa (siona), ñukã (siriano), kumaliphé (tariano), ñukaño (tatuyo), naĩ, nãi (tikuna), hiimasa (tinigua), be táñó, ñohká pũrí, ño ${ }^{\mathrm{h} k a ́}$ (tukano), betañố, ño ${ }^{h} k a ́$ (tuyuca), ñekina, uigonokidye (uitoto), ñî̉ kípũ, ñukipisa (wanano), tátachi (yagua)

8. Astrocaryum ciliatum F. Kahn \& B. Millán coco, coco de puerco, coco peludo

sieñe (andoque), beeiba, itsuva, meentnehee (miraña), bobaymeku (muinane), eruiruhí, ididoye, ruirü, sieñe (uitoto) 
9. Astrocaryum cuatrecasanum Dugand

chuchana

$\mathrm{p}^{\text {hirusava, }} \mathrm{p}^{\mathrm{h}}$ iruñi (koreguaje)

10. Astrocaryum ferrugineum F. Kahn \& B. Millán

kuu (tikuna), tótóse (yagua)

11. Astrocaryum gynacanthum Mart.

palma de cerrillo, palma de espina

ikoñedu (andoque), te hế (kakua), dịpirie (miraña), ł̇memi, meenimì néhe (muinane), bãb máam, weí, (nukak), xanaeboto (sikuani), ochi (tikuna), ñ $e^{h}$ tế, ne ${ }^{h}$ téño (tukano), ne téño (tuyuca), kikiño kikidye, ruirida, ruiridye, ruiregó, tidori (uitoto), mĩhî́, ñe tễnó, thễnó (wanano)

12. Astrocaryum jauari Mart

coco de sardina, yavarí

awara (carijona), hiabetoñì (cubeo), dekó', ut agn (kakua), yipirie (miraña), gisistremóomo, hłko néhee, taaba néhe (muinane), yopihiboto (sikuani), huirrima, okobeto (siona), díabe tañu (siriano), henípi (tariano), koma (tikuna), diábe tá (tukano), diabe táño (tuyuca), hìkoñekina, koriña, koruné, (uitoto), diañumúku (wanano), kuripa (yukuna)

13. Astrocaryum malybo H. Karst.

alúnka (damana)

14. Astrocaryum standleyanum L.H. Bailey

chunga, güinul, huéguerre

guinul (awa pit), higuá, werre (embera), wéger, wigirbü (waunana)

15. Astrocaryum urostachys Burret

etsohe, wikungo (cofán), chuchana, sirá, wikungo (secoya), chuchana, sirá (siona)

16. Astrocaryum spp.

dàapui (piapoco), dãĩ (tikuna)

17. Attalea allenii H.E. Moore

táparo

tonobá (embera), tapúrbü (waunana)

18. Attalea butyracea (Mutis ex L. f.) Wess. Boer

canambo, palma real, palma de vino

ümeh (bora), sapohe (cofán), kóchbot (jitnu), nulyi (kogui), buha tuuko (muinane), mabako (piapoco), ikutiñu (sáliba), purumaboto (sikuani), pa pa (siona), kurua (tikuna), barie (uitoto), mĩã phãpú, phãpú (wanano), kuluuala (wayuunaiki), tomohonase (yagua), mapanaré (yukuna)

19. Attalea cuatrecasana (Dugand) A.J. Hend. et al.

táparo

tapuru (embera)

20. Attalea insignis (Mart.) Drude

yagua

güaseretba (miraña), fat i tuuko, gekage, gistre tuuko, nibigai tuko (muinane), towihiboto (sikuani), bartydye, mota (tikuna, como $A$. cf insignis),yariyi (uitoto), yakwera (yukuna)

21. Attalea maripa (Aubl.) Mart.

cucurito, inayá, palma real

alitsi, mavako (baniva), bohoño (barasana), mariha (carijona), inayova (cofán), echídiñi (cubeo), kwétirri (curripaco), egắ (desano), pũtiñi (koreguaje), huáho (muinane), kaadĩdë, kurá, huyup (nukak), wisìri (piapoco), wächäì (piaroa), i ${ }^{\text {hkíño }}$ (piratapuyo), waibí (puinave), naxareboboto, (sikuani), waho (siona), i'gáño (siriano), vesiriphí (tariano), buño (tatuyo), woku, wookú (tikuna), i ikiño (tukano), inkí (tuyuca), mariha, yarina (uitoto), kíõ (wanano), uehirí (yukuna)

22. Attalea microcarpa Mart.

tukomeku (muinane), duku, küüru (tikuna)

23. Attalea phalerata Mart. ex Spreng.

chapaja

moru (tikuna)

24. Attalea plowmanii (Glassman) Zona

yaw kü (tikuna), kuy, yakuere (yukuna)

25. Attalea racemosa Spruce

coco, mavaco

kodime (andoque), ekuru (baniva), emumeke (cubeo), kwiapé (curripaco), níihiซigai tuko, tuuko (muinane), kusí (piaroa), boiünüm,

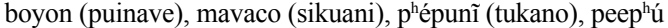
(tuyuca), baruyi uyoye, uiyodyi (uitoto), ñamá $\mathrm{p}^{\mathrm{h}} a \mathrm{p}^{\mathrm{h}} \mathrm{u}$ (wanano)

26. Attalea septuagenata Dugand

eri (tikuna, $A$. cf. septuagenata), kuhĩta (yukuna)

27. Attalea spp.

yapó (cubeo), behépũ (desano), kokbá' (kakua), huiúi (nukak), yapí (secoya), mapanariphépi (tariano), pấpố (wanano)

28. Bactris acanthocarpa Mart.

chontaduro de los peces

bubúmemëeku (miraña), faiba móomoo, neebáu (muinane), madi (piaroa), buibuiboto (sikuani), kuikúi (siona), date (tikuna), idatiñori, iñori, udatiñore (uitoto)

\section{Bactris balanophora Spruce}

\section{chontaduro falso}

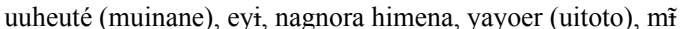
potáño (wanano)

30. Bactris barronis L.H. Bailey

chacarrá

alar (cuna)

31. Bactris bidentula Spruce

boobo mehe (miraña)

32. Bactris bifida Mart.

kawna (tikuna)

33. Bactris brongniartii Mart.

arapara (tikuna)

34. Bactris campestris Poepp. ex Mart.

dówirri (curripaco)

35. Bactris coloradonis L.H. Bailey

sin nuar (cuna)

36. Bactris concinna Mart

inzupara (cofán), paipigu (puinave), nukë (secoya), wi (siona)

37. Bactris corossilla $\mathbf{H}$. Karst.

coquito, cubarro

du (piaroa), huatiwí (siona), tuchi (tikuna), põ táño (wanano), kuparú (yukuna) 
38. Bactris elegans Barb. Rodr.

chonta, palma de espina

oheakon (andoque), gukureku, hanameku (muinane), pốtaño, pohtaño (tukano), eérì (uitoto)

39. Bactris fissifrons Mart.

sitanó (andoque), kaúhł̇ko (bora), kubarrì (carijona), mihĩñõ (tukano), zitoakał (uitoto), mĩhî́ sá (wanano)

\section{Bactris gasipaes Kunth}

chontaduro, cachipay, pejibá, pepire, pupuña

noepá (andoque), chánul (awa pit), wepi (baniva), hotaw, ineño (barasana), nené (cabiyarí), ineño (carapana), harehu ehł (carijona), omá (cofán), ṫné, ṫreñ̇̀ (cubeo), iko, nalu, (cuna), pípirri (curripaco), ríño (desano), hanga, hẽa, hẽ́e, hẽe sĩda, supi (embera), papí (guayabero), yüìutëgn (kakua), ine (koreguaje), hota, hotá, hotaño (macuna), méeme (miraña), amu móomoo, chuemí móomoo, famórahe móomoo, gaikuhe móomoo, theku, huchahi móomoo, meemedihe móomoo, mimeuhe móomoo, paaríba, tuuguiye móomoo (muinane), bĩdĩ, búyup, ĩrẽ, huniuni, huyũdĩ (nukak), mek (ocaina), pìpiri (piapoco), pahare (piaroa), uréño (piratapuyo), ineño (pisamira), mõm, muri (puinave),mĩũ ́nẽ , wiyapé́nẽ (secoya), hipiriboto (sikuani), bayớñe, eneño, manyokó́nẽ, uná (siona), iríño (siriano), ernde (taiwano), ireẽa (tanimuca), pípirip $^{\mathrm{h}} \mathrm{i}$ (tariano), ineño (tatuyo), íntü, ĩtü (tikuna), yaósa (tinigua), ũréñu (tukano), bíbira, bíbora, kachimeya (tunebo), ũnéño (tuyuca), bigina, farena himena, hiatkona himena, himena, iágł himena, imekena, kuuña himena, mógoioa, oikiñe, kł̇dóña, tero beña, zobina himena (uitoto), fré (wanano), härr, ür (waunana), t’üù (yuhup), pipirí (yukuna), uné (yurutí)

41. Bactris hirta Mart.

chontaduro de monte, chontaduro de rana

yaimu deku, sisimohomo (muinane), ut (puinave), nachii arü ĩtü (tikuna), ma károka f̃ré, potáñó (wanano)

42. Bactris killipii Burret

sisi nehéame (muinane), munuikori, pikiño eerekwe (uitoto)

43. Bactris macroacantha Mart.

$\operatorname{coco}$

ñeeino (andoque), hoda himena (uitoto)

44. Bactris maraja Mart.

espina, chontilla

gui, gui wala, mogor (cuna), buru móomoo, tuutuku (muinane), i', pahp, tëwpëdë (nukak), ainawiboto (sikuani), dawü we (ticuna), biri $\mathrm{mo}^{\mathrm{h}}$ kere, buneita himena, burumikiri, gisimeku, uitinigi (uitoto)

45. Bactris pilosa H. Karst.

\section{lata blanca}

sansagarra (embera)

46. Bactris riparia Mart.

chontadurillo

kateehłko (miraña), taaba móomoo (muinane), pa í ine (siona), ĩtü chikü (tikuna), buine himena, himairì (uitoto)

47. Bactris setulosa $\mathbf{H}$. Karst.

palma de cubarro

kubaruboto (sikuani), kahá (tunebo)

48. Bactris simplicifrons Mart.

chontadurillo oreñaw (barasana), umachúkusu (cofán), aaboméeme (miraña), burremomosuu, gisiri babaimeku, haaba móomoo, haani móomoo, memer imóomo (muinane), sute ëne, watosuné (siona), tuchi (tikuna), hoda himena, hoda himeru (uitoto)

49. Bactris spp.

nówapa (andoque), popui (cocama), ipki, nalu (cuna), chacarrá (embera), aldo (kogui), bahe móomoo, nebau (muinane), hamehe (ocaina), põrá kìríño (siriano), binakará (tunebo), ekiri, himaki, huikurtye, (uitoto), póre (yagua)

50. Chamaedorea pauciflora Mart.

aakaiba, lakae, ti aakaiba (miraña), citaganomeku, uheeka (muinane), huákó (secoya), huákó (siona), chata (tikuna), gúrie (uitoto)

51. Chamaedorea pinnatifrons (Jacq.) Oerst.

puivochosí (cofán), miihłbao (muinane), ñukuaéné (siona)

52. Chamaedorea sp.

pol (cuna)

53. Chelyocarpus ulei Dammer

a ibacom ba (miraña)

54. Cocos nucifera $\mathrm{L}$.

coco

kokoakãĩ (barí), amana (carijona), kokoñt (cubeo), okop (cuna), kókó (embera), koku (ika), kopbót (jitnu), kuko (kogui), petoñi (koreguaje), awü (tikuna), kukuño (tukano), kokbú (waunana), koko (yagua)

55. Copernicia tectorum (Kunth) Mart

sará

páutta (wayuunaiki)

56. Desmoncus cirrhifer A.H. Gentry \& Zardini

matamba

matamba ted (awa pit), guagai, wagaei, wagai hükára (embera)

57. Desmoncus giganteus A.J. Hend.

tuntu (siona)

58. Desmoncus mitis Mart.

foodá (andoque), imiya hakimoł (muinane), besotúntu (siona), turuma huikorao (uitoto)

59. Desmoncus orthacanthos Mart.

camahua, matamba

kamawa (piapoco), kämahuä (piaroa), kamuvé (sikuani)

60. Desmoncus polyacanthos Mart.

yasitara

kamawa (curripaco), bwiamesé (macuna), hakumoho, hibohakimoł, momo, tł̇ehakímoł (muinane), ka wan (puinave), kamuvé (sikuani), buu (tikuna), hittimoo, migoi hitimo, tiraña (uitoto), piherú (yukuna)

61. Desmoncus spp.

amábamu, miyabikimũ, náamemu (cubeo), mábi (curripaco), bupasantú (kakua), mitámba (kogui), kamuuaboto (sikuani), be dáh waridáh (siriano), kamavak á (tariano), waítudáh (tukano), beedá (tuyuca), wa ${ }^{\mathrm{h}}$ tu darí (wanano), piseró (yukuna)

62. Dictyocaryum ptarianum (Steyerm.) H.E. Moore \& Steyerm. bombona falsa

hỉhao (muinane), tau ya (tikuna), hikifegina, hikipena (uitoto) 


\section{Elaeis oleifera (Kunth) Cortés}

samake (cuna), seitabaha (kogui)

\section{Euterpe catinga Wallace}

asaí de sabana

manake (curripaco), totue (miraña), ÿ̈̈su (muinane), manaká (piaroa), yot pigot (puinave), ã a naa kü (tikuna), needa (uitoto),

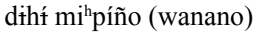

\section{Euterpe oleracea Mart.}

asaí de pará, huasaí de sabana, manaca, murrapo, naidí

nãhõemimueñi (cubeo), tarábwa mĩhî́, tarapấnẽ (desano), naidí (embera), murrap ${ }^{\mathrm{h}} \mathrm{o}$ (waunana)

\section{Euterpe precatoria Mart.}

\section{asaí, huasaí, murrapo}

manákai (achagua), pootá (andoque), naldisch (awa pit), wahu (carijona), mana (baniva), mihiño (barasana), manñeka (cabiyarí), manáka (cocama), divá (cofán), emimoe (cubeo), manáke (curripaco), mĩhî́ (desano), hinkató (embera), báha, guypani (guayabero), kerantëgn (kakua), sná (kogui), tooyige (miraña), tuuguiyì (muinane), yúbudi (nukak), manakai (piapoco), nenea (piaroa), wi píño (piratapuyo), yod pi, yot, yot pigot (puinave), nenichi (sáliba), manakái, manakaiboto (sikuani), inibue (siona), mihíño (siriano), fífia (tanimuca), waíra (tikuna), tsozúsa (tinigua), min piño (tukano), mi ${ }^{\mathrm{h}}$ píñõ (tuyuca), needa (uitoto), mi hí (wanano), malakala (yukuna)

67. Geonoma atrovirens Borchs. \& Balslev

irawa, chüüta-ne (tikuna)

68. Geonoma brongniartii Mart.

eyiipanae (miraña), níní (secoya)

69. Geonoma calyptrogynoidea Burret cuchilleja

dokiduá (embera), dokéri (waunana)

70. Geonoma camana Trail atibakomo (miraña), gurure (uitoto)

71. Geonoma cuneata $\mathrm{H}$. Wendl. ex Spruce kituá uí (embera)

72. Geonoma deversa (Poit.) Kunth

guaiko (embera), tataba (miraña), hiobo hiyui, miya hiyui (muinane), blui (nukak), wawarabotoo, vávara, (sikuani), sute dédé (siona), goguire (uitoto)

73. Geonoma divisa H.E. Moore

tumá pakurú (embera)

74. Geonoma interrupta (Ruiz \& Pav.) Mart. chuã (tikuna)

75. Geonoma lanata A. J. Hend. et al.

kuaske (awa pit)

76. Geonoma leptospadix Trail

goguirt (uitoto)

77. Geonoma macrostachys Mart

ubí

akie kakie, kofahe (cofán) bubumimeku, iibuimi (muinane), huansódédé, okópui, paí (secoya), dadu, nayahuëdadu, okó puí, yiha déré (siona), dea akü (tikuna), ñaigiri, ñaigúru, tinuikore (uitoto), bo ${ }^{\mathrm{h}}$ só muhĩ dáaka (wanano)

\section{Geonoma maxima (Poit.) Kunth}

puy falso

baru baru (baniva), zuhé (cofán), mariṕnin (curripaco), meikeze (miraña), idyúuku (muinane), emedere (siona), dea (tikuna), erert, fikaiñoereri, goguiri, guriri, huaguedadaerei (uitoto)

79. Geonoma poeppigiana Mart.

bubuy híyuhí (muinane), idatiñori, goguiri (uitoto)

80. Geonoma polyandra Skov

tsao he tsi (cofán), dédé bui, dídi (siona)

81. Geonoma pycnostachys Mart.

puy de paloma

bosó mohe (macuna), hiowoohiyui, hiyui, tabahiyui, víikume, yuimiku (muinane), dédé (secoya), diha dédé, tute dede (siona), dea püwí (tikuna), fikaingo ere, gekiri, goguiri, hoda himena,(uitoto), wachó muhî́ (wanano)

82. Geonoma triglochin Burret

sampablito

anhídadu, púi (siona)

83. Geonoma spp.

soaira (barí), híyuhi, tuumo hahéku (muinane), niní puĩ, wakó (secoya), goguire (uitoto), mîhĩ biki (wanano), uihuiyo (yukuna)

84. Hyospathe elegans Mart.

chúnohe (barasana), aganumeba (cofán), kadoemeíba (miraña), huasóui, lutawe oko, ma puĩ (secoya), dedewekó (siona), wochachi chikü (tikuna), nakri, yiiri (uitoto)

85. Iriartea deltoidea Ruiz \& Pav.

barrigona, pachuba, pambil

hiriwaime iwakuchano (carijona), bombo, bumbuhe (cofán), éwañi (cubeo), púpa (curripaco), ñumúñu, ñumúñu ñóre (desano), himentếgn, pu'tếgn (kakua), arrá (embera), orañi (koreguaje), hĩkõ (macuna), aayae, ayako, háyaeu, iyase (miraña), hayaku (muinane), bëi', huruda wa (nukak), ko ${ }^{\mathrm{h}}$ sáñodu (piratapuyo), nyoko (secoya), butsiboto, misíboto (sikuani), obá (siona), wa ${ }^{\mathrm{k}}$ káriñu (siriano),

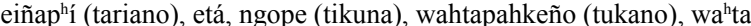
pák kañõ (tuyuca), fegona, híągłna (uitoto), ba bápo ${ }^{\mathrm{h}}$ koño (wanano), ar (waunana), kobónase (yagua), hẽñã (yukuna), ñoriñá atié tiróñi (yurutí)

86. Iriartella setigera (Mart.) H. Wendl.

bodoquera, yaripa

koedopeko, peko (andoque), mawi (baniva), pimpiñu (cubeo), mawi (curripaco), ñumúñu ñóre (desano), sabáhtë̀ngn (kakua), buhanñe kawne, buhugó (macuna), móomo igaiku (muinane), ú baká (nukak), mivi (piapoco), yurua (piaroa), u'púño (piratapuyo), tayó (puinave), liwai, mawiboto (sikuani), buhpúño (siriano), mavip $^{h}$ (tariano), buhpúño (tukano), bu ${ }^{\mathrm{h}} \mathrm{pup}^{\mathrm{h}} \mathrm{i}$ (tuyuca), handabeke, kł̈yuakał (uitoto), pũõ (wanano), mawiku (yukuna)

87. Iriartella stenocarpa Burret móomo igaiku (muinane), fuidorda (uitoto)

88. Itaya amicorum H.E. Moore marím ipa (miraña), chiwü (tikuna)

89. Leopoldinia major Wallace

kamaroboto (sikuani)

90. Leopoldinia piassaba Wallace

fibra, chiquichiqui, 
malama (baniva), maalama, maramapé (curripaco), chikichìki, maráma (piapoco), marama (piaroa), hañõn, maramá (puinave), sikisikiboto (sikuani)

91. Leopoldinia pulchra Mart.

yará

manikoli, manikore (curripaco), yuipa (puinave)

92. Leopoldinia sp.

manamazu (puinave)

93. Lepidocaryum tenue Mart.

puy

tado (andoque), hota mohe(barasana), ruchi (cabiyarí), muy (cubeo), aheko, ahi, tegpayage (miraña), beeremiku haheku, bibimł̇ku háheku, ċ̇gao háheku, deene háhe, diku háheku, niya háheku (muinane), tuí (puinave), muhí (taiwano), muiĩa (tanimuca), kotu, ngupe, waichara (tikuna), potamé (tukano), dikuháhe łmoháhe, ererí, iiamaikí, ropokire (uitoto), kaarú, karugiri (yukuna)

94. Manicaria saccifera Gaertn.

jicra, ubí

muichiãbo, wachi (cubeo), wati (curripaco), kaĩngát, kaĩntokëgn (kakua), tukira (embera), mekwátbak, taahiyłe (miraña), watiboto (sikuani), bo ${ }^{\mathrm{h}}$ somuhî́ (siriano), wahée (tanimuca), ampiapúne

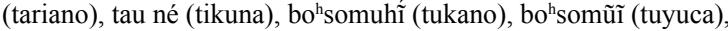
mũã pũrí (wanano), kéd, tứkür (waunana), wáhe (yukuna)

95. Manicaria cf. martiana Burret

ngumaku (tikuna)

96. Mauritia carana Wallace

caraná, canangucha de sabana

kwai (carijona), chinañi, muíñi, mũĩ (cubeo), tíña (curripaco), mohî́ (desano), tokết (kakua), iñéhe (miraña), dágui inóho (muinane), katànali, katanári (piapoco), mohĩño (piratapuyo), guom, tuí (puinave), muhíño (siriano), púne (tariano), muhiño (tukano), mũ̃ (tuyuca), kañakoná, duitekina (uitoto), mohî́, muhisa (wanano)

97. Mauritia flexuosa $\mathrm{L}$. f.

aguaje, canangucha, mirití, moriche

diwita (achagua), konta (andoque), tewi (baniva), reño (barasana), iñéhe (bora), neeño (carapana), kwai (carijona), kanongocho (cofán), nain, neiñ̇ (cubeo), inhoboto (cuiba), ítebł̇, (curripaco), néñu (desano), nohá (guayabero), kwátbot (jitnu), yak, ya’tëgn (kakua), nanikuni, neéñi (koreguaje), ínë'è̀tsóó'ò, ínëkáhá (miraña), kaamába inóho, kaatiku inóho, inóho, hł̇máhay usegay inóho, meenime kanifai inóho, miya inóho, nebau inóho, tuugiku inóho (muinane), eú (nukak), idéwi (piapoco), warí (piaroa), néeño (piratapuyo), iyõ (puinave), llĩde (sáliba), ma neé, soto neé (secoya), inóho, inohoboto (sikuani), kanangucho, neé (siona), neeñú (siriano), neẽa (tanimuca), teevidá, teuira (tariano), ne (tatuyo), dauri (var. de fruto rojo), nguchiaü nguã (var. de fruto ácido), okaimo (var. de fruto amarillo), tema, téma (nombre genérico),tema chikü (var. de mala calidad) (tikuna), kwí'osa (tinigua), nẽẽ, neeñõ (tukano), neé, ñumúñõ (tuyuca), konéna, hiaukiña, híduiki, hopadì kinena, ogoke kinena, pareka kinena, tuugiku kinena, ułcheparo kinena (uitoto), naa á (wanano), ndesé (yagua), itewi (yukuna)

98. Mauritia spp.

ua kinena riaña (uitoto)

99. Mauritiella aculeata (Kunth) Burret

caranaí

tananako (cofán), kadanarite (curripaco), bípima (macuna), iigüae tiiyaña (miraña), fiiboto inóho, ure inóho (muinane), uriá (piaroa), walamaboto (sikuani), ñeñechi (tikuna), głaitina, nuikaro, tíyaña, ziiyana (uitoto)

\section{Mauritiella armata (Mart.) Burret}

cananguchillo

kubañi (cubeo), mohã́ (desano), miu neéñi (koreguaje), dǘutëgn (kakua), siná (piaroa), pum (puinave), kãti neé (secoya), tseneboto

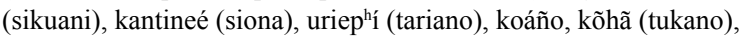
koấñõ (tuyuca), kõã, neki má ${ }^{k}$ ariño kwáño (wanano)

\section{Mauritiella sp.}

koaãka (tanimuca)

102. Oenocarpus bacaba Mart.

ibacaba, milpesillo

kudídi, upeli (baniva), akəi, wasekumu (carijona), boriyabeañi, kõhãñ் boriyabeañ̇ (cubeo), púperre (curripaco), ñumúñu (desano), síbim (kakua), chéereé, iihtnoho, ntgo taagaiho, taagaho (muinane), habutu, hubudi, yáab butu (nukak), makupàisi, pubèeri (piapoco), pio ü puori (piaroa), ñumúño (piratapuyo), ohaüboto (sikuani), ñumúño, ñumúñu mu táringa (siriano), punáma, pupeirip ${ }^{\mathrm{h}} \hat{\mathrm{h}}$ (tariano), pupechi (tikuna), ñumú ma ká, ñumú omfahá (tukano), ñumú me tá (tuyuca), gurina, itina (uitoto), da ñumuka, dañemaká (wanano), tóchi (yagua), wàwó (yuhup), pupé (yukuna), ñumá meká (yurutí)

\section{Oenocarpus balickii Kahn}

ñe (tikuna)

\section{Oenocarpus bataua Mart.}

\section{milpesos, seje, patabá, trupa}

makúpai (achagua), bateí, batú (andoque), chapil (awa pit), yaro, yäu (baniva), ñomuño (barasana), kuuruhu, tsitsihu (bora), kumu (carijona), nihuchu (cofán), bokohañu, boreyabeñu, duebokohañu, duibokane, hebukanu, kohañu, kõhãñt pũrãmãñt, pũrámañũ, yavekohañu (cubeo), ibe (cuna), púnama (curripaco), ñiłmí (desano), arú, sokarrõ, sokorrong, trupa, urabá, urúkena, urútha (embera), xü (guayabero), okú bot (jitnu), wátëgn (kakua), kõsa, kõsañ̇ (koreguaje), guakaria (macuna), koomehi, kòom (miraña), babayhu igai, komée, kuméerio, iidikuumee, haadió kuume, kirídyahe, tuhe kumee (muinane), yab, tërukë (nukak), pùnama (piapoco), bareu puori, isoi, peédi (piaroa), ñumúño pa ${ }^{\mathrm{h}}$ káño (piratapuyo), ium, vuó, wo, yum (puinave), gõsa (secoya), ataiboto, pewitsaboto, toxoloboto(sikuani), kosá, ungurahua (siona), ñumúño, ñumúñu wadíhñu (siriano), ñoõmĩá (tanimuca), punámap $^{\mathrm{h} i}$ (tariano), ñomiño (tatuyo), bòrúà, düü (tikuna), ñumú, ñumú pa káño (tukano), károwara, sítuma (tunebo), ñumú pa ${ }^{\mathrm{h}} k a ́$ wa ${ }^{\text {h } k a r i k a ́ ~(t u y u c a), ~ k o m a i ́ h e, ~ k o m e ́ e, ~ d o b o ́ m a n ̃ a, ~ h i i d ł k o ~ p a n ̃ a, ~}$ paatina, ure maña (uitoto), gỉbiño, ñimisa (wanano), sokarrõ (waunana), siməse, $\mathrm{t}^{\mathrm{h}}$ imasé (yagua), wàh (yuhup), punama (yukuna), ñumá (yurutí)

105. Oenocarpus circumtextus Mart.

milpesillo de sabana

emifoõa (tanimuca)

106. Oenocarpus makeru R. Bernal et al. makeru (yukuna)

107. Oenocarpus minor Mart. (incluyendo O. mapora H. Karst.) dompedrito, maquenque, milpesillo

sodyabatú (andoque), chicyora ${ }^{\text {h }}$ (bora), patsatsa nihonchó (cofán), parará, pắrara büüri, pie kuró (embera), chiikotsige (miraña), cherée, chetresuu (muinane), popere, tai' (nukak), kupéri, makapéiboto, makopahiboto (sikuani), shimbu, huikosa (siona), borua (tikuna), giridda, guruna, yerena (uitoto), piekuurhõ bä (waunana), kalu' lú (yukuna)

\section{Oenocarpus spp.}

bui ñoõmĩá, karuũ ruka, ñoõmĩ wãrua, ñoõmia karãka, wuiro ñoõmĩá (tanimuca), taagaiho, (uitoto), puhurrupere (yukuna) 


\section{Pholidostachys synanthera (Mart.) H.E. Moore}

kigao hahe (muinane), fekori, pekor (uitoto)

110. Phytelephas macrocarpa Ruiz \& Pav.

palma yarina, tagua, yarina

chipati (cocama), shishihe (cofán), ngumü chi (tikuna), pátiu (yagua)

111. Phytelephas schottii H. Wendl.

tagua

sagu (cuna), ãtá (embera), taaudau (waunana)

112. Phytelephas tenuicaulis (Barfod) A.J. Hend.

tagua

shishihe (cofán), sehua (siona)

113. Phytelephas sp.

sewa (secoya)

114. Prestoea acuminata (Willd.) H.E. Moore

palmito

murrap ${ }^{\mathrm{h}} \mathrm{o}$ (embera), buitsaha (inga)

115. Prestoea decurrens (H. Wendl. ex Burret) H.E. Moore chichi $\mathrm{p}^{\mathrm{h}} \mathrm{uru}$, sisimúrr (embera)

\section{Prestoea schultzeana (Burret) H.E. Moore}

zuteyecho (cofán), kahúe, naí (secoya), naí (siona), chaatü (tikuna)

117. Roystonea oleracea (Jacq.) O.F. Cook

mapora

mapórbot (jitnu), mapoloboto (sikuani)

118. Sabal mauritiiformis (H. Karst.) Griseb. ex H. Wendl.

soso (cuna)

119. Socratea exorrhiza (Mart.) H. Wendl.

araco, chuapo, zancona

huba (achagua), pooko (andoque), upa (baniva), hiriwa (carijona), anaku tsatsavó (cofán), éwant kíhiñì, ebáñt maihóbariño, ñobeañi, ñopoñu, piohoko (cubeo), ẽeñá, púpa (curripaco), mï̀ (desano), arra sĩi, hira (embera), komálbot (jitnu), himuntëgn (kakua),

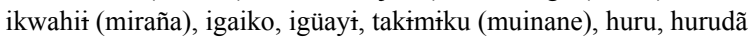
(nukak), poá (piapoco), poabä (piaroa), ko ${ }^{\mathrm{h}}$ sáño (piratapuyo), kupa, guom sowai (puinave), misiboto (sikuani), bonbon, ñikó (siona), gõháño (siriano), pupaphí (tariano), eta, etá irakü (tikuna), wahtáño, wa ${ }^{h}$ tá $^{\text {}}$ saro (tukano), wa $a^{\text {ht }}$ mé ${ }^{h}$ taña (tuyuca), dorida, ł̇meda (uitoto), k ósao, (wanano), häbübü (waunana), pupa (yukuna)

120. Syagrus orinocensis (Spruce) Burret

\section{churrubay}

churúbai (achagua), eesí (piapoco), oróboto (sikuani), bariyi (uitoto)

\section{Syagrus sancona H. Karst.}

sarare

pawénbot (jitnu), pawenaboto (sikuani)

122. Syagrus smithii (H.E. Moore) Glassman

coco

toókee (miraña), ngowechi ü (tikuna)

123. Synechanthus warscewiczianus $\mathbf{H}$. Wendl.

guaguarín

perõra, wichítua (embera), ẽeur (waunana)
124. Welfia regia $\mathbf{H}$. Wendl. ex André

amargo

ĩgedé, îkídi büüri, (embera), ĩgiri, ĩgir (waunana)

125. Wettinia augusta Poepp. ex Endl.

gistree, momó igaiku, (muinane), kodo dorida (uitoto)

126. Wettinia drudei (O.F. Cook \& Doyle) A.J. Hend.

dadar da, ̇̇dadarłda (uitoto)

\section{Wettinia hirsuta Burret}

lata

chuppí (embera)

128. Wettinia kalbreyeri (Burret) R. Bernal

gualte

waltit (awa pit)

129. Wettinia maynensis Spruce

corunta

kuyé (cofán), winiko (siona)

130. Wettinia oxycarpa Galeano \& R. Bernal

gualte (awa pit)

131. Wettinia quinaria (O.F. Cook \& Doyle) Burret

memé

guarnul (awa pit), meme (embera), chorr (waunana)

132. Wettinia radiata (O.F. Cook \& Doyle) R. Bernal

baqueta

tapú (embera)

133. Nombres de especies indeterminadas

kushíbai, kúshibaishina, dáhui (achagua), besuño, bitiño, bosómohiño, buhúuño, kohaño, hehékahé, mohíbikiño, ñahiño, riamuhiño, vihiño (barasana), anu, bunubũ, chikaanə, mĩtnĩ (barí), kumuchikinibə, menaba, tosoremi (carijona), naa (chimila), yuitsára (cocama), bahiñ்̃, pioñ̃ (cubeo), badeiboto, koboto, kotsiboto, hohomboto, machepaboto, manboto, michiboto, nak üdüboto, odoboto, pawenaboto, tseneneboto, yopiboto (cuiba), ila, napa, tagará, waa (cuna), puramu, watipie (curripaco), ãyüsü, hẽap ${ }^{\mathrm{h}} \mathrm{t}^{\mathrm{h}} \mathrm{a}$, hirakó kíru, meme ara, meme minik ${ }^{\mathrm{h}} \mathrm{o}$, pãìrara hua, $\mathrm{p}^{\mathrm{h}}$ ãsasa, sãk ${ }^{\mathrm{h}} \mathrm{u}$ 'da, tsa tsa ghasa, tosu, wagara, uk ${ }^{\mathrm{h}}$ ' da pare, usuk ${ }^{\mathrm{h}}$ ĩsa (embera), malontus (guambiano), kapa, kaparxéla, makófa, patówa, woibúwa (guayabero), ennəkənə, məro'ta, kəmme ${ }^{\text {h }}$ kia, siri, torko (ika), arákbot, kálaha, kaniébot, nakálbot, yabapút, yakorchít, yoíbot (jitnu), kob (jupda), tsashá (kamsá), álu, alunká, shakalaka, shishká, shúnu, kulksha, kuloxshá, hoka, nibikala, séina, seitaboka, ya (kogui), kãé kõsañi, chãsóñi, eriñit, vea orañi, viiñ̃ (koreguaje), bëİë'ì, tóókëİ'ìibà, $\mathrm{k}^{\mathrm{h} a m b u} \mathrm{f}^{\mathrm{y}} \mathrm{tu}$, koko tas ${ }^{\mathrm{y}}$, lamus, lamus tas ${ }^{\mathrm{y}}$,well $\mathrm{f}^{\mathrm{y}}$ tu (páez), kurùada, kuzìi, éeya, maháwita, máwi, púba, puzùi, táina, wàakézi (piapoco), som, yorod (puinave), kusi, wãcha ikuti (sáliba), üt überxanaeboto (sikuani), miúmérẽñu (siriano), gũũ, káámã, thowása (tinigua), bu tíño, ámara, akeba, áricha, arya, ewatá, rukua, rurkuicha, sakuá, sarayá, siba, sínkuacha (tunebo), wõ (tuyuca), niékero (uitoto), píerkúur piu, wágara (waunana), alana, paita, pattapan (wayuunaiki), còcóù (yuhup), katsána (yuko), mayaikáru (yukuna) 
Apéndice 2. Lista de nombres amerindios de las palmas de Colombia ordenados por lengua

\section{ACHAGUA}

1. churúbai: Syagrus orinocensis

2. dáhui: Indeterminada

3. diwita: Mauritia flexuosa

4. huba: Socratea exorrhiza

5. kumali: Astrocaryum chambira

6. kushíbai: Indeterminada

7. kúshibaishina: Indeterminada

8. makúpai: Oenocarpus bataua

9. manákai: Euterpe precatoria

\section{ANDOQUE}

10. bateí: Oenocarpus bataua

11. batú: Oenocarpus bataua

12. foodá: Desmoncus mitis

13. ikoñedu: Astrocaryum gynacanthum

14. kodime: Attalea racemosa

15. koedopeko: Iriartella setigera

16. konta: Mauritia flexuosa

17. ñeeino: Bactris macroacantha

18. noepá: Bactris gasipaes

19. nówapa: Bactris sp.

20. oheakon: Bactris elegans

21. peko: Iriartella setigera

22. pooko: Socratea exorrhiza

23. pootá: Euterpe precatoria

24. sieñe: Astrocaryum ciliatum

25. sitanó: Bactris fissifrons

26. sodyabatú: Oenocarpus minor

27. tado: Lepidocaryum tenue

28. takone: Astrocaryum chambira

\section{AWA PIT}

29. chánul: Bactris gasipaes
30. chapil: Oenocarpus bataua
31. gualte: Wettinia oxycarpa
32. guarnul: Wettinia quinaria
33. guinul: Astrocaryum standleyanum
34. kuaske: Geonoma sp. "lanata”
35. matamba ted: Desmoncus cirrhifer
36. naldisch: Euterpe precatoria
37. waltit: Wettinia kalbreyeri

\section{BANIVA}
38. alitsi: Attalea maripa
39. baru baru: Geonoma maxima
40. dumestri: Astrocaryum $\mathrm{sp}$.
41. ekuru: Attalea racemosa
42. kudídi: Oenocarpus bacaba
43. malama: Leopoldinia piassaba
44. mana: Euterpe precatoria
45. mavako: Attalea maripa
46. mawi: Iriartella setigera
47. tewi: Mauritia flexuosa
48. upa: Socratea exorrhiza
49. upeli: Oenocarpus bacaba
50. wepi: Bactris gasipaes
51. yaro: Oenocarpus bataua
52. yäu: Oenocarpus bataua

\section{BARASANA}

53. besuño: Indeterminada

54. betaño: Astrocaryum chambira

55. bitiño: Indeterminada

56. bohoño: Attalea maripa

57. bosómohiño: Indeterminada

58. buhúuño: Indeterminada

59. chúnohe: Hyospathe elegans

60. hehékahé: Indeterminada

61. hota mohe: Lepidocaryum tenue

62. hotaw: Bactris gasipaes

63. ineño: Bactris gasipaes

64. kohaño: Indeterminada

65. mihiño: Euterpe precatoria

66. mohíbikiño: Indeterminada

67. ñahiño: Indeterminada

68. ñomuño: Oenocarpus bataua

69. oreñaw: Bactris simplicifrons

70. reño: Mauritia flexuosa

71. riamuhiño: Indeterminada

72. vihiño: Indeterminada

\section{BARÍ}

73. anu: Indeterminada

74. bunubũ: Indeterminada

75. chikaanə: Indeterminada

76. kokoakãĩ: Cocos nucifera

77. mĩtnĩ: Indeterminada

78. soaira: Geonoma $\mathrm{sp}$

BORA

79. chicyora ${ }^{\mathrm{h}}$ : Oenocarpus minor

80. iñéhe: Mauritia flexuosa

81. kaúhiko: Bactris fissifrons

82. kuuruhu: Oenocarpus bataua

83. tsitsihu: Oenocarpus bataua

84. ümeh: Attalea butyracea

\section{CABIYARÍ}

85. manñeka: Euterpe precatoria

86. nené: Bactris gasipaes

87. ruchi: Lepidocaryum tenue

\section{CARAPANA}




88. $\quad$ ineño: Bactris gasipaes
89. neeño: Mauritia flexuosa
CARIJONA
90. akəi: Oenocarpus bacaba
91. amana: Cocos nucifera
92. $\quad$ awara: Astrocaryum jauari
93. harehu eht: Bactris gasipaes
94. hiriwa: Socratea exorrhiza
95. hiriwaime iwakuchano: Iriartea deltoidea
96. $\quad$ kubarri: Bactris fissifrons
97. kumu: Oenocarpus bataua
98. $\quad$ kumuchikinibə: Indeterminada
99. kwai: Mauritia carana
100. $\quad$ kwai: Mauritia flexuosa
101. mariha: Attalea maripa
102. menaba: Indeterminada
103. $\quad$ tosoremi: Indeterminada
104. wahu: Euterpe precatoria
105. wasekumu: Oenocarpus bacaba

\section{CHIMILA}

106. naa: Indeterminada

\section{COCAMA}

107. chipati: Phytelephas macrocarpa

108. manáka: Euterpe precatoria

109. popui: Bactris sp.

110. yuitsára: Indeterminada

\section{COFÁN}

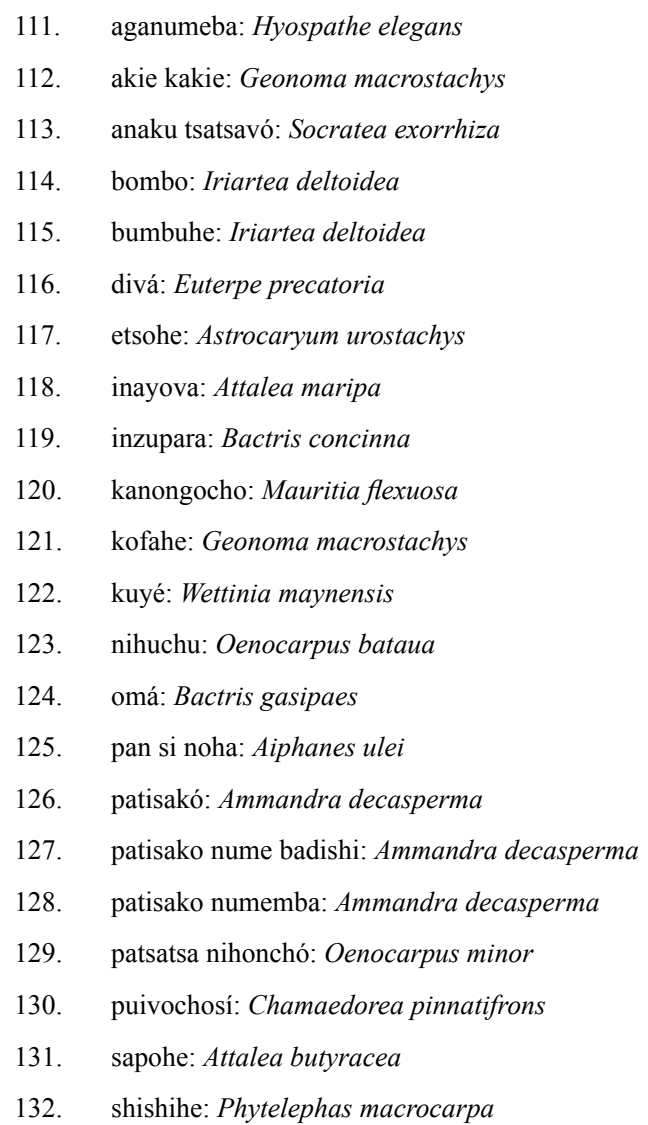

133. shishihe: Phytelephas tenuicaulis

134. tananako: Mauritiella aculeata

135. tsao he tsi: Geonoma polyandra

136. tuinfa: Astrocaryum chambira

137. umachúkusu: Bactris simplicifrons

138. wikungo: Astrocaryum urostachys

139. zuhé: Geonoma maxima

140. zuteyecho: Prestoea schultzeana

\section{CUBEO}

141. amábamu: Desmoncus sp.

142. bahiñ̃: Indeterminada

143. betoñi: Astrocaryum chambira

144. bokohañu: Oenocarpus bataua

145. boreyabeñu: Oenocarpus bataua

146. boriyabeañi: Oenocarpus bacaba

147. chinañi: Mauritia carana

148. duebokohañu: Oenocarpus bataua

149. duibokane: Oenocarpus bataua

150. ebáñ̇ maihóbariño: Socratea exorrhiza

151. echídiñi: Attalea maripa

152. emimoe: Euterpe precatoria

153. emumeke: Attalea racemosa

154. éwañi: Iriartea deltoidea

155. éwani kíhiñi: Socratea exorrhiza

156. hebukanu: Oenocarpus bataua

157. hiabetoñi: Astrocaryum jauari

158. hókiki: Astrocaryum chambira

159. iné: Bactris gasipaes

160. ث̀reñi: Bactris gasipaes

161. kãhíka tsiambo: Astrocaryum acaule

162. kõhãñi boriyabeañi: Oenocarpus bacaba

163. kõhãñi pũrãmãñi: Oenocarpus bataua

164. kohañu: Oenocarpus bataua

165. kokoñi: Cocos nucifera

166. kubañi: Mauritiella armata

167. miyabikimũ: Desmoncus sp.

168. mũ̃: Mauritia carana

169. muichiãbo: Manicaria saccifera

170. muíñi: Mauritia carana

171. mũuũuá: Astrocaryum chambira

172. muy: Lepidocaryum tenue

173. náamemu: Desmoncus sp.

174. nãhõemimueñi: Euterpe oleracea

175. nain: Mauritia flexuosa

176. neiñi: Mauritia flexuosa

177. ñobeañi: Socratea exorrhiza

178. ñopoñu: Socratea exorrhiza

179. ñúkañi: Astrocaryum chambira

180. pimpiñu: Iriartella setigera 


$$
\begin{aligned}
& \text { 181. piohoko: Socratea exorrhiza } \\
& \text { 182. pioñi: Indeterminada } \\
& \text { 183. pũrámañũ: Oenocarpus bataua } \\
& \text { 184. } \\
& \text { 185. yachi: Manicaria saccifera } \\
& \text { 186. yapó: Attalea } \text { sp. }
\end{aligned}
$$

\section{CUIBA}

187. badeiboto: Indeterminada
188. hohomboto: Indeterminada
189. inhoboto: Mauritia flexuosa
190. koboto: Indeterminada
191. kotsiboto: Indeterminada
192. machepaboto: Indeterminada
193. manboto: Indeterminada
194. michiboto: Indeterminada
195. naknüdüboto: Indeterminada
196. odoboto: Indeterminada
197. pawenaboto: Indeterminada
198. tseneneboto: Indeterminada
199. yopiboto: Indeterminada

\section{CUNA}

$\begin{array}{ll}\text { 200. } & \text { alar: Bactris barronis } \\ 201 . & \text { gui: Bactris maraja } \\ 202 . & \text { gui wala: Bactris maraja } \\ 203 . & \text { ibe: Oenocarpus bataua } \\ 204 . & \text { iko: Bactris gasipaes } \\ 205 . & \text { ila: Indeterminada } \\ 206 . & \text { ipki: Bactris sp. } \\ 207 . & \text { mogor: Bactris maraja } \\ 208 . & \text { nalu: Bactris gasipaes } \\ 209 . & \text { napa: Indeterminada } \\ 210 . & \text { okop: Cocos nucifera } \\ 211 . & \text { pol: Chamaedorea } \text { sp. } \\ 212 . & \text { sagu: Phytelephas schottii } \\ 213 . & \text { samake: Elaeis oleifera } \\ 214 . & \text { sin nuar: Bactris coloradonis } \\ 215 . & \text { soso: Sabal mauritiiformis } \\ 216 . & \text { tagará: Indeterminada } \\ 217 . & \text { waa: Indeterminada }\end{array}$

\section{CURRIPACO}

$\begin{array}{ll}218 . & \text { dówirri: Bactris campestris } \\ 219 . & \text { ẽeñá: Socratea exorrhiza } \\ 220 . & \text { ítebi: Mauritia flexuosa } \\ \text { 221. } & \text { kadanarite: Mauritiella aculeata } \\ 222 . & \text { kamawa: Desmoncus polyacanthos } \\ 223 . & \text { kumaria: Astrocaryum sp. } \\ 224 . & \text { kwétirri: Attalea maripa } \\ 225 . & \text { kwiapé: Attalea racemosa } \\ 226 . & \text { maalama: Leopoldinia piassaba }\end{array}$

242. wáketi: Astrocaryum chambira

243. wati: Manicaria saccifera

244. watipie: Indeterminada

\section{DAMANA}

245. alúnka: Astrocaryum malybo

246. shakána: Acrocomia aculeata

\section{DESANO}

247. behépũ: Attalea sp.

248. egấ: Attalea maripa

249. mîhî́: Euterpe precatoria

250. mii: Socratea exorrhiza

251. mohấ: Mauritiella armata

252. mohî́: Mauritia carana

253. néñu: Mauritia flexuosa

254. ñitmí: Oenocarpus bataua

255. $\quad \tilde{n}^{\mathrm{h}} \mathrm{k}^{\mathrm{h}}$ á $\mathrm{p}^{\mathrm{h}}$ ora: Astrocaryum chambira

256. ñumúñu: Iriartea deltoidea

257. ñumúñu: Oenocarpus bacaba

258. ñumúñu ñóre: Iriartea deltoidea

259. ríño: Bactris gasipaes

260. tarábwa mĩhî́: Euterpe oleracea

261. tarapắnẽ: Euterpe oleracea

\section{EMBERA}

262. arrá: Iriartea deltoidea

263. arra sĩ: Socratea exorrhiza

264. arú: Oenocarpus bataua

265. ãtá: Phytelephas schottii

266. ãyüsü: Indeterminada

267. chacarrá: Bactris spp.

268. chichi $\mathrm{p}^{\mathrm{h}} \mathrm{uru}$ : Prestoea decurrens

269. chuppí: Wettinia hirsuta

270. dokiduá: Geonoma calyptrogynoidea

271. guagai: Desmoncus cirrhifer

272. guaiko: Geonoma deversa 


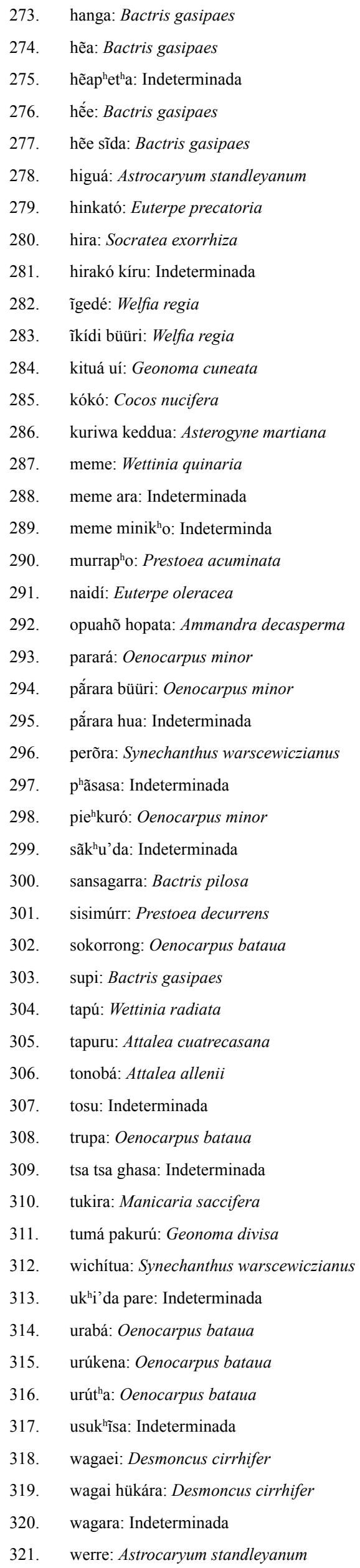

\section{GUAMBIANO}

322. malontus: Indeterminada

\section{GUAYABERO}

323. báha: Euterpe precatoria

324. guypani: Euterpe precatoria

325. kaméla: Astrocaryum sp.

326. kapa: Indeterminada

327. kaparxéla: Indeterminada

328. makófa: Indeterminada

329. nohá: Mauritia flexuosa

330. papí: Bactris gasipaes

331. patówa: Indeterminada

332. woibúwa: Indeterminada

333. xü: Oenocarpus bataua

IKA

334. ennəkənə: Indeterminada

335. kəmme $\mathrm{e}^{\mathrm{h}}$ kia: Indeterminada

336. koku: Cocos nucifera

337. məro'ta: Indeterminada

338. siri: Indeterminada

339. torko: Indeterminada

\section{INGA}

340. buitsaha: Prestoea acuminata

\section{JITNU}

341. arákbot: Indeterminada

342. kálaha: Indeterminada

343. kaniébot: Indeterminada

344. kóchbot: Attalea butyracea

345. komálbot: Socratea exorrhiza

346. kopbót: Cocos nucifera

347. kwátbot: Mauritia flexuosa

348. málibot: Aiphanes horrida

349. mapórbot: Roystonea oleracea

350. nakálbot: Indeterminada

351. okú bot: Oenocarpus bataua

352. pawénbot: Syagrus sancona

353. yabapút: Indeterminada

354. yakorchít: Indeterminada

355. yoíbot: Indeterminada

\section{JUPDA}

356. kob: Indeterminada

\section{KAKUA}

357. bupasantû́: Desmoncus sp.

358. dekó': Astrocaryum jauari

359. dúutëgn: Mauritiella armata

360. himentếgn: Iriartea deltoidea

361. himuntếgn: Socratea exorrhiza

362. kaĩngát: Manicaria saccifera

363. kaĩntokëgn: Manicaria saccifera 


\begin{tabular}{|c|c|}
\hline 364. & kerantếgn: Euterpe precatoria \\
\hline 365. & kokbá': Attalea sp. \\
\hline 366. & komtëgn: Astrocaryum chambira \\
\hline 367. & pu'tëgn: Iriartea deltoidea \\
\hline 368. & sabáhtếgn: Iriartella setigera \\
\hline 369. & síbim: Oenocarpus bacaba \\
\hline 370. & te hế: Astrocaryum gynacanthum \\
\hline 371. & tokết: Mauritia carana \\
\hline 372. & ut agn: Astrocaryum jauari \\
\hline 373. & wátégn: Oenocarpus bataua \\
\hline 374. & ya'tëgn: Mauritia flexuosa \\
\hline 375. & yak: Mauritia flexuosa \\
\hline 376. & yüutëgn: Bactris gasipaes \\
\hline
\end{tabular}

\section{KAMSÁ}

377. tsashá: Indeterminada

\section{KOGUI}

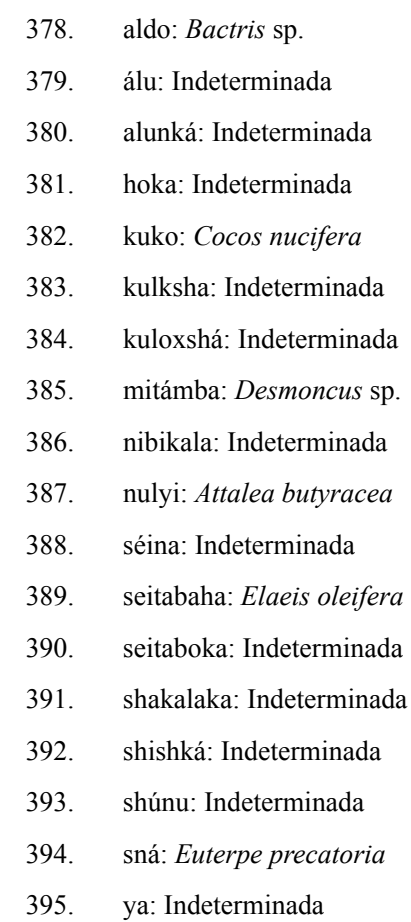

\section{KOREGUAJE}

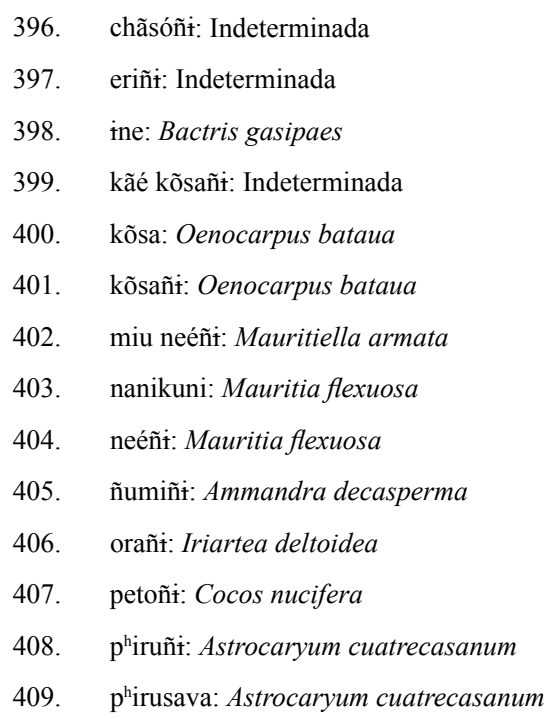
410. pũtiñi: Attalea maripa
411. vea orañi: Indeterminada
412. viiñ̃: Indeterminada

\section{MACUNA}

413. biptma: Mauritiella aculeata
414. bosó mohe: Geonoma pycnostachys
415. buhanñe kawne: Iriartella setigera
416. buhugó: Iriartella setigera
417. bwìmesé: Desmoncus polyacanthos
$418 . \quad$ guakaria: Oenocarpus bataua
419. hĩõ: Iriartea deltoidea
420. hota: Bactris gasipaes
421. hotá: Bactris gasipaes
422. hotaño: Bactris gasipaes

\section{MIRAÑA}

423. a ibacom ba: Chelyocarpus ulei

424. aaboméeme: Bactris simplicifrons

425. aakaiba: Chamaedorea pauciflora

426. aayae: Iriartea deltoidea

427. aheko: Lepidocaryum tenue

428. ahi: Lepidocaryum tenue

429. atibakomo: Geonoma camana

430. ayako: Iriartea deltoidea

431. bè̀'ì: Indeterminada

432. beeiba: Astrocaryum ciliatum

433. boobo mehe: Bactris bidentula

434. bubúmemëeku: Bactris acanthocarpa

435. chiikotsige: Oenocarpus minor

436. dipirie: Astrocaryum gynacanthum

437. eyiipanae: Geonoma brongniartii

438. güaseretba: Attalea insignis

439. iigüae: Mauritiella aculeata

440. iisuva: Astrocaryum ciliatum

441. iñee: Mauritia flexuosa

442. ikwahii: Socratea exorrhiza

443. inế'ềtsóó’ò: Mauritia flexuosa

444. iñéhe: Mauritia carana

445. ínềkáhá: Mauritia flexuosa

446. iyase: Iriartea deltoidea

447. kadoemeíba: Hyospathe elegans

448. kateehiko: Bactris riparia

449. koomehi: Oenocarpus bataua

450. kòomi: Oenocarpus bataua

451. lakae: Chamaedorea pauciflora

452. marím ipa: Itaya amicorum

453. méeme: Bactris gasipaes

454. meeninehee: Astrocaryum ciliatum

455. meikeze: Geonoma maxima

456. mekwátbak: Manicaria saccifera 


\begin{tabular}{|c|c|}
\hline 457. & nühü'è̀húü'ò: Astrocaryum chambira \\
\hline 458. & taahiyie: Manicaria saccifera \\
\hline 459. & tataba: Geonoma deversa \\
\hline 460. & tegpayage: Lepidocaryum tenue \\
\hline 461. & ti aakaiba: Chamaedorea pauciflora \\
\hline 462. & tiiyaña: Mauritiella aculeata \\
\hline 463. & tóókëİ'ìibà: Indeterminada \\
\hline 464. & toókee: Syagrus smithii \\
\hline 465. & tooyłge: Euterpe precatoria \\
\hline 466. & totue: Euterpe catinga \\
\hline 467. & yipirie: Astrocaryum jauari \\
\hline
\end{tabular}

\section{MUINANE}

468. amu móomoo: Bactris gasipaes

469. babayhu igai: Oenocarpus bataua

470. bahe móomoo: Bactris sp.

471. beeremiku haheku: Lepidocaryum tenue

472. bibimiku háheku: Lepidocaryum tenue

473. bobaymeku: Astrocaryum ciliatu

474. bubumimeku: Geonoma macrostachys

475. bubuy híyuhí: Geonoma poeppigiana

476. buha tuuko: Attalea butyracea

477. burremomosuu: Bactris simplicifrons

478. buru móomoo: Bactris maraja

479. chéereé: Oenocarpus bacaba

480. cherée: Oenocarpus minor

481. chetresuu: Oenocarpus minor

482. chuemì móomoo: Bactris gasipaes

483. cigao háheku: Lepidocaryum tenue

484. citaganomeku: Chamaedorea pauciflora

485. dágui inóho: Mauritia carana

486. deene háhe: Lepidocaryum tenue

487. diku háheku: Lepidocaryum tenue

488. faiba móomoo: Bactris acanthocarpa

489. famórahe móomoo: Bactris gasipaes

490. fat $\dot{\mathrm{i}}$ tuuko: Attalea insignis

491. fiiboto inóho: Mauritiella aculeata

492. gaikuhe móomoo: Bactris gasipaes

493. gekage: Attalea insignis

494. gisire tuuko: Attalea insignis

495. gisiremóomo: Astrocaryum jauari

496. gisiree: Wettinia augusta

497. gisiri babaimeku: Bactris simplicifrons

498. gukureku: Bactris elegans

499. haaba móomoo: Bactris simplicifrons

500. haadió kuume: Oenocarpus bataua

501. haani móomoo: Bactris simplicifrons

502. hakumoho: Desmoncus polyacanthos

503. hanameku: Bactris elegans

504. háyaeu: Iriartea deltoidea
505. hayaku: Iriartea deltoidea

506. hibohakimoi: Desmoncus polyacanthos

507. hthao: Dictyocaryum ptarianum

508. hiko néhee: Astrocaryum jauari

509. hłmáhay usegay inóho: Mauritia flexuosa

510. hiobo hiyui: Geonoma deversa

511. hiowoohiyui: Geonoma pycnostachys

512. hiyui: Geonoma pycnostachys

513. híyyuhi: Geonoma sp.

514. huáho: Attalea maripa

515. huchahi móomoo: Bactris gasipaes

516. idyúuku: Geonoma maxima

517. igaiko: Socratea exorrhiza

518. igüayi: Socratea exorrhiza

519. theku: Bactris gasipaes

520. iibuimi: Geonoma macrostachys

521. iidtkuumee: Oenocarpus bataua

522. iihinoho: Oenocarpus bacaba

523. imemi: Astrocaryum gynacanthum

524. imiya hakimoi: Desmoncus mitis

525. inoho: Mauritia flexuosa

526. kaamába inóho: Mauritia flexuosa

527. kaatłku inóho: Mauritia flexuosa

528. kigao hahe: Pholidostachys synanthera

529. kirídyahe: Oenocarpus bataua

530. komée: Oenocarpus bataua

531. kuméerio: Oenocarpus bataua

532. matáigahiba: Astrocaryum chambira

533. meemedihe móomoo: Bactris gasipaes

534. meenime kanifai inóho: Mauritia flexuosa

535. meenimi néhe: Astrocaryum gynacanthum

536. memer imóomo: Bactris simplicifrons

537. miihibao: Chamaedorea pinnatifrons

538. miya hiyui: Geonoma deversa

539. miya inóho: Mauritia flexuosa

540. mimeuhe móomoo: Bactris gasipaes

541. momo: Desmoncus polyacanthos

542. momó igaiku: Wettinia augusta

543. móomo: Bactris gasipaes

544. móomo igaiku: Iriartella setigera

545. móomo igaiku: Iriartella stenocarpa

546. nebau: Bactris sp.

547. nebau inóho: Mauritia flexuosa

548. neebáu: Bactris acanthocarpa

549. néhe: Astrocaryum chambira

550. nibigai tuko: Attalea insignis

551. nigo taagaiho: Oenocarpus bacaba

552. níihivigai tuko: Attalea racemosa

553. niya háheku: Lepidocaryum tenue 


\begin{tabular}{|c|c|c|c|}
\hline 554. & paaríba: Bactris gasipaes & 601. & tërukë: Oenocarpus bataua \\
\hline 555. & sisi nehéame: Bactris killipii & 602. & tëwpëdë: Bactris maraja \\
\hline 556. & sisimohomo: Bactris hirta & 603. & ú baká: Iriartella setigera \\
\hline 557. & taaba móomoo: Bactris riparia & 604. & ut: Astrocaryum chambira \\
\hline 558. & taaba néhe: Astrocaryum jauari & 605. & wamni: Astrocaryum chambira \\
\hline 559. & taagaho: Oenocarpus bacaba & 606. & weí: Astrocaryum gynacanthum \\
\hline 560. & tabahiyui: Geonoma pycnostachys & 607. & yáab butu: Oenocarpus bacaba \\
\hline 561. & takimiku: Socratea exorrhiza & 608. & yab: Oenocarpus bataua \\
\hline 562. & ttehakimot: Desmoncus polyacanthos & 609. & yúbudi: Euterpe precatoria \\
\hline 563. & tuhe kumee: Oenocarpus bataua & \multicolumn{2}{|c|}{ OCAINA } \\
\hline 564. & tukomeku: Attalea microcarpa & 610. & hamehe: Bactris sp. \\
\hline 565. & tuugiku inóho: Mauritia flexuosa & 611. & mek: Bactris gasipaes \\
\hline 566. & tuuguiye móomoo: Bactris gasipaes & \multicolumn{2}{|c|}{ PÁEZ } \\
\hline 567. & tuuguiyi: Euterpe precatoria & 612. & $\mathrm{k}^{\mathrm{h}} \mathrm{ambu} \mathrm{f}^{\mathrm{y} t u}$ : Indeterminada \\
\hline 568. & tuuko: Attalea racemosa & 613. & koko tas ${ }^{\mathrm{y}}$ : Indeterminada \\
\hline 569. & tuumo hahéku: Geonoma sp. & 614. & lamus: Indeterminada \\
\hline 570. & tuutuku: Bactris maraja & 615 & lamus tas ${ }^{\mathrm{y}}$ : Indeterminada \\
\hline 571. & uheeka: Chamaedorea pauciflora & 616. & well fytu: Indeterminada \\
\hline 572. & ure inóho: Mauritiella aculeata & \multicolumn{2}{|c|}{ PIAPOCO } \\
\hline 573. & uuheuté: Bactris balanophora & 617. & chìkichìki: Leopoldinia piassaba \\
\hline 574. & víikume: Geonoma pycnostachys & 618. & dàapui: Astrocaryum sp. \\
\hline 575. & yaimu deku: Bactris hirta & 619. & eesí: Syagrus orinocensis \\
\hline 576. & ÿ̈su: Euterpe catinga & 620 & éeya: Indeterminada \\
\hline 577. & yuimiku: Geonoma pycnostachys & 621. & idéwi: Mauritia flexuosa \\
\hline \multicolumn{2}{|c|}{ NUKAK } & 622. & kamawa: Desmoncus orthacanthos \\
\hline 578. & bãb: Astrocaryum gynacanthum & 623. & katànali: Mauritia carana \\
\hline 579. & bëi': Iriartea deltoidea & 624. & katanári: Mauritia carana \\
\hline 580. & bĩdĩ: Bactris gasipaes & 625 & kumàli: Astrocaryum chambira \\
\hline 581. & blui: Geonoma deversa (Transcripción dudosa por el tipo de & 626. & kurùada: Indeterminada \\
\hline \multicolumn{2}{|r|}{ estructura silábica; ‘bl’ no es una secuencia en lenguas amazónicas) } & 627. & kuzìi: Indeterminada \\
\hline 582. & búyup: Bactris gasipaes & 628. & mabako: Attalea butyracea \\
\hline 583. & eú: Mauritia flexuosa & 629. & maháwita: Indeterminada \\
\hline 584. & habutu: Oenocarpus bacaba & 630. & makupàisi: Oenocarpus bacaba \\
\hline 585. & hubudi: Oenocarpus bacaba & 631. & manakai: Euterpe precatoria \\
\hline 586. & huiúi: Attalea sp. & 632. & maráma: Leopoldinia piassaba \\
\hline 587. & huniuni: Bactris gasipaes & 633. & máwi: Indeterminada \\
\hline 588. & huru: Socratea exorrhiza & 634. & mivi: Iriartella setigera \\
\hline 589. & hurudã: Socratea exorrhiza & 635. & pìpiri: Bactris gasipaes \\
\hline 590. & huruda wa: Iriartea deltoidea & 636. & poá: Socratea exorrhiza \\
\hline 591. & huyũdĩ: Bactris gasipaes & 637. & púba: Indeterminada \\
\hline 592. & huyup: Attalea maripa & 638. & pubèeri: Oenocarpus bacaba \\
\hline 593. & i’: Bactris maraja & 639. & pùnama: Oenocarpus bataua \\
\hline 594. & ĩrẽ̃: Bactris gasipaes & 640. & puzùi: Indeterminada \\
\hline 595. & kaadĩdë: Attalea maripa & 641. & táina: Indeterminada \\
\hline 596. & kurá: Attalea maripa & 642. & wàakézi: Indeterminada \\
\hline 597. & máam: Astrocaryum gynacanthum & 643. & wisìri: Attalea maripa \\
\hline 598. & pahp: Bactris maraja & \multicolumn{2}{|c|}{ PIAROA } \\
\hline 599. & popere: Oenocarpus minor & 644. & bareu puori: Oenocarpus bataua \\
\hline 600. & tai': Oenocarpus minor & 645. & $\mathrm{du}$ : Bactris corossilla \\
\hline
\end{tabular}




$\begin{array}{ll}\text { 646. } & \text { isoi: Oenocarpus bataua } \\ 647 . & \text { kämahuä: Desmoncus orthacanthos } \\ 648 . & \text { kumàli: Astrocaryum chambira } \\ \text { 649. } & \text { kusí: Attalea racemosa } \\ 650 . & \text { madi: Bactris acanthocarpa } \\ 651 . & \text { manaká: Euterpe catinga } \\ 652 . & \text { marama: Leopoldinia piassaba } \\ 653 . & \text { nenea: Euterpe precatoria } \\ 654 . & \text { pahare: Bactris gasipaes } \\ 655 . & \text { peédi: Oenocarpus bataua } \\ 656 . & \text { pio ü puori: Oenocarpus bacaba } \\ 657 . & \text { poabä: Socratea exorrhiza } \\ 658 . & \text { siná: Mauritiella armata } \\ 659 . & \text { uriá: } \text { Mauritiella aculeata } \\ 660 . & \text { wächäi: Attalea maripa } \\ 661 . & \text { warí: Mauritia flexuosa } \\ 662 . & \text { yarí: Astrocaryum chambira } \\ 663 . & \text { yurua: Iriartella setigera }\end{array}$

\section{PIRATAPUYO}

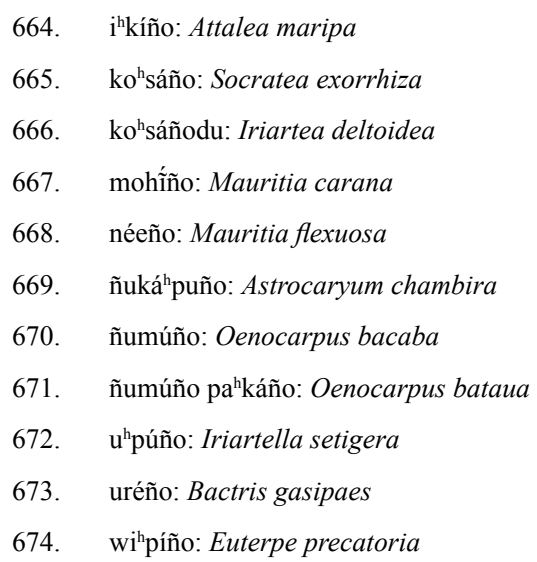

\section{PISAMIRA}

675. ineño: Bactris gasipaes

\section{PUINAVE}

$\begin{array}{ll}\text { 676. } & \text { boiünüm: Attalea racemosa } \\ 677 . & \text { boyon: Attalea racemosa } \\ 678 . & \text { guom: } \text { Mauritia carana } \\ 679 . & \text { guom sowai: Socratea exorrhiza } \\ 680 . & \text { hañõn: Leopoldinia piassaba } \\ 681 . & \text { ium: Oenocarpus bataua } \\ 682 . & \text { iyõ: } \text { Mauritia flexuosa } \\ 683 . & \text { ka wan: Desmoncus polyacanthos } \\ 684 . & \text { kumaki: } \text { Astrocaryum chambira } \\ 685 . & \text { kupa: Socratea exorrhiza } \\ 686 . & \text { manamazu: Leopoldinia } \text { sp. } \\ 687 . & \text { maramá: Leopoldinia piassaba } \\ 688 . & \text { mõm: Bactris gasipaes } \\ 689 . & \text { muri: Bactris gasipaes } \\ 690 . & \text { paipigu: Bactris concinna } \\ 691 . & \text { pum: Mauritiella armata }\end{array}$

692. som: Indeterminada

693. tayó: Iriartella setigera

694. tuí: Lepidocaryum tenue

695. tuí: Mauritia carana

696. udkám: Astrocaryum acaule

697. ut: Bactris hirta

698. vuó: Oenocarpus bataua

699. waibí: Attalea maripa

700. wo: Oenocarpus bataua

701. yodpi: Euterpe precatoria

702. yorod: Indeterminda

703. yot: Euterpe precatoria

704. yot pigot: Euterpe catinga

705. yot pigot: Euterpe precatoria

706. yuipa: Leopoldinia pulchra

707. yum: Oenocarpus bataua

\section{SÁLIBA}

708. ikutiñu: Attalea butyracea

709. kumaliñu: Astrocaryum chambira

710. kusi: Indeterminada

711. 1lĩde: Mauritia flexuosa

712. ñala: Acrocomia aculeata

713. nenichi: Euterpe precatoria

714. wãcha ikuti: Indeterminada

\section{SECOYA}

715. chuchana: Astrocaryum urostachys

716. dédé: Geonoma pycnostachys

717. gõsa: Oenocarpus bataua

718. huákó: Chamaedorea pauciflora

719. huansódédé: Geonoma macrostachys

720. huasóui: Hyospathe elegans

721. kahúe: Prestoea schultzeana

722. kãti neé: Mauritiella armata

723. lutawe oko: Hyospathe elegans

724. ma neé: Mauritia flexuosa

725. ma puĩ: Hyospathe elegans

726. mĩũ f́nẽ: Bactris gasipaes

727. naí: Prestoea schultzeana

728. níní: Geonoma brongniartii

729. niní puĩ: Geonoma sp.

730. nukë: Bactris concinna

731. nyoko: Iriartea deltoidea

732. okópui: Geonoma macrostachys

733. paí: Geonoma macrostachys

734. sewa: Phytelephas sp.

735. sirá: Astrocaryum urostachys

736. soto neé: Mauritia flexuosa

737. wakó: Geonoma sp.

738. wikungo: Astrocaryum urostachys 
739. wiyapé́nẽ: Bactris gasipaes
740. yaṕ́: Attalea sp.

\section{SIKUANI}

741. ainawiboto: Bactris maraja

742. ataiboto: Oenocarpus bataua

743. buibuiboto: Bactris acanthocarpa

744. butsiboto: Iriartea deltoidea

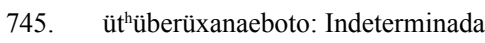

746. hipiriboto: Bactris gasipaes

747. inohoboto: Mauritia flexuosa

748. inóho: Mauritia flexuosa

749. kamaroboto: Leopoldinia major

750. kamuuaboto: Desmoncus sp.

751. kamuvé: Desmoncus orthacanthos

752. kamuvé: Desmoncus polyacanthos

753. kubaruboto: Bactris setulosa

754. kumaliboto: Astrocaryum chambira

755. kumari: Astrocaryum chambira

756. kupéri: Oenocarpus minor

757. liwai: Iriartella setigera

758. makapéiboto: Oenocarpus minor

759. makopahiboto: Oenocarpus minor

760. manakái: Euterpe precatoria

761. manakaiboto: Euterpe precatoria

762. mapoloboto: Roystonea oleracea

763. matawakuliboto: Astrocaryum acaule

764. mavaco: Attalea racemosa

765. mawiboto: Iriartella setigera

766. misíboto: Iriartea deltoidea

767. misiboto: Socratea exorrhiza

768. naxareboboto: Attalea maripa

769. ohaüboto: Oenocarpus bacaba

770. oróboto: Syagrus orinocensis

771. pawenaboto: Syagrus sancona

772. pewitsaboto: Oenocarpus bataua

773. purumaboto: Attalea butyracea

774. sikisikiboto: Leopoldinia piassaba

775. towihiboto: Attalea insignis

776. toxoloboto: Oenocarpus bataua

777. tseneboto: Mauritiella armata

778. vávara: Geonoma deversa

779. walamaboto: Mauritiella aculeata

780. watiboto: Manicaria saccifera

781. wawarabotoo: Geonoma deversa

782. xanaeboto: Astrocaryum gynacanthum

783. yawalaboto: Acrocomia aculeata

784. yopihiboto: Astrocaryum jauari

\section{SIONA}

785. anhídadu: Geonoma triglochin
786. bayóñne: Bactris gasipaes

787. besotúntu: Desmoncus mitis

788. beto: Astrocaryum chambira

789. bonbon: Socratea exorrhiza

790. chambira: Astrocaryum chambira

791. chuchana: Astrocaryum urostachys

792. dadu: Geonoma macrostachys

793. dédé bui: Geonoma polyandra

794. dedewekó: Hyospathe elegans

795. dídi: Geonoma polyandra

796. diha dédé: Geonoma pycnostachys

797. emedere: Geonoma maxima

798. eneño: Bactris gasipaes

799. huákó: Chamaedorea pauciflora

800. huatiwí: Bactris corossilla

801. huikosa: Oenocarpus minor

802. huirrima: Astrocaryum jauari

803. inibue: Euterpe precatoria

804. kanangucho: Mauritia flexuosa

805. kantineé: Mauritiella armata

806. kosá: Oenocarpus bataua

807. kuikúi: Bactris acanthocarpa

808. manyokónnẽ: Bactris gasipaes

809. naí: Prestoea schultzeana

810. nayahuëdadu: Geonoma macrostachys

811. neé: Mauritia flexuosa

812. ñikó: Socratea exorrhiza

813. ñukuaéné: Chamaedorea pinnatifrons

814. nyũkwa: Astrocaryum chambira

815. obá: Iriartea deltoidea

816. okó puí: Geonoma macrostachys

817. okobeto: Astrocaryum jauari

818. ora mio: Aiphanes ulei

819. pa í ine: Bactris riparia

820. pa pa: Attalea butyracea

821. púi: Geonoma triglochin

822. sehua: Phytelephas tenuicaulis

823. shimbu: Oenocarpus minor

824. sirá: Astrocaryum urostachys

825. sute dédé: Geonoma deversa

826. sute ëne: Bactris simplicifrons

827. tuntu: Desmoncus giganteus

828. tute dede: Geonoma pycnostachys

829. túte sewa: Ammandra decasperma

830. uná: Bactris gasipaes

831. ungurahua: Oenocarpus bataua

832. waho: Attalea maripa

833. watosuné: Bactris simplicifrons

834. wi: Bactris concinna 


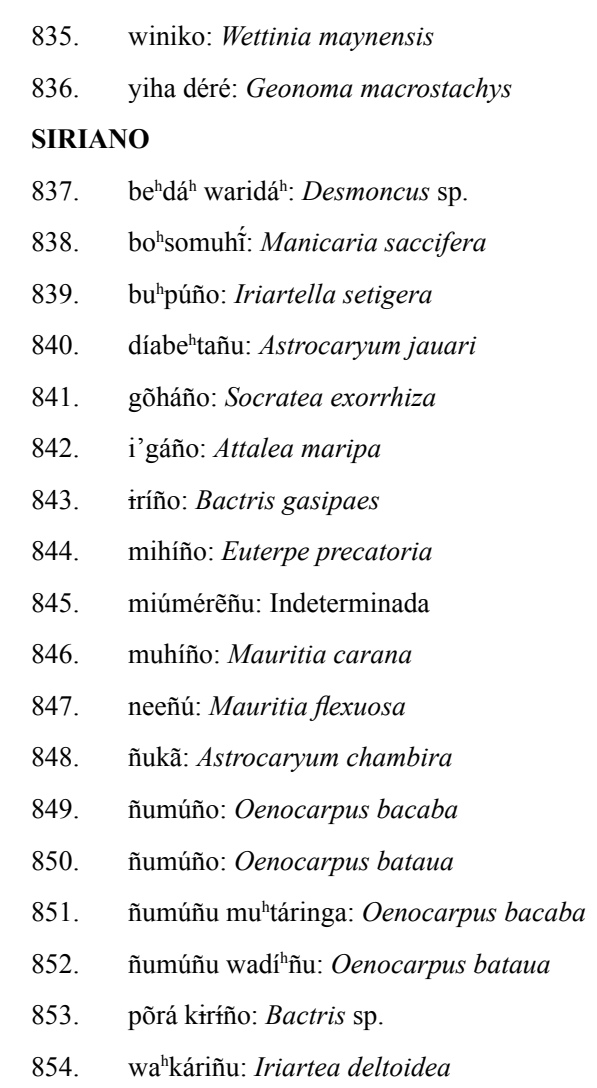

\section{TAIWANO}

855. ernde: Bactris gasipaes

856. muhí: Lepidocaryum tenue

\section{TANIMUCA}

857. bui ñoõmĩá: Oenocarpus sp.

858. emifoõa: Oenocarpus circumtextus

859. fífia: Euterpe precatoria

860. ireẽa: Bactris gasipaes

861. karuũ ruka: Oenocarpus sp.

862. koaãka: Mauritiella sp.

863. muiña: Lepidocaryum tenue

864. neẽa: Mauritia flexuosa

865. ñomia: Oenocarpus bataua

866. ñoõmĩ wãrua: Oenocarpus sp.

867. ñoõmia karãka: Oenocarpus sp.

868. wahée: Manicaria saccifera

869. wuiro ñoõmĩá: Oenocarpus sp.

\section{TARIANO}

870. ampiapúne: Manicaria saccifera

871. eiñap ${ }^{\mathrm{h}} \mathbf{1}:$ Iriartea deltoidea

872. henípi: Astrocaryum jauari

873. kamavak há: Desmoncus sp.

874. kumaliphé: Astrocaryum chambira

875. mapanariphépi: Attalea sp.

876. mavip ${ }^{\mathrm{h}}$ i: Iriartella setigera

877. pípiriphi: Bactris gasipaes

878. punáma: Oenocarpus bacaba

879. punámap ${ }^{\mathrm{h}} \mathrm{i}$ Oenocarpus bataua
880. púne: Mauritia carana

881. pupaphí: Socratea exorrhiza

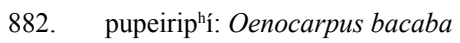

883. teevidá: Mauritia flexuosa

884. teuíra: Mauritia flexuosa

885. uriep ${ }^{\mathrm{h}} \mathrm{i}:$ Mauritiella armata

886. vesirip ${ }^{\mathrm{h}}$ : Attalea maripa

\section{TATUYO}
887. buño: Attalea maripa
888. ineño: Bactris gasipaes
889. ne: Mauritia flexuosa
890. ก̃omiño: Oenocarpus bataua
891. ñukaño: Astrocaryum chambira

\section{TIKUNA}

892. ã a naa kü: Euterpe catinga

893. arapara: Bactris brongniartii

894. awü: Cocos nucifera

895. borua: Oenocarpus minor

896. buu: Desmoncus polyacanthos

897. chaatü: Prestoea schulzeana

898. chata: Chamaedorea pauciflora

899. chiwü: Itaya amicorum

900. chuã: Geonoma interrupta

901. chúa: Geonoma interrupta

902. chüüta-ne: Geonoma atrovirens

903. dãi: Astrocaryum sp.

904. date: Bactris acanthocarpa

905. dauri: Mauritia flexuosa, var. de fruto rojo

906. dawü we: Bactris maraja

907. dea: Geonoma maxima

908. dea akü: Geonoma macrostachys

909. dea püwí: Geonoma pycnostachys

910. duku: Attalea microcarpa

911. düü: Oenocarpus bataua

912. eri: Attalea cf. septuagenata

913. etá: Iriartea deltoidea

914. eta: Socratea exorrhiza

915. etá irakü: Socratea exorrhiza

916. gũũ: Indeterminada

917. íntü: Bactris gasipaes

918. irawa: Geonoma atrovirens

919. Iitü: Bactris gasipaes

920. Iitü chikü: Bactris riparia

921. káámã: Indeterminada

922. kawna: Bactris bifida

923. koma: Astrocaryum jauari

924. kotu: Lepidocaryum tenue, nombre genérico

925. kurua: Attalea butyracea

926. kuu: Astrocaryum ferrugineum 


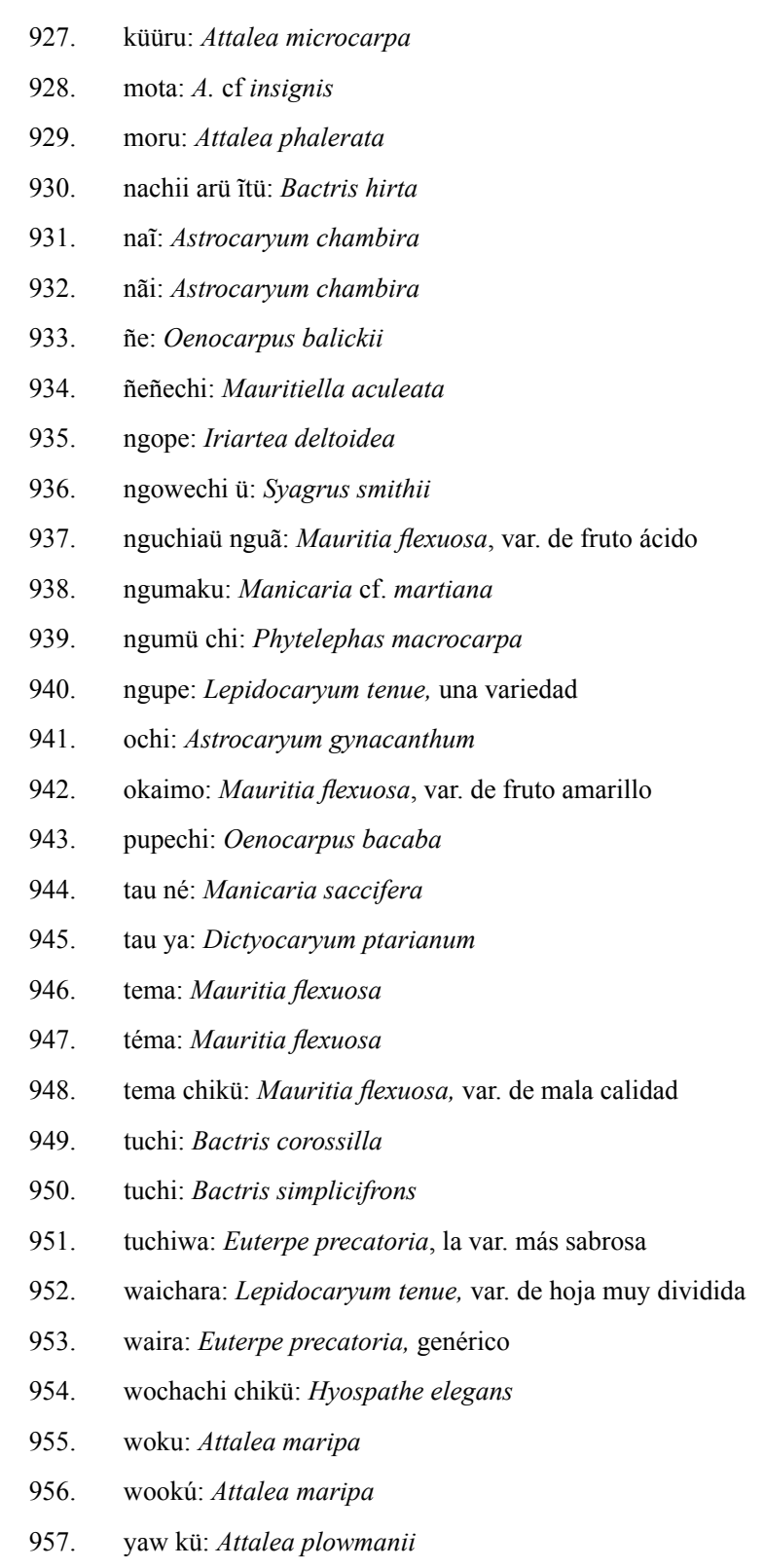

\section{TINIGUA}

958. hiimasa: Astrocaryum chambira

959. kwí'osa: Mauritia flexuosa

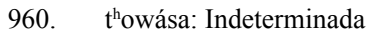

961. tsozúsa: Euterpe precatoria

962. yaósa: Bactris gasipaes

\section{TUKANO}

963. be táñó: Astrocaryum chambira

964. bo bomuhî́: Manicaria saccifera

965. bu ${ }^{\mathrm{h}}$ púño: Iriartella setigera

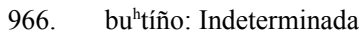

967. diábe tá: Astrocaryum jauari

968. inkiño: Attalea maripa

969. koáño: Mauritiella armata

970. kõhã: Mauritiella armata

971. kukuño: Cocos nucifera

972. mihĩñõ: Bactris fissifrons

973. min $^{\mathrm{h}}$ piño: Euterpe precatoria
974.
muhiño: Mauritia carana
975. nẽẽ: Mauritia flexuosa
976. neeñõ: Mauritia flexuosa
977. $\tilde{\text { ne }}$ tế: Astrocaryum gynacanthum
978. ne $\mathrm{h}^{\mathrm{h}}$ téño: Astrocaryum gynacanthum
979. ño ká: Astrocaryum chambira
980. ño ká pũrí: Astrocaryum chambira
981. ñumú: Oenocarpus bataua
982. ñumú mahká: Oenocarpus bacaba
983. ñumú omfahá: Oenocarpus bacaba
984. ñumú pa $a^{\mathrm{h} k a ́ n ̃ o: ~ O e n o c a r p u s ~ b a t a u a ~}$
985. pépunĩ: Attalea racemosa
986. pohtáño: Bactris elegans
987. potamé: Lepidocaryum tenue
988. pốtaño: Bactris elegans
989. ũréñu: Bactris gasipaes
990. wa ${ }^{\text {h }} \mathrm{a}^{\mathrm{h}}$ saro: Socratea exorrhiza
991. watáño: Socratea exorrhiza
992. wahtapahkeño: Iriartea deltoidea
993. waítudáh : Desmoncus sp.

\section{TUNEBO}

994. akeba: Indeterminada

995. ámara: Indeterminada

996. áricha: Indeterminada

997. arya: Indeterminada

998. bíbira: Bactris gasipaes

999. bíbora: Bactris gasipaes

1000. binakará: Bactris sp.

1001. ewatá: Indeterminada

1002. kachimeya: Bactris gasipaes

1003. ka ká: Bactris setulosa

1004. károwara: Oenocarpus bataua

1005. rukua: Indeterminada

1006. rurkuicha: Indeterminada

1007. sakuá: Indeterminada

1008. sarayá: Indeterminada

1009. siba: Indeterminada

1010. sínkuacha: Indeterminada

1011. sítuma: Oenocarpus bataua

\section{TUYUCA}

1012. beedá ${ }^{\mathrm{h}}$ : Desmoncus sp.

1013. betañṍ: Astrocaryum chambira

1014. bo bonũ̃: Manicaria saccifera

1015. bu ${ }^{\mathrm{h}}$ pup $^{\mathrm{h}}$ í: Iriartella setigera

1016. diabe táño: Astrocaryum jauari

1017. i ikí: Attalea maripa

1018. koấño: Mauritiella armata

1019. min píño: Euterpe precatoria

1020. mũ̃: Mauritia carana 


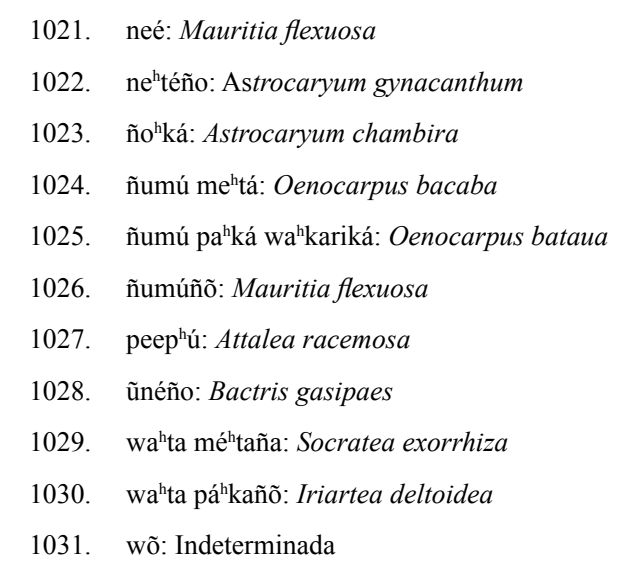

\section{UITOTO}

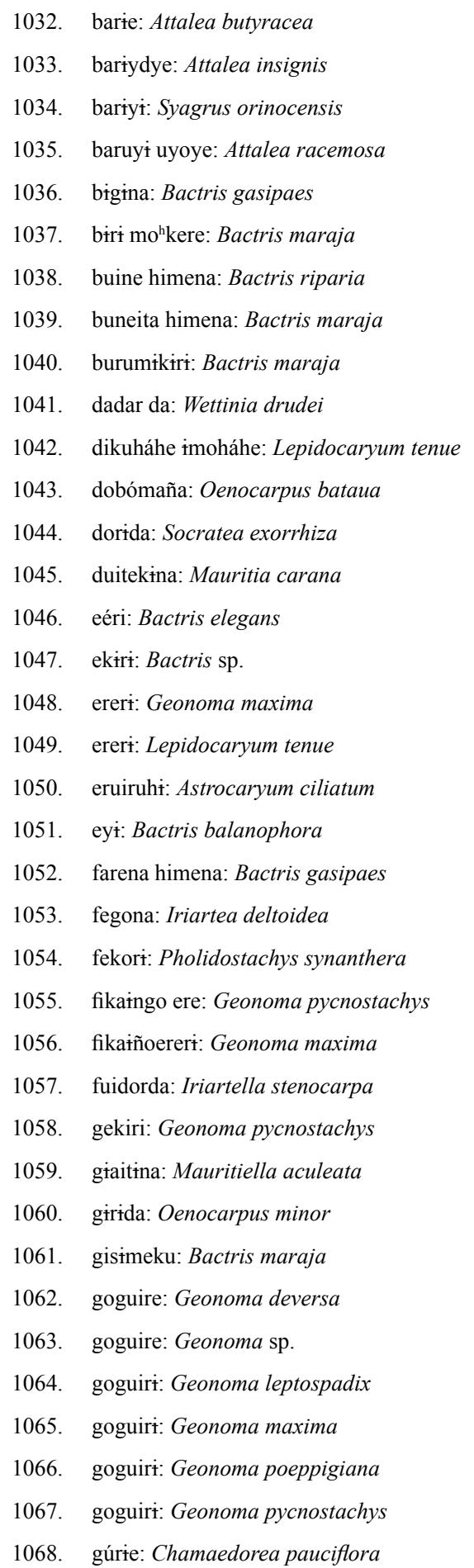

1069. gurina: Oenocarpus bacaba

1070. guriri: Geonoma maxima

1071. guruna: Oenocarpus minor

1072. gurure: Geonoma camana

1073. handabeke: Iriartella setigera

1074. harina: Attalea maripa

1075. harive: Attalea maripa

1076. hiaigina: Iriartea deltoidea

1077. htałkona himena: Bactris gasipaes

1078. hiaukiña: Mauritia flexuosa

1079. híduikì: Mauritia flexuosa

1080. hiidiko paña: Oenocarpus bataua

1081. hłkifegina: Dictyocaryum ptarianum

1082. hikipena: Dictyocaryum ptarianum

1083. hìkoñekina: Astrocaryum jauari

1084. himairi: Bactris riparia

1085. himaki: Bactris sp.

1086. himena: Bactris gasipaes

1087. himena ifué: Aiphanes ulei

1088. hitimoo: Desmoncus polyacanthos

1089. hoda himena: Bactris simplicifrons

1090. hoda himena: Bactris macroacantha

1091. hoda himena: Geonoma pycnostachys

1092. hoda himeru: Bactris simplicifrons

1093. hopadi kinena: Mauritia flexuosa

1094. huaguedadaerei: Geonoma maxima

1095. huikuriye: Astrocaryum ciliatum

1096. iágł himena: Bactris gasipaes

1097. idadarida: Wettinia drudei

1098. idatiñori: Bactris acanthocarpa

1099. ̇datinnori: Geonoma poeppigiana

1100. ididoye: Astrocaryum ciliatum

1101. ifue himena: Aiphanes ulei

1102. iiamaiki: Lepidocaryum tenue

1103. imeda: Socratea exorrhiza

1104. imekena: Bactris gasipaes

1105. iñori: Bactris acanthocarpa

1106. itina: Oenocarpus bacaba

1107. kañakoná: Mauritia carana

1108. kidóña: Bactris gasipaes

1109. kïyuakai: Iriartella setigera

1110. kikiño kikidye: Astrocaryum gynacanthum

1111. kodo dorida: Wettinia augusta

1112. komaíhe: Oenocarpus bataua

1113. komée: Oenocarpus bataua

1114. konéna: Mauritia flexuosa

1115. koriña: Astrocaryum jauari

1116. koruné: Astrocaryum jauari

1117. kuuña himena: Bactris gasipaes 

1118. mariha: Attalea maripa
1119. migoi hitimo: Desmoncus polyacanthos
1120. mógołoa: Bactris gasipaes
1121. munuikori: Bactris killipii
1122. nagnora himena: Bactris balanophora
1123. ñaigiri: Geonoma macrostachys
1124. ñaigúru: Geonoma macrostachys
1125. nakri: Hyospathe elegans
1126. needa: Euterpe catinga
1127. needa: Euterpe precatoria
1128. ñekina: Astrocaryum chambira
1129. niékero: Indeterminada
1130. nuikaro: Mauritiella aculeata
1131. ogoke kinena: Mauritia flexuosa
1132. oiktñe: Bactris gasipaes
1133. paatina: Oenocarpus bataua
1134. pareka kinena: Mauritia flexuosa
1135. pekor: Pholidostachys synanthera
1136. pikiño eerekwe: Bactris killipii
1137. ropokire: Lepidocaryum tenue
1138. ruiregó: Astrocaryum gynacanthum
1139. ruirda: Astrocaryum gynacanthum
1140. ruirtdye: Astrocaryum gynacanthum
1141. ruirui: Astrocaryum ciliatum
1142. sieñe: Astrocaryum ciliatum
1143. taagaiho: Oenocarpus sp.
1144. tero beña: Bactris gasipaes
1145. tidori: Astrocaryum gynacanthum
1146. tinuikore: Geonoma macrostachys
1147. tiraña: Desmoncus polyacanthos
1148. tíyaña: Mauritiella aculeata
1149. turuma huikorao: Desmoncus mitis
1150. tuugiku kinena: Mauritia flexuosa
1151. ua kinena riaña: Mauritia sp.
1152. udatiñore: Bactris acanthocarpa
1153. uicheparo kinena: Mauritia flexuosa
1154. uigonokidye: Astrocaryum chambira
1155. uitintgi: Bactris maraja
1156. uiyodyi: Attalea racemosa
1157. ure maña: Oenocarpus bataua
1158. yarina: Attalea maripa
1159. yariyi: Attalea insignis
1160. yayoer: Bactris balanophora
1161. yerena: Oenocarpus minor
1162. yiiri: Hyospathe elegans
1163. ziiyana: Mauritiella aculeata
1164. zitoakai: Bactris fissifrons
1165. zobina himena: Bactris gasipaes

\section{WANANO}

1166. ba $^{\mathrm{h}}$ tápo ${ }^{\mathrm{h}} \mathrm{koño:} \mathrm{Iriartea} \mathrm{deltoidea}$

1167. bo bó muhĩ dáaka: Geonoma macrostachys

1168. dañumuka: Oenocarpus bacaba

1169. dañemaká: Oenocarpus bacaba

1170. diañumúku: Astrocaryum jauari

1171. dihh́ mi ${ }^{\mathrm{h}}$ píño: Euterpe catinga

1172. doká sarí: Astrocaryum acaule

1173. gibiño: Oenocarpus bataua

1174. rré: Bactris gasipaes

1175. k kósao: Socratea exorrhiza

1176. kíõ: Attalea maripa

1177. kõã: Mauritiella armata

1178. ma ${ }^{\mathrm{h} k a ́ r o k a}$ tré: Bactris hirta

1179. m̃̃ potáño: Bactris balanophora

1180. mĩã $\mathrm{p}^{\mathrm{h} a ̃ p u ́: ~ A t t a l e a ~ b u t y r a c e a ~}$

1181. mîhî́: Astrocaryum gynacanthum

1182. mîhî́ bikt: Geonoma sp.

1183. mînî́ sá: Bactris fissifrons

1184. minpí: Euterpe precatoria

1185. mohî́: Mauritia carana

1186. mũã pũrí: Manicaria saccifera

1187. muhisa: Mauritia carana

1188. naa á: Mauritia flexuosa

1189. ñamá $\mathrm{p}^{\mathrm{h}} \mathrm{p}^{\mathrm{h} u ́}$ : Attalea racemosa

1190. ñe $\mathrm{h}^{\mathrm{h}}$ tếñó: Astrocaryum gynacanthum

1191. neki má kariño kwáño: Mauritiella armata

1192. ก̃̃̄inkípũ: Astrocaryum chambira

1193. ñimisa: Oenocarpus bataua

1194. ñukiptsa: Astrocaryum chambira

1195. pấpố: Attalea $\mathrm{sp}$.

1196. p pãpú: Attalea butyracea

1197. põ ${ }^{\mathrm{h}}$ táño: Bactris corossilla

1198. potáñó: Bactris hirta

1199. pũõ: Iriartella setigera

1200. thếñó: Astrocaryum gynacanthum

1201. wachó muhî́: Bactris corossilla

1202. wachó muhî́: Geonoma pycnostachys

1203. wa ${ }^{\mathrm{h}}$ tu darí(Desmoncus $\mathrm{sp}$.

\section{WAUNANA}

1204. ar: Iriartea deltoidea

1205. chorr: Wettinia quinaria

1206. dokéri: Geonoma calyptrogynoidea

1207. ẽeur: Synechanthus warscewiczianus

1208. häbübü: Socratea exorrhiza

1209. härr: Bactris gasipaes

1210. ĩgiri: Welfia regia

1211. I Igir: Welfia regia

1212. kéd: Manicaria saccifera

1213. kokbú́: Cocos nucifera 

1214. murrap ${ }^{\mathrm{h}} \mathrm{O}$ : Euterpe oleracea
1215. opúahõ: Ammandra decasperma
1216. piekuurhõ bä: Oenocarpus minor
1217. píerkúur piu: Indeterminada
1218. sokarrõ: Oenocarpus bataua
1219. taaudau: Phytelephas schottii
1220. tapúrbü: Attalea allenii
1221. tû́kür: Manicaria saccifera
1222. ür: Bactris gasipaes
1223. wágara: Indeterminada
1224. wéger: Astrocaryum standleyanum
1225. wigirbü: Astrocaryum standleyanum

\section{WAYUUNAIKI}

1226. alana: Indeterminada

1227. kuluuala: Attalea butyracea

1228. paita: Indeterminada

1229. pattapan: Indeterminada

1230. páutta: Copernicia tectorum

\section{YAGUA}

1231. kobónase: Iriartea deltoidea

1232. koko: Cocos nucifera

1233. ndesé: Mauritia flexuosa

1234. pátiu: Phytelephas macrocarpa

1235. póre: Bactris sp.

1236. siməse: Oenocarpus bataua

1237. tátachi: Astrocaryum chambira

1238. thimasé: Oenocarpus bataua

1239. tóchi: Oenocarpus bacaba

1240. tomohonase: Attalea butyracea

1241. tótóse: Astrocaryum ferrugineum

\section{YUHUP}

1242. còcóù: Indeterminada

1243. tüùu: Bactris gasipaes

1244. wàh: Oenocarpus bataua

1245. wàwó: Oenocarpus bacaba

\section{YUKO}

1246. katsána: Indeterminada

\section{YUKUNA}

1247. hẽñã: Iriartea deltoidea

1248. itewi: Mauritia flexuosa

1249. kaarú: Lepidocaryum tenue

1250. kalu' lú: Oenocarpus minor

1251. karugiri: Lepidocaryum tenue

1252. kuhĩta: Attalea septuagenata

1253. kuparú: Bactris corossilla

1254. kuripa: Astrocaryum jauari

1255. kuy: Attalea plowmanii

1256. makeru: Oenocarpus makeru

1257. malakala: Euterpe precatoria
1258. mapanaré: Attalea butyracea

1259. mawiku: Iriartella setigera

1260. mayaikáru: Indeterminada

1261. piherú: Desmoncus polyacanthos

1262. pipirí: Bactris gasipaes

1263. piseró: Desmoncus sp.

1264. puhurrupere: Oenocarpus sp.

1265. punama: Oenocarpus bataua

1266. pupa: Socratea exorrhiza

1267. pupé: Oenocarpus bacaba

1268. uehirí: Attalea maripa

1269. uihuiyo: Geonoma sp.

1270. wáhe: Manicaria saccifera

1271. yakuere: Attalea plowmanii

1272. yakwera: Attalea insignis

\section{YURUTÍ}

1273. ñoriñá atié tiróñi: Iriartea deltoidea

1274. ñumá: Oenocarpus bataua

1275. ñumá meká: Oenocarpus bacaba

1276. uné: Bactris gasipaes 
Apéndice 3. Lista general de nombres amerindios de las palmas de Colombia. Se anota el nombre amerindio, el nombre científico, en paréntesis la lengua, entre corchetes la referencia en la Literatura citada.

1. ã a naa kü: Euterpe catinga (tikuna) [Prado, 2008]

2. a ibacom ba: Chelyocarpus ulei (miraña) [Galeano 1671 (COL), 1988]

3. aaboméeme: Bactris simplicifrons (miraña) [Galeano, 1991]

4. aakaiba: Chamaedorea pauciflora (miraña) [Henderson, 1995]

5. aayae: Iriartea deltoidea (miraña) [Sánchez 1456 (COL), 1988]

6. aganumeba: Hyospathe elegans (cofán) [Pedersen \& Balslev, 1990]

7. aheko: Lepidocaryum tenue (miraña) [Sánchez, 1997]

8. ahi: Lepidocaryum tenue (miraña) [Galeano, 1991]

9. ainawiboto: Bactris maraja (sikuani) [Sánchez, 1989]

10. akeba: Indeterminada (tunebo) [Romayne, 1997]

11. akie kakie: Geonoma macrostachys (cofán) [Balslev et al., 1997]

12. akəi: Oenocarpus bacaba (carijona) [Robayo, 1993]

13. alana: Indeterminada (wayuunaiki) [Pérez van Leenden, 1996]

14. alar: Bactris barronis (cuna) [Henderson, 2000]

15. aldo: Bactris sp. (kogui) [Carbonó de la Hoz, 1987]

16. alitsi: Attalea maripa (baniva) [Guánchez \& Romero, 1998]

17. álu: Indeterminada (kogui) [Ortiz, 1994]

18. alúnka: Astrocaryum malybo (damana) [Reichel-Dolmatoff, 1989]

19. alunká: Indeterminada (kogui) [Ortiz, 1994]

20. amábamu: Desmoncus sp. (cubeo) [Hablante anónimo, Bogotá, com. pers., 2004]

21. amana: Cocos nucifera (carijona) [Robayo, 1993]

22. ámara: Indeterminada (tunebo) [Romayne, 1997]

23. ampiapúne: Manicaria saccifera (tariano) [Domingo Muniz y Jhon Batista, Piriquito, Brasil, com. pers., 2004]

24. amu móomoo: Bactris gasipaes (muinane) [Kronik et al., 1999]

25. anaku tsatsavó: Socratea exorrhiza (cofán) [Cerón, 1995]

26. anhídadu: Geonoma triglochin (siona) [Balslev et al., 1997]

27. anu: Indeterminada (barí) [Mogollón, 1995]

28. ar: Iriartea deltoidea (waunana) [Bernal \& Galeano, 1993]

29. arákbot: Indeterminada (jitnu) [Buenaventura, 1993]

30. arapara: Bactris brongniartii (tikuna) [Prado, 2008]

31. áricha: Indeterminada (tunebo) [Romayne, 1997]

32. arrá: Iriartea deltoidea (embera) [Bernal \& Galeano, 1993]

33. arra sĩi: Socratea exorrhiza (embera) [Binder et al., 1995]

34. arú: Oenocarpus bataua (embera) [Jorge Eliécer Restrepo com. pers., 1999]

35. arya: Indeterminada (tunebo) [Romayne, 1997]

36. ãtá: Phytelephas schottii (embera) [Bernal \& Galeano, 1993, como P. seemannii]

37. ataiboto: Oenocarpus bataua (sikuani) [Sánchez, 1989]

38. atibakomo: Geonoma camana (miraña) [Galeano, 1991]

39. awara: Astrocaryum jauari (carijona) [Robayo, 1993]

40. awü: Cocos nucifera (tikuna) [Montes, 1995]

41. ayako: Iriartea deltoidea (miraña) [Galeano, 1991]

42. ãyüsü: Indeterminada (embera) [Llerana, 1994]

43. bãb: Astrocaryum gynacanthum (nukak) [Cabrera et al., 1999]

44. babayhu igai: Oenocarpus bataua (muinane) [Kronik et al., 1999]

45. badeiboto: Indeterminada (cuiba) [Merchán, 1993]

46. báha: Euterpe precatoria (guayabero) [Tobar, 1994]

47. bahe móomoo: Bactris sp. (muinane) [Kronik et al., 1999]

48. bahiñi: Indeterminada (cubeo) [Valencia, 1994]
49. ba ${ }^{\mathrm{h}}$ tápo ${ }^{\mathrm{h}}$ koño: Iriartea deltoidea (wanano) [Borrero \& Pérez, 2004]

50. bareu puori: Oenocarpus bataua (piaroa) [Guánchez \& Romero, 1998]

51. barie: Attalea butyracea (uitoto) [Kronik et al., 1999]

52. bartydye: Attalea insignis (uitoto) [Kronik et al., 1999]

53. bariyi: Syagrus orinocensis (uitoto) [Galeano, 1991, como $S$. inajai]

54. baru baru: Geonoma maxima (baniva) [Espina 250 (COL), 1977]

55. baruył uyoye: Attalea racemosa (uitoto) [Sánchez, 1997]

56. bateí: Oenocarpus bataua (andoque) [Galeano, 1991]

57. batú: Oenocarpus bataua (andoque) [Henderson, 1995]

58. bayớñe: Bactris gasipaes (siona) [Vickers \& Plowman, 1984]

59. bëlë’ì: Indeterminada (miraña) [Seifart, 2002]

60. beedáh: Desmoncus sp. (tuyuca) [Avelino González, Taina, Vaupés, com. pers., 2004]

61. beeiba: Astrocaryum ciliatum (miraña) [Galeano, 1991, como $A$. sciophilum]

62. beeremiku haheku: Lepidocaryum tenue (muinane) [Kronik et al., 1999]

63. be dáh ${ }^{\text {h }}$ waridáh $:$ Desmoncus sp. (siriano) [María Noemí Uribe, Ibacaba, Vaupés, com. pers., 2004]

64. behépũ: Attalea sp. (desano) [Luz Mila Santa Cruz y Matilde Arango, Naná, Vaupés, com. pers., 2004]

65. be ${ }^{\mathrm{h}}$ táñó: Astrocaryum chambira (tukano) [Graciliano Lima, Panuré, Guaviare, com. pers., 1999]

66. bëi': Iriartea deltoidea (nukak) [Cabrera et al., 1999]

67. besotúntu: Desmoncus mitis (siona) [Borchsenius et al., 1998]

68. besuño: Indeterminada (barasana) [García \& Monguí, 1975]

69. betañố: Astrocaryum chambira (tuyuca) [Avelino González, Taina, Vaupés, com. pers., 2004]

70. betaño: Astrocaryum chambira (barasana) [García \& Monguí, 1975]

71. beto: Astrocaryum chambira (siona) [Borchsenius et al., 1998]

72. betoñi: Astrocaryum chambira (cubeo) [Paulina Aguía, Mitú, Vaupés, com. pers., 2004]

73. bibimiku háheku: Lepidocaryum tenue (muinane) [Kronik et al., 1999]

74. bíbira: Bactris gasipaes (tunebo) [Patiño, 1960, como B. macana]

75. bíbora: Bactris gasipaes (tunebo) [Patiño, 1960]

76. bĩdĩ: Bactris gasipaes (nukak) [Cabrera et al., 1999]

77. bigina: Bactris gasipaes (uitoto) [Kronik et al., 1999]

78. binakará: Bactris sp. (tunebo) [Romayne, 1997]

79. bipima: Mauritiella aculeata (macuna) [Schultes, 1974]

80. biri mo ${ }^{\mathrm{h}}$ kere: Bactris maraja (uitoto) [Galeano 1316 (COL), 1987]

81. bitiño: Indeterminada (barasana) [García \& Monguí, 1975]

82. blui: Geonoma deversa (nukak) [Cárdenas \& Politis, 2000]

83. bobaymeku: Astrocaryum ciliatum (muinane) [Kronik et al., 1999, como A. sciophilum]

84. bohoño: Attalea maripa (barasana) [García \& Monguí, 1975]

85. bo bó muhĩ dáaka: Geonoma macrostachys (wanano) [Bernal 3632 (COL), 2004]

86. bo ${ }^{\mathrm{h}}$ somuhî́: Manicaria saccifera (siriano) [María Noemí Uribe, Ibacaba, Vaupés, com. pers., 2004]

87. bo ${ }^{\mathrm{h}}$ somuhî́: Manicaria saccifera (tukano) [Avelino González, Taina, Vaupés, com. pers., 2004]

88. bo ${ }^{\mathrm{h}}$ somũĩ: Manicaria saccifera (tuyuca) [Avelino González, Taina, Vaupés, com. pers., 2004]

89. boiünúm: Attalea racemosa (puinave) [Bernal 2106 (COL), 1994] 
90. bokohañu: Oenocarpus bataua (cubeo) [Pedersen \& Balslev, 1990]

91. bombo: Iriartea deltoidea (cofán) [Cerón, 1995]

92. bonbon: Socratea exorrhiza (siona) [Borchsenius et al., 1998]

93. boobo mehe: Bactris bidentula (miraña) [Galeano 1702 (COL), 1988]

94. boreyabeñu: Oenocarpus bataua (cubeo) [Pedersen \& Balslev, 1990]

95. boriyabeañi: Oenocarpus bacaba (cubeo) [Paulina Aguía, Mitú, Vaupés, com. pers., 2004]

96. borua: Oenocarpus minor (tikuna) [Prado, 2008; Montes, 1995, como bòrúà, y como Oenocarpus bataua]

97. bosó mohe: Geonoma pycnostachys (macuna) [Henderson, 1995]

98. bosómohiño: Indeterminada (barasana) [García \& Monguí, 1975]

99. boyon: Attalea racemosa (puinave) [Triana 23 (COL), 1979]

100. bubúmemëeku: Bactris acanthocarpa (miraña) [Henderson, 1995]

101. bubumimeku: Geonoma macrostachys (muinane) [Kronik et al., 1999]

102. bubuy híyuhí: Geonoma poeppigiana (muinane) [Kronik et al., 1999, como bubuy híllyuhi]

103. buha tuuko: Attalea butyracea (muinane) [Kronik et al., 1999]

104. buhanñe kawne: Iriartella setigera (macuna) [Henderson, 1995]

105. bu púño: Iriartella setigera (siriano) [María Noemí Uribe, Ibacaba, Vaupés, com. pers., 2004]

106. bu púño: Iriartella setigera (tukano) [Avelino González, Taina, Vaupés, com. pers., 2004]

107. bu ${ }^{\mathrm{h}}$ pup ${ }^{\mathrm{h}}$ í: Iriartella setigera (tuyuca) [Avelino González, Taina, Vaupés, com. pers., 2004]

108. butíño: Indeterminda (tucano) [Gallo, 1972]

109. buhugó: Iriartella setigera (macuna) [García Barriga 14270 (COL), 1952]

110. buhúuño: Indeterminada (barasana) [García \& Monguí, 1975]

111. bui ñoõmĩá: Oenocarpus sp. (tanimuca) [Zaleth Cordero, Bogotá, com. pers., 2004]

112. buibuiboto: Bactris acanthocarpa (sikuani) [Sánchez, 1989]

113. buine himena: Bactris riparia (uitoto) [Kronik et al., 1999]

114. buitsaha: Prestoea acuminata (inga) [Bernal 2476 (COL), 2000]

115. bumbuhe: Iriartea deltoidea (cofán) [Balslev et al., 1997]

116. buneita himena: Bactris maraja (uitoto) [Sánchez, 1997]

117. bunubũ: Indeterminada (barí) [Mogollón, 2000]

118. buño: Attalea maripa (tatuyo) [Bostrom, 1998]

119. bupasantǘ: Desmoncus sp. (kakua) [Arbino Furia, Taina, Vaupés, com. pers., 2004]

120. burremomosuu: Bactris simplicifrons (muinane) [Galeano, 1991]

121. buru móomoo: Bactris maraja (muinane) [Kronik et al., 1999]

122. burumikiri: Bactris maraja (uitoto) [Kronik et al., 1999]

123. butsiboto: Iriartea deltoidea (sikuani) [Sánchez, 1989]

124. buu: Desmoncus polyacanthos (tikuna) [Prado, 2008]

125. búyup: Bactris gasipaes (nukak) [Cárdenas \& Politis, 2000]

126. bwiamesé: Desmoncus polyacanthos (macuna) [Schultes 16233 (COL), 1952]

127. chaatü: Prestoea schulzeana (tikuna) [Prado, 2008]

128. chacarrá: Bactris spp. (embera) [Bernal \& Galeano, 1993]

129. chambira: Astrocaryum chambira (siona) [Johnson, 1986]

130. chánul: Bactris gasipaes (awa pit) [Calvache, 2000]

131. chapil: Oenocarpus bataua (awa pit) [Balslev et al., 1997]

132. chãsóñi: Indeterminada (koreguaje) [Cook et al., 2001]

133. chata: Chamaedorea pauciflora (tikuna) [Prado, 2008]

134. chéereé: Oenocarpus bacaba (muinane) [Kronik et al., 1999]
135. cherée: Oenocarpus minor (muinane) [Kronik et al., 1999, como O. mapora]

136. chetresuu: Oenocarpus minor (muinane) [Sánchez, 1997, como O. mapora]

137. chichi $\mathrm{p}^{\mathrm{h}} \mathrm{uru}$ : Prestoea decurrens (embera) [Llerena, 1994, como indet.]

138. chicyora ${ }^{\text {h: }}$ Oenocarpus minor (bora) [Henderson, 1995, como $O$ mapora]

139. chiikotsige: Oenocarpus minor (miraña) [Galeano, 1991, como O. mapora]

140. chikaanə: Indeterminada (barí) [Key, 2000]

141. chinañi: Mauritia carana (cubeo) [Borrero \& Pérez, 2004]

142. chipati: Phytelephas macrocarpa (cocama) [Faust, 1978]

143. chikichiki: Leopoldinia piassaba (piapoco) [Pharris de Klumpp, 1995]

144. chiwü: Itaya amicorum (tikuna) [Prado, 2008]

145. chorr: Wettinia quinaria (waunana) [Binder et al., 1995]

146. chuã: Geonoma interrupta (tikuna) [Prado, 2008]

147. chúa: Geonoma interrupta (tikuna) [Montes 1995, como Mauritia carana]

148. chuchana:Astrocaryum urostachys (secoya) [Borchsenius et al., 1998]

149. chuchana:Astrocaryum urostachys (siona) [Balslev et al., 1997]

150. chuemt móomoo: Bactris gasipaes (muinane) [Kronik et al., 1999]

151. chúnohe: Hyospathe elegans (barasana) [Henderson, 1995]

152. chuppí: Wettinia hirsuta (embera) [Bernal 1147 (COL), 1986]

153. churúbai: Syagrus orinocensis (achagua) [Meléndez, 1998, como indet.]

154. chüüta-ne: Geonoma atrovirens (tikuna)[Prado, 2008]

155. cigao háheku: Lepidocaryum tenue (muinane) [Galeano, 1991]

156. citaganomeku: Chamaedorea pauciflora (muinane) [Henderson, 1995]

157. còcóù: Indeterminada (yuhup) [Ospina, 1999]

158. dàapui: Astrocaryum sp.(piapoco) [Reinoso, 1993]

159. dadar da: Wettinia drudei (uitoto) [Galeano 1491 (COL), 1988]

160. dadu: Geonoma macrostachys (siona) [Balslev et al., 1997]

161. dágui inóho: Mauritia carana (muinane) [Galeano, 1991]

162. dahñumuka: Oenocarpus bacaba (wanano) [Borrero \& Pérez, 2004]

163. dáhui: Indeterminada (achagua) [Meléndez, ined.]

164. dãi: Astrocaryum sp. (tikuna) [Montes, 1995 ]

165. dañemaká: Oenocarpus bacaba (wanano) [Emilia Gómez, Mitú , Vaupés, com. pers., 2004]

166. date: Bactris acanthocarpa (tikuna) [Prado, 2008]

167. dauri: Mauritia flexuosa, variedad de fruto rojo (tikuna) [Prado, 2008]

168. dawü we: Bactris maraja (tikuna) [Prado, 2008]

169. dea: Geonoma maxima (tikuna) [Prado, 2008]

170. dea akü: Geonoma macrostachys (tikuna) [Prado, 2008]

171. dea püwí: Geonoma pycnostachys (tikuna) [Prado, 2008]

172. dédé: Geonoma pycnostachys (secoya) [Balslev et al., 1997, como G. stricta]

173. dédé bui: Geonoma polyandra (siona) [Henderson, 1995]

174. dedewekó: Hyospathe elegans (siona) [Borchsenius et al., 1998]

175. deene háhe: Lepidocaryum tenue (muinane) [Kronik et al., 1999, como Lepidocaryum sp.]

176. dekó': Astrocaryum jauari (kakua) [Arbino Furia, Taina, Vaupés, com. pers., 2004]

177. diábe tá: Astrocaryum jauari (tucano) [Graciliano Lima, Panuré, Guaviare, com. pers., 1999] 
178. diabe ${ }^{\mathrm{h}}$ táño: Astrocaryum jauari (tuyuca) [Avelino González, Taina, Vaupés, com. pers., 2004]

179. díabe ${ }^{\mathrm{h}}$ tañu: Astrocaryum jauari (siriano) [María Noemí Uribe, Ibacaba, Vaupés, com. pers., 2004]

180. diañumúku: Astrocaryum jauari (wanano) [Cristóbal Texeira Barbosa, Ibacaba, Vaupés, com. pers., 2004]

181. dídi: Geonoma polyandra (siona) [Borchsenius et al., 1998]

182. diha dédé: Geonoma pycnostachys (siona) [Balslev et al., 1997, como G. stricta]

183. dịh' mi ${ }^{\mathrm{h}}$ píño: Euterpe catinga (wanano) [Cristóbal Texeira Barbosa, Ibacaba, Vaupés, com. pers., 2004]

184. diku háheku: Lepidocaryum tenue (muinane) [Galeano, 1991]

185. dikuháhe imoháhe: Lepidocaryum tenue (uitoto) [Kronik et al., 1999, como Lepidocaryum sp.]

186. dipirie: Astrocaryum gynacanthum (miraña) [Sánchez 1324 (COL), 1988]

187. divá: Euterpe precatoria (cofán) [Cerón, 1995]

188. diwita: Mauritia flexuosa (achagua) [Meléndez, inéd.]

189. dobómaña: Oenocarpus bataua (uitoto) [Kronik et al., 1999]

190. doká sarí: Astrocaryum acaule (wanano) [Hablante anónimo, Naná, Vaupés, com. pers., 2004]

191. dokéri: Geonoma calyptrogynoidea (waunana) [Hablante anónimo, Bajo San Juan, Chocó, com. pers., 1998]

192. dokiduá: Geonoma calyptrogynoidea (embera) [Bernal \& Galeano, 1993, como G. congesta]

193. dorida: Socratea exorrhiza (uitoto) [Galeano, 1991]

194. dówirri: Bactris campestris (curripaco) [Bernal 2094 (COL), 1994]

195. du: Bactris corossilla (piaroa) [Henderson, 2000]

196. duebokohañu: Oenocarpus bataua (cubeo) [Balick, 1986a]

197. duibokane: Oenocarpus bataua (cubeo) [Zarucchi 1851 (COL), 1976]

198. duitekina: Mauritia carana (uitoto) [Galeano, 1991]

199. duku: Attalea microcarpa (tikuna) [Prado, 2008]

200. dumestri: Astrocaryum sp. (baniva) [Guánchez \& Romero, 1998]

201. düü: Oenocarpus bataua (tikuna) [Montes, 1993; Prado, 2008]

202. düutëgn: Mauritiella armata (kakua) [Arbino Furia, Taina, Vaupés, com. pers., 2004]

203. ebáñi maihóbariño: Socratea exorrhiza (cubeo) [Paulina Aguía, Mitú, Vaupés, com. pers., 2004]

204. echídiñi: Attalea maripa (cubeo) [Hablante anónimo, com. pers. 2004]

205. ẽeñá: Socratea exorrhiza (curripaco) [Eliana Garrido, Mitú , Vaupés, com. pers., 2004]

206. eéri: Bactris elegans (uitoto) [Galeano, 1991]

207. eesí: Syagrus orinocensis (piapoco) [Pharris de Klumpp, 1995]

208. ẽeur: Synechanthus warscewiczianus (waunana) [Binder et al., 1995]

209. éeya: Indeterminda (piapoco) [Reinoso, 1993]

210. egã́: Attalea maripa (desano) [Luz Mila Santa Cruz y Matilde Arango, Naná, Vaupés, com. pers., 2004]

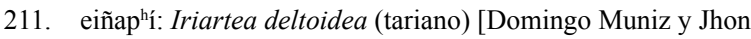
Batista, Piriquito, Brasil, com. pers., 2004]

212. ekiri: Bactris sp. (uitoto) [Kronik et al., 1999]

213. ekuru: Attalea racemosa (baniva) [Guánchez \& Romero, 1998]

214. emedere: Geonoma maxima (siona) [Borchsenius et al., 1998]

215. emifoõa: Oenocarpus circumtextus (tanimuca) [Zaleth Cordero, Bogotá, 532 (COL), 2004]

216. emimoe: Euterpe precatoria (cubeo) [Borrero \& Pérez, 2004]

217. emumeke: Attalea racemosa (cubeo) [Galeano 1191 (COL), 1993]
218. eneño: Bactris gasipaes (siona) [Patiño, 1960]

219. ennəkənə: Indeterminada (ika) [Zalabata, 1995]

220. ereri: Geonoma maxima (uitoto) [Sánchez, 1997]

221. ereri: Lepidocaryum tenue (uitoto) [Galeano, 1991]

222. eri: Attalea cf. septuagenata (tikuna) [Prado, 2008]

223. eriñi: Indeterminada (koreguaje) [Cook et al., 2001]

224. ernde: Bactris gasipaes (taiwano) [Patiño, 1960]

225. eruiruht: Astrocaryum ciliatum (uitoto) [Galeano 1315 (COL), 1987]

226. eta: Socratea exorrhiza (tikuna) [Prado, 2008]

227. etá: Iriartea deltoidea (tikuna) [Victorino Bautista, Leticia, Amazonas, com. pers., 1999]

228. etá irakü: Socratea exorrhiza (tikuna) [Victorino Bautista, Leticia, Amazonas, com. pers., 1999]

229. etsohe: Astrocaryum urostachys (cofán) [Cerón, 1995]

230. eú: Mauritia flexuosa (nukak) [Gutiérrez 015 (COL), 1995]

231. éwañi: Iriartea deltoidea (cubeo) [Hablante anónimo, com. pers., 2004]

232. éwant kíhiñi:: Socratea exorrhiza (cubeo) [Hablante anónimo, com. pers., 2004]

233. ewatá: Indeterminada (tunebo) [Romayne, 1997]

234. eyì: Bactris balanophora (uitoto) [Sánchez, 1997]

235. eyiipanae: Geonoma brongniartii (miraña) [Galeano 1561 (COL), 1988]

236. faiba móomoo: Bactris acanthocarpa (muinane) [Kronik et al., 1999]

237. famórahe móomoo: Bactris gasipaes (muinane) [Kronik et al., 1999

238. farena himena: Bactris gasipaes (uitoto) [Sánchez, 1997]

239. fat i tuuko: Attalea insignis (muinane) [Kronik et al., 1999]

240. fegona: Iriartea deltoidea (uitoto) [Galeano, 1991]

241. fekori: Pholidostachys synanthera (uitoto) [Galeano, 1991]

242. fiiboto inóho: Mauritiella aculeata (muinane) [Kronik et al., 1999]

243. fiífia: Euterpe precatoria (tanimuca) [Zaleth Cordero, Bogotá, 462 (COL), 2004]

244. fikaingo ere: Geonoma pycnostachys (uitoto) [Sánchez, 1997, como G. stricta]

245. fikatñoerert: Geonoma maxima (uitoto) [Galeano, 1991]

246. foodá: Desmoncus mitis (andoque) [La Rotta 137 (COL), 1982]

247. fuidorda: Iriartella stenocarpa (uitoto) [Henderson, 1995]

248. gaikuhe móomoo: Bactris gasipaes (muinane) [Kronik et al., 1999]

249. gíbĩno: Oenocarpus bataua (wanano) [Emilia Gómez, Mitú , Vaupés, com. pers., 2004]

250. gekage: Attalea insignis (muinane) [Sánchez, 1997]

251. gekiri: Geonoma pycnostachys (uitoto) [Sánchez, 1997, como G arundinacea]

252. giaitina: Mauritiella aculeata (uitoto) [Galeano, 1991]

253. girida: Oenocarpus minor (uitoto) [Galeano, 1991, como $O$. mapora]

254. gisimeku: Bactris maraja (uitoto) [Kronik et al., 1999]

255. gisire tuuko: Attalea insignis (muinane) [Kronik et al., 1999]

256. gisiree: Wettinia augusta (muinane) [Bernal 2585 (COL), 2001]

257. gisiremóomo: Astrocaryum jauari (muinane) [Sánchez, 1997]

258. gisìi babaimeku: Bactris simplicifrons (muinane)[Sánchez, 1997]

259. goguire: Geonoma deversa (uitoto) [Sánchez, 1997]

260. goguire: Geonoma sp. (uitoto) [Kronik et al., 1999]

261. goguirt: Geonoma leptospadix (uitoto) [Galeano, 1991]

262. goguiri: Geonoma maxima (uitoto) [Galeano, 1991] 
263. goguirt: Geonoma poeppigiana (uitoto) [Galeano, 1991]

264. goguiri: Geonoma pycnostachys (uitoto) [Galeano, 1991, como G. stricta var. piscicauda]

265. gõháño: Socratea exorrhiza (siriano) [Gaudencio Rodríguez, Ibacaba, Vaupés, com. pers., 2004]

266. gõsa: Oenocarpus bataua (secoya) [Balslev et al., 1997]

267. guagai: Desmoncus cirrhifer (embera) [Bernal \& Galeano, 1993]

268. guaiko: Geonoma deversa (embera) [Bernal 1148 (COL), 1986]

269. guakaria: Oenocarpus bataua (macuna) [Pedersen \& Balslev, 1990]

270. gualte: Wettinia oxycarpa (awa pit) [Borchsenius et al., 1998]

271. guarnul: Wettinia quinaria (awa pit) [González, 1994]

272. güaseretba: Attalea insignis (miraña) [Sánchez, 1997]

273. gui wala: Bactris maraja (cuna) [Henderson, 2000]

274. gui: Bactris maraja (cuna) [Henderson, 2000]

275. guinul: Astrocaryum standleyanum (awa pit) [González, 1994]

276. gukureku: Bactris elegans (muinane) [Kronik et al., 1999]

277. guom: Mauritia carana (puinave) [Hablante anónimo, Puerto Inírida, Guainía, com. pers., 1994]

278. guom sowai: (Socratea exorrhiza) (puinave) [Hablante anónimo, com. pers., 1994]

279. gúrie: Chamaedorea pauciflora (uitoto) [Kronik et al., 1999]

280. gurina: Oenocarpus bacaba (uitoto) [Kronik et al., 1999]

281. guriri: Geonoma maxima (uitoto) [Galeano, 1991]

282. guruna: Oenocarpus minor (uitoto) [Sánchez, 1997, como $O$. mapora]

283. gurure: Geonoma camana (uitoto) [Galeano, 1991]

284. gũũ: Indeterminada (tikuna) [Montes, 1995]

285. guypani: Euterpe precatoria (guayabero) [Klein 8 (COL), 1967]

286. haaba móomoo: Bactris simplicifrons (muinane) [Kronik et al., 1999]

287. haadió kuume: Oenocarpus bataua (muinane) [Kronik et al., 1999]

288. haani móomoo: Bactris simplicifrons (muinane) [Kronik et al., 1999]

289. häbübü: Socratea exorrhiza (waunana) [Binder et al., 1995]

290. habutu: Oenocarpus bacaba (nukak) [Cabrera et al., 1999]

291. hakumoho: Desmoncus polyacanthos (muinane) [Galeano, 1991]

292. hamehe: Bactris sp. (ocaina) [Patiño, 1960]

293. hanameku: Bactris elegans (muinane) [Kronik et al., 1999]

294. handabeke: Iriartella setigera (uitoto) [Galeano 1307 (COL), 1987]

295. hanga: Bactris gasipaes (embera) [Patiño, 1960]

296. hañõn: Leopoldinia piassaba (puinave) [Hablante anónimo, Bogotá, com. pers., 1999]

297. harehu ehí: Bactris gasipaes (carijona) [Robayo, 1993]

298. harina: Attalea maripa (uitoto) [Kronik et al., 1999]

299. harive: Attalea maripa (uitoto) [Galeano 860 (COL), 1986]

300. härr: Bactris gasipaes (waunana) [Sánchez \& Castro, 1977]

301. háyaeu: Iriartea deltoidea (muinane) [Sánchez 580 (COL), 1988]

302. hayaku: Iriartella setigera (muinane) [Urrego 399 (COL), 1989]

303. hẽa: Bactris gasipaes (embera) [Llerena, 1994]

304. hẽap ${ }^{\mathrm{h}} \mathrm{t}^{\mathrm{h}} \mathrm{a}$ : Indeterminada (embera) [Llerena, 1994]

305. hebukanu: Oenocarpus bataua (cubeo) [Henderson, 1995]

306. hếe: Bactris gasipaes (embera) [Key, 2000]

307. hẽe sĩda: Bactris gasipaes (embera) [Binder et al., 1995]

308. hehékahé: Indeterminada (barasana) [García \& Monguí, 1975]

309. hẽñã: Iriartea deltoidea (yukuna) [José Yepes Matapí \& Elí Yukuna, La Pedrera, Amazonas, com. pers., 1991]
310. henípi: Astrocaryum jauari (tariano) [Domingo Muniz y Jhon Batista, Piriquito, Brasil, com. pers 2004]

311. hiabetoñi: Astrocaryum jauari (cubeo) [Valencia, 1994]

312. hiatgina: Iriartea deltoidea (uitoto) [Kronik et al., 1999]

313. hiałkona himena: Bactris gasipaes (uitoto) [Sánchez, 1997]

314. hiaukiña: Mauritia flexuosa (uitoto) [Kronik et al., 1999]

315. hibohakimoi: Desmoncus polyacanthos (muinane) [Kronik et al., 1999]

316. híduiki: Mauritia flexuosa (uitoto) [Kronik et al., 1999]

317. higuá: Astrocaryum standleyanum (embera) [La Rotta 705 (COL), 1985]

318. hihao: Dictyocaryum ptarianum (muinane) [Galeano, 1991]

319. hiidł̇ko paña: Oenocarpus bataua (uitoto) [Kronik et al., 1999]

320. hiimasa: Astrocaryum chambira (tinigua) [Tobar, 1993, como Astrocaryum sp.]

321. hiktfegina: Dictyocaryum ptarianum (uitoto) [Galeano, 1991]

322. hikipena: Dictyocaryum ptarianum (uitoto) [Kronik et al., 1999]

323. hłłko néhee: Astrocaryum jauari (muinane) [Kronik et al., 1999]

324. hĩkõ: Iriartea deltoidea (macuna) [Smothermon et al., 1995]

325. hikoñekina: Astrocaryum jauari (uitoto) [Kronik et al., 1999]

326. himáhay usegay inóho: Mauritia flexuosa (muinane) [Kronik et al., 1999]

327. himatri: Bactris riparia (uitoto) [Galeano, 1991]

328. himaki: Bactris sp. (uitoto) [Patiño, 1960]

329. himena: Bactris gasipaes (uitoto) [Galeano, 1991]

330. himena ifué: Aiphanes ulei (uitoto) [Galeano 1494 (COL), 1988]

331. himentếgn: Iriartea deltoidea (kakua) [Patricia Gómez, Taina, Vaupés, com. pers., 2004]

332. himuntëgn: Socratea exorrhiza (kakua) [Arbino Furia, Taina, Vaupés, com. pers., 2004]

333. hinkató: Euterpe precatoria (embera) [La Rotta 703 (COL), 1985]

334. hiobo hiyui: Geonoma deversa (muinane) [Sánchez, 1997]

335. hiowoohiyui: Geonoma pycnostachys (muinane) [Henderson, 1995, como G. stricta]

336. hipiriboto: Bactris gasipaes (sikuani) [Sánchez, 1989]

337. hira: Socratea exorrhiza (embera) [Bernal 1204 (COL), 1986]

338. hirakó kíru: Indeterminada (embera) [Binder et al., 1995]

339. hiriwa: Socratea exorrhiza (carijona) [Robayo, 1993]

340. hiriwaime iwakuchano: Iriartea deltoidea (carijona) [Robayo, 1993]

341. hittmoo: Desmoncus polyacanthos (uitoto) [Galeano, 1991]

342. hiyui: Geonoma pycnostachys (muinane) [Sánchez, 1997, como G. stricta var. piscicauda]

343. híyyuhi: Geonoma sp. (muinane) [Kronik et al., 1999, como hillyuhi]

344. hoda himena: Bactris simplicifrons (uitoto) [Galeano, 1991]

345. hoda himena: Bactris macroacantha (uitoto) [Sánchez, 1997]

346. hoda himena: Geonoma pycnostachys (uitoto) [Sánchez, 1997, como G. stricta var. stricta]

347. hoda himeru: Bactris simplicifrons (uitoto) [Henderson, 1995]

348. hohomboto: Indeterminada (cuiba) [Merchán, 1993]

349. hoka: Indeterminada (kogui) [Reichel Dolmatoff, 1985]

350. hókṫki: Astrocaryum chambira (cubeo) [Paulina Aguía, Mitú, Vaupés, com. pers., 2004]

351. hopadi kinena: Mauritia flexuosa (uitoto) [Kronik et al., 1999]

352. hota: Bactris gasipaes (macuna) [Smothermon \& Smothermon, 1993]

353. hotá: Bactris gasipaes (macuna) [Patiño, 1960]

354. hota mohe: Lepidocaryum tenue (barasana) [Henderson, 1995] 
355. hotaño: Bactris gasipaes (macuna) [Smothermon \& Smothermon, 1993]

356. hotaw: Bactris gasipaes (barasana) [Patiño, 1960]

357. huaguedadaerei: Geonoma maxima (uitoto) [Sánchez, 1997]

358. huákó: Chamaedorea pauciflora (secoya) [Borchsenius et al., 1998]

359. huákó: Chamaedorea pauciflora (siona) [Borchsenius et al., 1998]

360. huansódédé: Geonoma macrostachys (secoya) [Borchsenius et al., 1998]

361. huasóui: Hyospathe elegans (secoya) [Borchsenius et al., 1998]

362. huatiwí: Bactris corossilla (siona) [Borchsenius et al., 1998]

363. huáho: Attalea maripa (muinane) [Kronik et al., 1999]

364. huba: Socratea exorrhiza (achagua) [Meléndez, 1998, como indet.]

365. hubudi: Oenocarpus bacaba (nukak) [Cabrera et al., 1999]

366. huchahi móomoo: Bactris gasipaes (muinane) [Kronik et al., 1999]

367. huikosa: Oenocarpus minor (siona) [Balslev et al., 1997, como $O$. mapora]

368. huikuriye: Bactris sp. (uitoto) [Kronik et al., 1999]

369. huirrima: Astrocaryum jauari (siona) [Borchsenius et al., 1998]

370. huiúi: Attalea sp. (nukak) [Gutiérrez 031 (COL), 1995]

371. huniuni: Bactris gasipaes (nukak) [Gutiérrez 020 (COL), 1995]

372. huru: Socratea exorrhiza (nukak) [Cárdenas \& Politis, 2000]

373. hurudã: Socratea exorrhiza (nukak) [Cabrera et al., 1999]

374. huruda wa: Iriartea deltoidea (nukak) [Cárdenas \& Politis, 2000]

375. huyũdĩ: Bactris gasipaes (nukak) [Cabrera et al., 1999]

376. huyup: Attalea maripa (nukak) [Cabrera et al., 1999]

377. i': Bactris maraja (nukak) [Cabrera et al., 1999]

378. i'gáño: Attalea maripa (siriano) [María Noemí Uribe, Ibacaba Vaupés, com. pers., 2004]

379. iági himena: Bactris gasipaes (uitoto) [Kronik et al., 1999]

380. ibe: Oenocarpus bataua (cuna) [Duke, 1972]

381. ̇dadarida: Wettinia drudei (uitoto) [Galeano, 1991]

382. ̇datiñori: Bactris acanthocarpa (uitoto) [Galeano, 1991]

383. idatĩnori: Geonoma poeppigiana (uitoto) [Galeano, 1991]

384. idéwi: Mauritia flexuosa (piapoco) [Pharris de Klumpp, 1995]

385. łdidoye: Astrocaryum ciliatum (uitoto) [Vester 11 (COL), 1990]

386. idyúuku: Geonoma maxima (muinane) [Kronik et al., 1999]

387. ifue himena: Aiphanes ulei (uitoto) [Galeano, 1991]

388. igaiko: Socratea exorrhiza (muinane) [Galeano, 1991]

389. igedé: Welfia regia (embera) [Bernal \& Galeano, 1993]

390. ĩgir: Welfia regia (waunana) [Binder et al., 1995, como iguir]

391. Ĩgiri: Welfia regia (waunana) [Bernal \& Galeano, 1993]

392. igüayi: Socratea exorrhiza (muinane) [Sánchez, 1997, como igüallit]

393. theku: Bactris gasipaes (muinane) [Kronik et al., 1999]

394. i'kí: Attalea maripa (tuyuca) [Avelino González, Taina, Vaupés, com. pers., 2004]

395. i'kíño: Attalea maripa (piratapuyo) [Carlos Acosta, Ibacaba, Vaupés, com. pers., 2004]

396. itkiño: Attalea maripa (tucano) [Gallo, 1972]

397. iiamaikì: Lepidocaryum tenue (uitoto) [Kronik et al., 1999]

398. iibuimi: Geonoma macrostachys (muinane) [Kronik et al., 1999]

399. iidikuumee: Oenocarpus bataua (muinane) [Kronik et al., 1999]

400. iigüae: Mauritiella aculeata (miraña) [Galeano, 1991]

401. iihtnoho: Oenocarpus bacaba (muinane) [Kronik et al., 1999]

402. iłsuva: Astrocaryum ciliatum (miraña) [Sánchez 1130 (COL), 1988]
403. îkídi büüri: Welfia regia (embera) [Binder et al., 1995

404. iko: Bactris gasipaes (cuna) [Duke, 1972]

405. ikoñedu: Astrocaryum gynacanthum (andoque) [Galeano, 1991]

406. ikutiñu: Attalea butyracea (sáliba) [Benaissa, 1991]

407. ikwahit: Socratea exorrhiza (miraña) [Sánchez 1097 (COL), 1988]

408. ila: Indeterminada (cuna) [Llerena, 1994]

409. '̇meda: Socratea exorrhiza (uitoto) [Kronik et al., 1999]

410. imekena: Bactris gasipaes (uitoto) [Torres 085 (COL), 1994]

411. ìmemi: Astrocaryum gynacanthum (muinane) [Kronik et al., 1999]

412. imiya hakimot: Desmoncus mitis (muinane) [Kronik et al., 1999]

413. inaiyá: Bactris gasipaes (tanimuca) [Patiño, 1960]

414. inayova: Attalea maripa (cofán) [Borchsenius et al., 1998]

415. ine: Bactris gasipaes (koreguaje) [Cook et al., 2001]

416. iné Bactris gasipaes (cubeo) [Patiño, 1960]

417. ínëiëİtsóóò: Mauritia flexuosa (miraña) [Seifart, 2002]

418. iñee: Mauritia flexuosa (miraña) [Sánchez 1226 (COL), 1988]

419. iñéhe: Mauritia carana (miraña) [Galeano, 1991]

420. iñéhe: Mauritia flexuosa (bora) [Pedersen \& Balslev, 1998]

421. ínëkáhá: Mauritia flexuosa (miraña) [Seifart, 2002]

422. inneño: Bactris gasipaes (barasana) [García \& Monguí, 1975]

423. inneño: Bactris gasipaes (carapana) [Metzger, 2000]

424. ineño: Bactris gasipaes (pisamira) [González de Pérez, 2000]

425. ̇neño: Bactris gasipaes (tatuyo) [Bostrom, 1998]

426. inhoboto: Mauritia flexuosa (cuiba) [Merchán, 1993]

427. inibue: Euterpe precatoria (siona) [Borchsenius et al., 1998]

428. inóho: Mauritia flexuosa (sikuani) [Balick, 1986b]

429. inohoboto: Mauritia flexuosa (sikuani) [Sánchez, 1989]

430. iñori: Bactris acanthocarpa (uitoto) [Sánchez, 1997]

431. íntü: Bactris gasipaes (tikuna) [Victorino Bautista, Leticia, Amazonas, com. pers., 1999]

432. inzupara: Bactris concinna (cofán) [Cerón, 1995]

433. ipki: Bactris sp. (cuna) [Duke, 1972]

434. irawa: Geonoma atrovirens (tikuna) [Prado, 2008]

435. ̃̃ễ: Bactris gasipaes (nukak) [Cabrera et al., 1999]

436. Irré: Bactris gasipaes (wanano) [Emilia Gómez, Mitú, Vaupés, com. pers., 2004]

437. ireẽa: Bactris gasipaes (tanimuca) [Zaleth Cordero, Bogotá, com. pers., 2004]

438. †reñi: Bactris gasipaes (cubeo) [Paulina Aguía, Mitú, Vaupés, com. pers., 2004]

439. ̇ríño: Bactris gasipaes (siriano) [Gaudencio Rodríguez, Ibacaba, Vaupés, com. pers., 2004]

440. isoi: Oenocarpus bataua (piaroa) [Guánchez \& Romero, 1998]

441. ítebì: Mauritia flexuosa (curripaco) [Eliana Garrido, Mitú, Vaupés, com. pers., 2004]

442. itewi: Mauritia flexuosa (yukuna) [Zaleth Cordero, com. pers., 2004]

443. itina: Oenocarpus bacaba (uitoto) [Galeano, 1991]

444. ĩtü: Bactris gasipaes (tikuna) [Prado, 2008]

445. ̃tü chikü: Bactris riparia (tikuna) [Prado, 2008]

446. ium: Oenocarpus bataua (puinave) [Hablante anónimo, Bogotá 1999]

447. iyase: Iriartea deltoidea (miraña) [La Rotta 408 (COL), 1984]

448. iyõ: Mauritia flexuosa (puinave) [Pedersen \& Balslev, 1998]

449. ka wan: Desmoncus polyacanthos (puinave) [Triana 93 (COL), 1980]

450. kaadĩdë: Attalea maripa (nukak) [Cabrera et al., 1999] 
451. káámã: Indeterminada (tikuna) [Montes, 1995]

452. kaamába inóho: Mauritia flexuosa (muinane) [Kronik et al., 1999]

453. kaarú: Lepidocaryum tenue (yukuna) [Henderson, 1995]

454. kaatiku inóho: Mauritia flexuosa (muinane) [Kronik et al., 1999]

455. kachimeya: Bactris gasipaes (tunebo) [Patiño, 1960]

456. kadanarite: Mauritiella aculeata (curripaco) [Pabón 256 (COL), 1977]

457. kadoemeíba: Hyospathe elegans (miraña) [Galeano, 1991]

458. kãé kõsañi: Indeterminda (koreguaje) [Cook et al., 2001]

459. kãhíka tsiambo: Astrocaryum acaule (cubeo) [Hablante anónimo, Naná, Vaupés, com. pers., 2004]

460. kahá: Bactris setulosa (tunebo) [Romayne, 1997]

461. kahúe: Prestoea schultzeana (secoya) [Henderson, 1995]

462. kaingát: Manicaria saccifera (kakua) [Patricia Gómez, Taina, Vaupés, com. pers., 2004]

463. kaĩntokëgn: Manicaria saccifera (kakua) [Arbino Furia, Taina, Vaupés, com. pers., 2004]

464. kálaha: Indeterminada (jitnu) [Buenaventura, 1993]

465. kalu' lú: Oenocarpus minor (yukuna) [José Yepes Matapí \& Elí Yukuna, La Pedrera, Amazonas, com. pers., 1991]

466. kämahuä: Desmoncus orthacanthos (piaroa) [María Paula Balcázar, Bogotá, com. pers., 2004]

467. kamaroboto: Leopoldinia major (sikuani) [Sánchez, 1989]

468. kamavakhá: Desmoncus sp. (tariano) [Domingo Muniz y Jhon Batista, Piriquito, Brasil, com. pers., 2004]

469. kamawa: Desmoncus orthacanthos (piapoco) [Balcázar 1249 (COL), 2004]

470. kamawa: Desmoncus polyacanthos (curripaco) [Pabón 329 (COL), 1977]

471. kaméla: Astrocaryum sp. (guayabero) [Tobar, 1994]

472. kamuuaboto: Desmoncus (sikuani) [Sánchez, 1989]

473. kamuvé: Desmoncus orthacanthos (sikuani) [Henderson, 1995]

474. kamuvé: Desmoncus polyacanthos (sikuani) [Henderson, 1995]

475. kañakoná: Mauritia carana (uitoto) [Galeano, 1991]

476. kanangucho: Mauritia flexuosa (siona) [Borchsenius et al., 1998]

477. kaniébot: Indeterminada (jitnu) [Buenaventura, 1993]

478. kanongocho: Maurita flexuosa (cofán) [Pedersen \& Balslev, 1990]

479. kantineé: Mauritiella armata (siona) [Borchsenius et al., 1998]

480. kapa: Indeterminada (guayabero) [Tobar, 1994]

481. kaparxéla: Indeterminada (guayabero) [Tobar, 1994]

482. károwara: Oenocarpus bataua (tunebo) [Romayne, 1997]

483. karugiri: Lepidocaryum tenue (yukuna) [Henderson, 1995]

484. karuũ ruka: Oenocarpus sp. (tanimuca) [Zaleth Cordero, Bogotá, com. pers., 2004]

485. katànali: Mauritia carana (piapoco) [Pharris de Klumpp, 1995, como Mauritia sp.]

486. katanári: Mauritia carana (piapoco) [Reinoso, 1993]

487. kateehiko: Bactris riparia (miraña) [Galeano, 1991]

488. kãti neé: Mauritiella armata (secoya) [Borchsenius et al., 1998]

489. katsána: Indeterminada (yuko) [Robayo, 1997]

490. kaúhłko: Bactris fissifrons (bora) [Henderson, 2000]

491. kawna: Bactris bifida (tikuna) [Prado, 2008, como kauna]

492. kéd: Manicaria saccifera (waunana) [Bernal \& Galeano, 1993]

493. kerantếgn: Euterpe precatoria (kakua) [Patricia Gómez, Taina, Vaupés, com. pers., 2004]

494. $\mathrm{k}^{\mathrm{h}}$ ambu $\mathrm{f}^{\mathrm{y}} \mathrm{tu}$ : Indeterminada (páez) [Rojas, 1993]

495. knósao: Socratea exorrhiza (wanano) [Emilia Gómez, Mitú, Vaupés, com. pers., 2004]

496. kidóña: Bactris gasipaes (uitoto) [Kronik et al., 1999]
497. kigao hahe: Pholidostachys synanthera (muinane) [Galeano, 1991]

498. küyuakai: Iriartella setigera (uitoto) [Galeano, 1991]

499. kikiño kikidye: Astrocaryum gynacanthum (uitoto) [Kronik et al., 1999]

500. kí̃: Attalea maripa (wanano) [Emilia Gómez, Mitú, Vaupés, com. pers., 2004]

501. kirídyahe: Oenocarpus bataua (muinane) [Kronik et al., 1999]

502. kituá uí: Geonoma cuneata (embera) [Bernal, Galeano, Restrepo \& Jaidonesama (Manuel) Domicó 1161 (COL), 1986]

503. kõã: Mauritiella armata (wanano) [Hablante anónimo, Naná, Vaupés, com. pers., 2004]

504. koaãka: Mauritiella sp. (tanimuca) [Cordero 500 (COL), 2004]

505. koáño: Mauritiella armata (tucano) [Gallo, 1972, como indet.]

506. koấñõ: Mauritiella armata (tuyuca) [Avelino González, Taina, Vaupés, com. pers., 2004]

507. kob: Indeterminada (jupda) [Erickson \& Erickson 1993]

508. kobónase: Iriartea deltoidea (yagua) [Chaumeil, 1998]

509. koboto: Indeterminada (cuiba) [Merchán, 1993]

510. kóchbot: Attalea butyracea (jitnu) [Buenaventura, 1993]

511. kodime: Attalea racemosa (andoque) [Galeano, 1991]

512. kodo dorida: Wettinia augusta (uitoto) [Kronik et al., 1999]

513. koedopeko: Iriartella setigera (andoque) [Balcázar, Nicolás y Mario Andoke 682 (COL), 1998]

514. kofahe: Geonoma macrostachys (cofán) [Borchsenius et al., 1998]

515. kõhã: Mauritiella armata (tucano) [Avelino González, Taina, Vaupés, com. pers., 2004]

516. kõhãñi boriyabeañi:Oenocarpus bacaba (cubeo) [William González, Mitú- Vaupés, com. pers., 2004]

517. kõhãñi pũrãmãñi:Oenocarpus bataua (cubeo) [William González, Mitú- Vaupés, com. pers., 2004]

518. kohaño: Indeterminada (barasana) [García \& Monguí, 1975]

519. kohañu: Oenocarpus bataua (cubeo) [Pedersen \& Balslev, 1990]

520. ko ${ }^{\mathrm{h}}$ sáño: Socratea exhorriza (piratapuyo) [Carlos Acosta, Ibacaba, Vaupés, com. pers., 2004]

521. $\mathrm{ko}^{\mathrm{h}}$ sáñodu: Iriartea deltoidea (piratapuyo) [Carlos Acosta, Ibacaba, Vaupés, com. pers., 2004]

522. kokbá': Attalea sp. (kakua) [Arbino Furia, Taina, Vaupés, com. pers., 2004]

523. kokbû́: Cocos nucifera (waunana) [Hablante anónimo, Bajo San Juan, Chocó, com. pers., 1998]

524. koko tas ${ }^{\mathrm{y}}$ : Indeterminada (páez) [Rojas, 1993]

525. kókó: Cocos nucifera (embera) [Binder et al., 1995]

526. koko: Cocos nucifera (yagua) [Chaumeil, 1998]

527. kokoakãĩ: Cocos nucifera (barí) [Mogollón, 1995]

528. kokoñi: Cocos nucifera (cubeo) [Valencia, 1994]

529. koku: Cocos nucifera (ika) [Zalabata, 1995]

530. koma: Astrocaryum jauari (tikuna) [Prada SP-B73 (COL), 1985; Prado, 2008]

531. komaíhe: Oenocarpus bataua (uitoto) [Balick, 1986a]

532. komálbot: Socratea exorrhiza (jitnu) [Buenaventura, 1993]

533. komée: Oenocarpus bataua (muinane) [Pedersen \& Balslev, 1990]

534. komée: Oenocarpus bataua (uitoto) [Pedersen \& Balslev, 1990]

535. komtếgn: Astrocaryum chambira (kakua) [Patricia Gómez, Taina, Vaupés, com. pers., 2004]

536. konéna: Mauritia flexuosa (uitoto) [Pedersen \& Balslev, 1990]

537. konta: Mauritia flexuosa (andoque) [Galeano, 1991]

538. koomehi: Oenocarpus bataua (miraña) [Galeano, 1991]

539. kòomi: Oenocarpus bataua (miraña) [Seifart, 2002]

540. kopbót: Cocos nucifera (jitnu) [Buenaventura, 1993] 
541. koriña: Astrocaryum jauari (uitoto) [Kronik et al., 1999]

542. koruné: Astrocaryum jauari (uitoto) [Henderson, 1995]

543. kõsa: Oenocarpus bataua (koreguaje) [Cook et al., 2001]

544. kosá: Oenocarpus bataua (siona) [Henderson, 1995]

545. kõsañi: Oenocarpus bataua (koreguaje) [Cook et al., 2001]

546. kotsiboto: Indeterminada (cuiba) [Merchán, 1993]

547. kotu: Lepidocaryum tenue (tikuna) [Prado, 2008; Montes 1995, como kòtù]

548. kuaske: Geonoma lanata (awa pit) [Borchsenius et al., 1998, como G. leptospadix]

549. kubañi: Mauritiella armata (cubeo) [Hablante anónimo, Naná Vaupés, com. pers., 2004]

550. kubarri: Bactris fissifrons (carijona) [Schultes 5363 (COL), 1943]

551. kubaruboto: Bactris setulosa (sikuani) [Sánchez, 1989]

552. kudídi: Oenocarpus bacaba (baniva) [Henderson, 1995]

553. kuhĩta: Attalea septuagenata (yukuna) [José Yepes Matapí \& Elí Yukuna, La Pedrera, Amazonas, com. pers., 1991]

554. kuikúi: Bactris acanthocarpa (siona) [Borchsenius et al., 1998]

555. kuko: Cocos nucifera (kogui) [Ortiz, 1994]

556. kukuño: Cocos nucifera (tucano) [Gallo, 1972]

557. kulksha: Indeterminada (kogui) [Ortiz, 1994]

558. kuloxshá: Indeterminda (kogui) [Reichel Dolmatoff, 1985]

559. kuluuala: Attalea butyracea (wayuunaiki) [Key, 2000]

560. kumaki: Astrocaryum chambira (puinave) [Guánchez \& Romero, 1998, como Astrocaryum sp.]

561. kumali: Astrocaryum chambira (piapoco) [Pharris de Klumpp, 1995]

562. kumàli: Astrocaryum chambira (piaroa) [Pharris de Klumpp, 1995]

563. kumali: Astrocaryum chambira (achagua) [Meléndez, inéd.]

564. kumaliboto: Astrocaryum sp. (sikuani) [Hablante anónimo, Bogotá, 1998]

565. kumaliñu: Astrocaryum chambira (sáliba) [Benaissa, 1991]

566. kumalip ${ }^{\text {hé: }}$ Astrocaryum chambira (tariano) [Domingo Muniz y Jhon Batista, Piriquito, Brasil, com. pers 2004]

567. kumari: Astrocaryum chambira (sikuani) [Guánchez \& Romero, 1998, como Astrocaryum sp.]

568. kumaria: Astrocaryum sp. (curripaco) [Guánchez \& Romero, 1998]

569. kuméerio: Oenocarpus bataua (muinane) [Kronik et al., 1999]

570. kumu: Oenocarpus bataua (carijona) [Pedersen \& Balslev, 1990]

571. kumuchikinibə: Indeterminada (carijona) [Robayo, 1993]

572. kupa: Socratea exorrhiza (puinave) [Guánchez \& Romero, 1998]

573. kuparú: Bactris corossilla (yukuna) [Henderson, 2000]

574. kupéri: Oenocarpus minor (sikuani) [Balick 1201 (COL), 1978]

575. kurá: Attalea maripa (nukak) [Cárdenas \& Politis, 2000]

576. kuripa: Astrocaryum jauari (yukuna) [José Yepes Matapí \& Elí Yukuna, La Pedrera, Amazonas, com. pers., 1991]

577. kuriwa keddua: Asterogyne martiana (embera) [La Rotta 693 (COL), 1985]

578. kurua: Attalea butyracea (tikuna) [Prado, 2008]

579. kurùada: Indeterminada (piapoco) [Pharris de Klumpp, 1995]

580. kushíbai: Indeterminada (achagua) [Meléndez, 1998]

581. kúshibaishina: Indeterminada (achagua) [Meléndez, 1998]

582. kusí: Attalea racemosa (piaroa) [Guánchez \& Romero, 1998]

583. kusi: Indeterminada (sáliba) [Benaissa, 1991]

584. kuu: Astrocaryum ferrugineum (tikuna) [Prado, 2008]

585. kuuña himena:Bactris gasipaes (uitoto) [Kronik et al., 1999]

586. küüru: Attalea microcarpa (tikuna) [Prado, 2008]

587. kuuruhu: Oenocarpus bataua (bora) [Borgtoft P.\& Balslev 1990]
588. kuy: Attalea plowmanii (yukuna) [Galeano 2050 (COL), 1990]

589. kuyé: Wettinia maynensis (cofán) [Cerón, 1995]

590. kuzì: Indeterminada (piapoco) [Reinoso, 1993]

591. kwai: Mauritia carana (carijona) [Robayo, 1993]

592. kwai: Mauritia flexuosa (carijona) [Robayo, 1993]

593. kwátbot: Mauritia flexuosa (jitnu) [Buenaventura, 1993]

594. kwétirri: Attalea maripa (curripaco) [Guánchez \& Romero, 1998]

595. kwí'osa: Mauritia flexuosa (tinigua) [Tobar, 1993]

596. kwiapé: Attalea racemosa (curripaco) [Guánchez \& Romero, 1998]

597. kəmme ${ }^{\text {h }}$ kia: Indeterminada (ika) [Zalabata, 1995]

598. lakae: Chamaedorea pauciflora (miraña) [Galeano, 1991]

599. lamus tas ${ }^{\mathrm{y}}$ : Indeterminada (páez) [Rojas, 1993]

600. lamus: Indeterminada (páez) [Slocum \& Gerdel, 1983]

601. liwai: Iriartella setigera (sikuani) [Guánchez \& Romero, 1998]

602. 1lĩde: Mauritia flexuosa (sáliba) [Benaissa, 1991]

603. lutawe oko: Hyospathe elegans (secoya) [Borchsenius et al., 1998]

604. ma neé: Mauritia flexuosa (secoya) [Vickers \& Plowman, 1984]

605. ma puĩ: Hyospathe elegans (secoya) [Vickers \& Plowman, 1984 como Hyospathe sp.]

606. maalama: Leopoldinia piassaba (curripaco) [Rojas, 1997]

607. máam: Astrocaryum gynacanthum (nukak) [Cárdenas \& Politis, 2000]

608. mabako: Attalea butyracea (piapoco) [Narváez \& Stauffer, 1999]

609. mábi: Desmoncus sp. (curripaco) [Eliana Garrido, Mitú, Vaupés, com. pers., 2004]

610. machepaboto: Indeterminada (cuiba) [Merchán, 1993]

611. madi: Bactris acanthocarpa (piaroa) [María Paula Balcázar, Bogotá, com. pers., 2004]

612. maháwita: Indeterminada (piapoco) [Reinoso, 1993]

613. ma károka ĩé: Bactris hirta (wanano) [Bernardo Rodríguez, Naná, Vaupés, com. pers., 2004]

614. makapéiboto: Oenocarpus minor (sikuani) [Silva 189 (COL), 1977]

615. makeru: Oenocarpus makeru (yukuna) [Henderson, 1995]

616. makófa: Indeterminada (guayabero) [Tobar, 1994]

617. makopahiboto: Oenocarpus minor (sikuani) [Balick, 1986a, como O. mapora]

618. makúpai: Oenocarpus bataua (achagua) [Meléndez, 1998]

619. makupàisi: Oenocarpus bacaba (piapoco) [Pharris de Klumpp, 1995

620. malakala: Euterpe precatoria (yukuna) [José Yepes Matapí \& Elí Yukuna, La Pedrera, Amazonas, com. pers., 1991]

621. malama: Leopoldinia piassaba (baniva) [Guánchez \& Romero, 1998]

622. málibot: Aiphanes horrida (jitnu) [Buenaventura, 1993]

623. malontus: Indeterminada (guambiano) [Pabón, 1995]

624. mana: Euterpe precatoria (baniva) [Guánchez \& Romero, 1998]

625. manaká: Euterpe catinga (piaroa) [Guánchez \& Romero, 1998]

626. manáka: Euterpe precatoria (cocama) [Victor Petrucci, com. pers., 2005]

627. manákai: Euterpe precatoria (achagua) [Meléndez, inéd.]

628. manakai: Euterpe precatoria (piapoco) [Hablante anónimo, Bogotá, com. pers., 1999]

629. manakái: Euterpe precatoria (sikuani) [Henderson, 1995]

630. manakaiboto: Euterpe precatoria (sikuani) [Sánchez, 1989]

631. manake: Euterpe catinga (curripaco) [Bernal 2116 (COL), 1994]

632. manáke: Euterpe precatoria (curripaco) [Eliana Garrido, Mitú, Vaupés, com. pers., 2004] 
633. manamazu: Leopoldinia sp. (puinave) [Triana 170 (COL), 1980]

634. manboto: Indeterminada (cuiba) [Merchán, 1993]

635. manikoli: Leopoldinia sp. (curripaco) [Espina 270 (COL), 1977]

636. manikore: Leopoldinia pulchra (curripaco) [Bernal 2105 (COL), 1994]

637. manñeka: Euterpe precatoria (cabiyarí) [Schultes 14865 (COL), 1951]

638. manyokónẽ̃: Bactris gasipaes (siona) [Vickers \& Plowman, 1984]

639. mapanaré: Attalea butyracea (yukuna) [José Yepes Matapí \& Elí Yukuna, La Pedrera, Amazonas, com. pers., 1991]

640. mapanariphépi: Attalea sp. (tariano) [Domingo Muniz y Jhon Batista, Piriquito, Brasil, com. pers., 2004]

641. mapoloboto: Roystonea oleracea (sikuani) [Sánchez, 1989]

642. mapórbot: Roystonea oleracea (jitnu) [Buenaventura, 1993]

643. maráma: Leopoldinia piassaba (piapoco) [Guánchez \& Romero, 1998]

644. marama: Leopoldinia piassaba (piaroa) [Guánchez \& Romero, 1998]

645. maramá: Leopoldinia piassaba (puinave) [Bernal 2117 (COL), 1994]

646. maramapé: Leopoldinia piassaba (curripaco) [Espina 224 (COL), 1977]

647. mariha: Attalea maripa (carijona) [Robayo, 1993, como indet.]

648. mariha: Attalea maripa (uitoto) [Galeano, 1991]

649. marím ipa: Itaya amicorum (miraña) [Henderson, 1995]

650. mariṕ́nin: Geonoma maxima (curripaco) [Hablante anónimo, Puerto Inírida, Guainía, com. pers., 1994]

651. matáigahiba: Astrocaryum chambira (muinane) [Kronik et al., 1999, como A. aculeatum]

652. matamba ted: Desmoncus cirrhifer (awa pit) [González 181 (COL), 1992]

653. matawakuliboto: Astrocaryum acaule (sikuani) [Sánchez, 1989]

654. mavaco: Attalea racemosa (sikuani) [Guánchez \& Romero, 1998]

655. mavako: Attalea maripa (baniva) [Henderson, 1995]

656. mavip ${ }^{\mathrm{h}}$ : Iriartella setigera (tariano) [Domingo Muniz y Jhon Batista, Piriquito, Brasil, com. pers., 2004]

657. máwi: Indeterminada (piapoco) [Reinoso, 1993]

658. mawi: Iriartella setigera (baniva) [Guánchez \& Romero, 1998]

659. mawi: Iriartella setigera (curripaco) [Hablante anónimo, Puerto Inírida, Guainía, 1994]

660. mawiboto: Iriartella setigera (sikuani) [Sánchez, 1989]

661. mawiku: Iriartella setigera (yukuna) [Balcázar 657 (COL), 1998]

662. mayaikáru: Indeterminada (yukuna) [Pabón 877 (COL), 1979]

663. méeme: Bactris gasipaes (miraña) [Galeano, 1991]

664. meemedihe móomoo: Bactris gasipaes (muinane) [Kronik et al., 1999]

665. meenime kanifai inóho: Mauritia flexuosa (muinane) [Kronik et al., 1999]

666. meenimt néhe: Astrocaryum gynacanthum (muinane) [Kronik et al., 1999]

667. meeninehee: Astrocaryum ciliatum (miraña) [Sánchez 892 (COL), 1988]

668. meikeze: Geonoma maxima (miraña) [Sánchez, 1997]

669. mek: Bactris gasipaes (ocaina) [Patiño, 1960]

670. mekwátbak: Manicaria saccifera (miraña) [Galeano 1584 (COL), 1988]

671. meme: Wettinia quinaria (embera) [Bernal \& Galeano, 1993]

672. meme ara: Indeterminada (embera) [Llerena, 1993]

673. meme minik ${ }^{\mathrm{h}} \mathrm{o}$ : Indeterminada (embera) [Llerena, 1993]

674. memer imóomo: Bactris simplicifrons (muinane) [Sánchez, 1997]
675. menaba: Indeterminada (carijona) [Robayo, 1993]

676. mĩ potáño: Bactris balanophora (wanano) [Bernal 3664 (COL), 2004]

677. mĩã phãpú: Attalea butyracea (wanano) [Bernal 3607 (COL), 2004]

678. michiboto: Indeterminada (cuiba) [Merchán, 1993]

679. migoi hitimo: Desmoncus polyacanthos (uitoto) [Kronik et al., 1999]

680. mîhî́: Astrocaryum gynacanthum (wanano) [Bernardo Rodríguez, Naná, Vaupés, com. pers., 2004]

681. mîhí: Euterpe precatoria (desano) [Luz Mila Santa Cruz y Matilde Arango, Naná, Vaupés, com. pers., 2004]

682. mîhî̀ biki: Geonoma sp. (wanano) [Bernardo Rodríguez, Naná, Vaupés, com. pers., 2004]

683. mîhî́ sá: Bactris fissifrons (wanano) [Avelino González \& Gustavo Trinidad, Taina, Vaupés, com. pers., 2004]

684. mihĩño: Bactris fissifrons (tucano) [Avelino González \& Gustavo Trinidad, Taina, Vaupés, com. pers., 2004]

685. mihiño: Euterpe precatoria (barasana) [García \& Monguí, 1975]

686. mihíño: Euterpe precatoria (siriano) [Gaudencio Rodríguez, Ibacaba, Vaupés, com. pers., 2004]

687. minhí: Euterpe precatoria (wanano) [Emilia Gómez, Mitú, Vaupés, com. pers., 2004]

688. min piño: Euterpe precatoria (tucano) [Avelino González, Taina, Vaupés, com. pers., 2004]

689. mi ${ }^{\mathrm{h}}$ píñõ: Euterpe precatoria (tuyuca) [Avelino González, Taina, Vaupés, com. pers., 2004]

690. mit: Socratea exorrhiza (desano) [Schultes, 1974]

691. miihibao: Chamaedorea pinnatifrons (muinane) [Kronik et al., 1999]

692. mimeuhe móomoo: Bactris gasipaes (muinane) [Kronik et al., 1999]

693. misíboto: Iriartea deltoidea (sikuani) [Balick 1195 (COL), 1978]

694. misiboto: Socratea exorrhiza (sikuani) [Sánchez, 1989]

695. mitámba: Desmoncus sp. (kogui) [Reichel Dolmatoff, 1985]

696. mĩtnĩ: Indeterminada (barí) [Mogollón, 1995]

697. mĩũ t́nẽ: Bactris gasipaes (secoya) [Vickers \& Plowman, 1984]

698. miu neéñt: Mauritiella armata (koreguaje) [Cook et al., 2001]

699. miúmérẽñu: Indeterminada (siriano) [Trujillo et al., 1980]

700. mivi: Iriartella setigera (piapoco) [Pabón E., Espina \& Domínguez 168 (COL), 1977]

701. miya hiyui: Geonoma deversa (muinane) [Sánchez, 1997]

702. miya inóho: Mauritia flexuosa (muinane) [Galeano, 1991]

703. miyabikimũ: Desmoncus sp. (cubeo) [William González, Mitú, Vaupés, com. pers., 2004]

704. mógoioa: Bactris gasipaes (uitoto) [Kronik et al., 1999]

705. mogor: Bactris maraja (cuna) [Henderson, 2000]

706. mohấ: Mauritiella armata (desano) [Bernardita González, Naná, Vaupés, com. pers., 2004]

707. mohî́: Mauritia carana (desano) [Luz Mila Santa Cruz y Matilde Arango, Naná, Vaupés, com. pers., 2004]

708. mohî́: Mauritia carana (wanano) [Emilia Gómez, Mitú, Vaupés, com. pers., 2004]

709. mohíbikiño: Indeterminada (barasana) [García \& Monguí S. 1975]

710. mohĩño: Mauritia carana (piratapuyo) [Carlos Acosta, Ibacaba, Vaupés, com. pers., 2004]

711. mõm: Bactris gasipaes (puinave) [Bernal 1994]

712. momo: Desmoncus polyacanthos (muinane) [Galeano, 1991]

713. momó igaiku: Wettinia augusta (muinane) [Kronik et al., 1999]

714. mómoo: Bactris sp. (muinane) [Patiño, 1960] 
715. mota: A. cf insignis (tikuna) [Prado, 2008]

716. muhí: Lepidocaryum tenue (taiwano) [Schultes 14736 (COL), 1951, como moohé́]

717. móomo igaiku: Iriartella setigera (muinane) [Galeano, 1991]

718. moru: Attalea phalerata (tikuna) [Bernal \& Grussmacher 2929 (COL), 2001; Prado, 2008]

719. mũã pũrí: Manicaria saccifera (wanano) [Cristóbal Texeira Barbosa, Ibacaba, Vaupés, com. pers., 2004]

720. muhíño: Mauritia carana (siriano) [María Noemí Uribe, Ibacaba, Vaupés, com. pers., 2004]

721. muhiño: Mauritia carana (tucano) [Gallo, 1972]

722. muhisa: Mauritia carana (wanano) [Borrero \& Pérez, 2004]

723. mũĩ: Mauritia carana (cubeo) [Hablante anónimo, com. pers., 2004]

724. mũ̃: Mauritia carana (tuyuca) [Avelino González, Taina, Vaupés, com. pers., 2004]

725. mũ̃̃chiãbo: Manicaria saccifera (cubeo) [William González, Mitú, Vaupés, com. pers., 2004]

726. muíñi: Mauritia carana (cubeo) [Valencia, 1994]

727. mũuũká: Astrocaryum chambira (cubeo) [Hablante anónimo, Bogotá, 1998]

728. munuikori: Bactris killipii (uitoto) [Kronik et al., 1999]

729. muri: Bactris gasipaes (puinave) [Guánchez \& Romero, 1998]

730. murrap ${ }^{\mathrm{h}} \mathrm{o}$ : Euterpe oleracea (waunana) [Hablante anónimo, Bajo San Juan, Chocó, 1998]

731. murrap $^{\mathrm{h}} \mathrm{o}$ : Prestoea acuminata (embera) [Pedersen \& Balslev, 1990]

732. muy: Lepidocaryum tenue (cubeo) [Cordero 724 (COL), 2004]

733. məro'ta: Indeterminada (ika) [Zalabata, 1995]

734. naa á: Mauritia flexuosa (wanano) [Emilia Gómez, Mitú, Vaupés, com. pers., 2004]

735. naa: Indeterminada (chimila) [Trillos 1997]

736. náamemu: Desmoncus sp. (cubeo) [Hablante anónimo, Naná, Vaupés, 2004]

737. nachii arü îtü: Bactris hirta (tikuna) [Prado, 2008, como nachii arü itü]

738. nagnora himena: Bactris balanophora (uitoto) [Sánchez, 1997]

739. ñahiño: Indeterminada (barasana) [García \& Monguí, 1975]

740. nãhõemimueñi: Euterpe oleracea (cubeo) [William González, Mitú, Vaupés, com. pers., 2004]

741. naĩ: Astrocaryum chambira (tikuna) [Victorino Bautista, Leticia, Amazonas, com. pers., 1999]

742. nãi: Astrocaryum chambira (tikuna) [Prado, 2008]

743. naí: Prestoea schultzeana (secoya) [Borchsenius et al., 1998]

744. naí: Prestoea schultzeana (siona) [Henderson, 1995]

745. naidí: Euterpe oleracea (embera) [Bernal \& Galeano, 1993]

746. ñaigiri: Geonoma macrostachys (uitoto) [Galeano, 1991]

747. ñaigúru: Geonoma macrostachys (uitoto) [Henderson, 1995]

748. nain: Mauritia flexuosa (cubeo) [Schultes 13843 (COL), 1951]

749. nakálbot: Indeterminada (jitnu) [Buenaventura, 1993]

750. nak ${ }^{\text {h }}$ düboto: Indeterminada (cuiba) [Merchán G. 1993]

751. nakrì: Hyospathe elegans (uitoto) [Galeano, 1991]

752. ñala: Acrocomia aculeata (sáliba) [Benaissa, 1991]

753. naldisch: Euterpe precatoria (awa pit) [González, 1994]

754. nalu: Bactris gasipaes (cuna) [Patiño, 1960]

755. ñamá $\mathrm{p}^{\mathrm{h}} a \mathrm{p}^{\mathrm{h} u ́}$ : Attalea racemosa (wanano) [Bernardo Rodríguez, Naná, Vaupés, com. pers., 2004]

756. nanikuni: Mauritia flexuosa (koreguaje) [Pedersen \& Balslev, 1990]

757. napa: Indeterminda (cuna) [Llerena, 1994]

758. naxareboboto: Attalea maripa (sikuani) [Sánchez, 1989]
759. nayahuëdadu: Geonoma macrostachys (siona) [Balslev et al., 1997]

760. ndesé: Mauritia flexuosa (yagua) [Pedersen \& Balslev, 1990]

761. ne: Mauritia flexuosa (tatuyo) [Henderson, 1995]

762. ̃e: Oenocarpus balickii (tikuna) [Prado, 2008]

763. nebau: Bactris sp. (muinane) [Kronik et al., 1999]

764. nebau inóho: Mauritia flexuosa (muinane) [Kronik et al., 1999]

765. neé: Mauritia flexuosa (siona) [Pedersen \& Balslev, 1990]

766. nẽẽ: Mauritia flexuosa (tucano) [Graciliano Lima, Panuré, Guaviare, com. pers., 1999]

767. neé: Mauritia flexuosa (tuyuca) [Tamayo, 1998]

768. neẽa: Mauritia flexuosa (tanimuca) [Zaleth Cordero, Bogotá, com. pers., 2004]

769. neebáu: Bactris acanthocarpa (muinane) [Sánchez, 1997]

770. needa: Euterpe catinga (uitoto) [Galeano, 1991]

771. needa: Euterpe precatoria (uitoto) [Henderson, 1995; Kronik et al., 1999]

772. ñeeino: Bactris macroacantha (andoque) [Galeano, 1991]

773. neéñĩ: Mauritia flexuosa (koreguaje) [Cook et al., 2001]

774. neeño: Mauritia flexuosa (carapana) [Metzger, 2000]

775. néeño: Mauritia flexuosa (piratapuyo) [Carlos Acosta, Ibacaba, Vaupés, com. pers., 2004]

776. neeñõ: Mauritia flexuosa (tucano) [Gallo, 1972]

777. neeñú: Mauritia flexuosa (siriano) [Trujillo et al., 1980]

778. nehe: Astrocaryum chambira (muinane) [Kronik et al., 1999, como A. aculeatum]

779. néhe: Astrocaryum chambira (muinane) [Kronik et al., 1999, como A. aculeatum

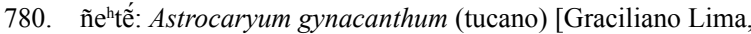
Panuré, Guaviare, com. pers., 1999]

781. ñe $\mathrm{e}^{\mathrm{h}}$ tẽnó: Astroacaryum gynacanthum (wanano) [Cristóbal Texeira Barbosa, Ibacaba, Vaupés, com. pers., 2004]

782. ne néño: Astrocaryum gynacanthum (tucano) [Avelino González, Taina, Vaupés, com. pers., 2004]

783. ne téño: Astrocaryum gynacanthum (tuyuca) [Avelino González, Taina, Vaupés, com. pers., 2004]

784. neiñt: Mauritia flexuosa (cubeo) [William González, Mitú, Vaupés, com. pers., 2004]

785. nek̇ máhkariño kwáño: Mauritiella armata (wanano) [Avelino González y Gustavo Trinidad, Taina, Vaupés, com. pers., 2004]

786. ñekina: Astrocaryum chambira (uitoto) [Galeano, 1991, como $A$. aculeatum ]

787. nené: Bactris gasipaes (cabiyarí) [Patiño, 1960]

788. nenea: Euterpe precatoria (piaroa) [Narváez \& Stauffer, 1999]

789. ñeñechi: Mauritiella aculeata (tikuna) [Prado, 2008]

790. nenichi: Euterpe precatoria (sáliba) [Benaissa, 1991]

791. néñu: Mauritia flexuosa (desano) [Luz Mila Santa Cruz y Matilde Arango, Naná, Vaupés, com. pers., 2004]

792. ngope: Iriartea deltoidea (tikuna) [Prado, 2008]

793. ngowechi ü: Syagrus smithii (tikuna) [Prado, 2008]

794. nguchiaü nguã Mauritia flexuosa, var. de fruto ácido (tikuna) [Prado, 2008]

795. ngumaku: Manicaria cf. martiana (tikuna) [Prado, 2008, como Manicaria martiana]

796. ngumü chi: Phytelephas macrocarpa (tikuna) [Prado, 2008]

797. ngupe: Lepidocaryum tenue, una variedad (tikuna) [Prado, 2008]

798. nibigai tuko: Attalea insignis (muinane) [Sánchez 329 (COL), 1988]

799. nibikala: Indetermindad (kogui) [Ortiz, 1989]

800. niékero: Indeterminada (uitoto) [Victor Petrucci, com. pers., 2005] 
801. nigo taagaiho: Oenocarpus bacaba (muinane) [Kronik et al., 1999]

802. ก̃̃̄ kípũ: Astrocaryum chambira (wanano) [Emilia Gómez, Mitú, Vaupés, com. pers., 2004]

803. nihuchu: Oenocarpus bataua (cofán) [Otoniel Díaz y grupo de jóvenes del Comité de Botánica del pueblo Cofán]

804. níihivigai tuko: Attalea racemosa (muinane) [Sánchez, 1997]

805. ̃ïmí: Oenocarpus bataua (desano) [Luz Mila Santa Cruz y Matilde Arango, Naná, Vaupés, com. pers., 2004]

806. ñikó: Socratea exorrhiza (siona) [Balslev et al., 1997]

807. niya háheku: Lepidocaryum tenue (muinane) [Kronik et al., 1999]

808. ñimisa: Oenocarpus bataua (wanano) [Borrero \& Pérez, 2004]

809. níní: Geonoma brongniartii (secoya) [Borchsenius et al., 1998]

810. niní puĩ: Geonoma (secoya) [Vickers \& Plowman, 1984]

811. ñobeañi: Socratea exorrhiza (cubeo) [Martínez 1711 (COL), 1993]

812. noepá: Bactris gasipaes (andoque) [Galeano, 1991]

813. nohá: Mauritia flexuosa (guayabero) [Tobar, 1994]

814. ño ná: Astrocaryum chambira (tucano) [Gallo, 1972]

815. ño ká: Astrocaryum chambira (tuyuca) [Avelino González, Taina, Vaupés, com. pers., 2004]

816. $\tilde{\text { ño }} \mathrm{k}^{\mathrm{h}}$ á $\mathrm{p}^{\mathrm{h}}$ ora: Astrocaryum chambira (desano) [Bernardita González, Naná, Vaupés, com. pers., 2004]

817. ño ká pũrí: Astrocaryum chambira (tucano) [Hermana Clarisa, Iauarate, Brasil, com. pers., 2004]

818. ñomia: Oenocarpus bataua (tanimuca) [Pedersen \& Balslev, 1990]

819. ̃omiño: Oenocarpus bataua (tatuyo) [Whisler \& Whisler, 1978]

820. ñomuño: Oenocarpus bataua (barasana) [García \& Monguí, 1975]

821. ก̃oõmĩ wãrua: Oenocarpus sp. (tanimuca) [Zaleth Cordero, Bogotá, com. pers., 2004]

822. ñoõmia karãka: Oenocarpus sp. (tanimuca) [Zaleth Cordero, Bogotá, com. pers., 2004]

823. ñopoñu: Socratea exorrhiza (cubeo) [Borrero \& Pérez, 2004]

824. ñoriñá atié tiróñi: Iriartea deltoidea (yurutí) [María Montoya, Yavaraté, Vaupés, com. pers., 2004]

825. nówapa: Bactris sp. (andoque) [Patiño, 1960]

826. nühü'èhúü'ò: Astrocaryum chambira (miraña) [Seifart, 2002]

827. nuikaro: Mauritiella aculeata (uitoto) [Kronik et al., 1999]

828. ñukã: Astrocaryum chambira (siriano) [Benaissa, 1991]

829. ñukáh puño: Astrocaryum chambira (piratapuyo) [Carlos Acosta, Ibacaba, Vaupés, com. pers., 2004]

830. ñúkañi: Astrocaryum chambira (cubeo) [Paulina Aguía, Mitú, Vaupés, com. pers., 2004]

831. ñukaño: Astrocaryum chambira (tatuyo) [Bostrom, 1998]

832. nukë: Bactris concinna (secoya) [Borchsenius et al., 1998]

833. ñukipisa: Astrocaryum chambira (wanano) [Borrero \& Pérez, 2004]

834. ñukuaéné: Chamaedorea pinnatifrons (siona) [Borchsenius et al., 1998]

835. nulyi: Attalea butyracea (kogui) [Carbonó de la Hoz, 1987, como Scheelea sp.]

836. ñumá meká: Oenocarpus bacaba (yurutí) [María Montoya, Yavaraté, Vaupés, com. pers., 2004]

837. ñumá: Oenocarpus bataua (yurutí) [María Montoya, Yavaraté, Vaupés, com. pers., 2004]

838. ñumiñi: Ammandra decasperma (koreguaje) [Cook et al., 2001]

839. ñumú: Oenocarpus bataua (tucano) [Gallo, 1972]

840. ñumú pa ${ }^{\mathrm{h} k a ́ n ̃ o: ~ O e n o c a r p u s ~ b a t a u a ~(t u c a n o) ~[A v e l i n o ~ G o n z a ́ l e z, ~}$ Taina, Vaupés, com. pers., 2004]
841. ñumú ma ká: Oenocarpus bacaba (tucano) [Hermana Clarisa, Iauarate, Brasil, com. pers., 2004]

842. ñumú me tá: Oenocarpus bacaba (tuyuca) [Avelino González, Taina, Vaupés, com. pers., 2004]

843. ñumú omfahá: Oenocarpus bacaba (tucano) [Norma Nelly Sabana, Naná, Vaupés, com. pers., 2004]

844. ñumú pa ${ }^{\mathrm{h}}$ ká wa ${ }^{\mathrm{h}}$ kariká: Oenocarpus bataua (tuyuca) [Avelino González, Taina, Vaupés, com. pers., 2004]

845. ñumúño pa káño: Oenocarpus bataua (piratapuyo) [Carlos Acosta, Ibacaba, Vaupés, com. pers., 2004]

846. ñumúñõ: Mauritia flexuosa (tuyuca) [Avelino González, Taina, Vaupés, com. pers., 2004]

847. ñumúño: Oenocarpus bacaba (piratapuyo) [Carlos Acosta, Ibacaba, Vaupés, com. pers., 2004]

848. ̃umúño: Oenocarpus bacaba (siriano) [Gaudencio Rodríguez, Ibacaba, Vaupés, com. pers., 2004]

849. ñumúño: Oenocarpus bataua (siriano) [Gaudencio Rodríguez, Ibacaba, Vaupés, com. pers., 2004]

850. ก̃umúñu mu ${ }^{\mathrm{h}}$ táringa: Oenocarpus bacaba (siriano) [María Noemi Uribe, Ibacaba, Vaupés, com. pers., 2004]

851. ñumúñu ñóre: Iriartea deltoidea (desano) [Bernardita González, Naná, Vaupés, com. pers., 2004]

852. ñumúñu wadíñnu: Oenocarpus bataua (siriano) [María Noemí Uribe, Ibacaba, Vaupés, com. pers., 2004]

853. ñumúñu: Iriartea deltoidea (desano) [Luz Mila Santa Cruz y Matilde Arango, Naná, Vaupés, com. pers., 2004]

854. ñumúñu: Oenocarpus bacaba (desano) [Bernardita González, Naná, Vaupés, com. pers., 2004]

855. nyoko: Iriartea deltoidea (secoya) [Balslev et al., 1997]

856. nyũkwa: Astrocaryum chambira (siona) [Borchsenius et al., 1998]

857. obá: Iriartea deltoidea (siona) [Balslev et al., 1997]

858. ochi: Astrocaryum gynacanthum (tikuna) [Prado, 2008]

859. odoboto: Indeterminada (cuiba) [Merchán, 1993]

860. ogoke kinena: Mauritia flexuosa (uitoto) [Kronik et al., 1999]

861. ohaüboto: Oenocarpus bacaba (sikuani) [Luis García, Cumaribo, Vichada, com. pers., 1999]

862. oheakon: Bactris elegans (andoque) [Balcázar 150 (COL), 1998]

863. oikiñe: Bactris gasipaes (uitoto) [Kronik et al., 1999]

864. okaimo: (Mauritia flexuosa, var. de fruto amarillo) (tikuna) [Prado, 2008]

865. okó puí: Geonoma macrostachys (siona) [Balslev et al., 1997]

866. okobeto: Astrocaryum jauari (siona) [Borchsenius et al., 1998]

867. okop: Cocos nucifera (cuna) [Llerena, 1987]

868. okópui: Geonoma macrostachys (secoya) [Balslev et al., 1997]

869. okú bot: Oenocarpus bataua (jitnu) [Buenaventura, 1993]

870. omá: Bactris gasipaes (cofán) [Cerón, 1995]

871. opuahõ hopata: Ammandra decasperma (embera) [Binder et al., 1995]

872. opúahõ: Ammandra decasperma (waunana) [Hablante anónimo, Bajo San Juan, Chocó, com. pers., 1998]

873. ora mio: Aiphanes ulei (siona) [Balslev et al., 1997]

874. orañi: Iriartea deltoidea (koreguaje) [Cook et al., 2001, como Iriartea sp.]

875. oreñaw: Bactris simplicifrons (barasana) [Henderson, 2000]

876. oróboto: Syagrus orinocensis (sikuani) [Balick, 1986b; Henderson, 1995]

877. pa í ine: Bactris riparia (siona) [Borchsenius et al., 1998]

878. pa pa: Attalea butyracea (siona) [Balslev et al., 1997]

879. paaríba: Bactris gasipaes (muinane) [Kronik et al., 1999]

880. paatina: Oenocarpus bataua (uitoto) [Kronik et al., 1999]

881. pahare: Bactris gasipaes (piaroa) [Guánchez \& Romero, 1998] 
882. pahp: Bactris maraja (nukak) [Cárdenas \& Politis, 2000]

883. paí: Geonoma macrostachys (secoya) [Balslev et al., 1997]

884. paipigu: Bactris concinna (puinave) [Henderson, 2000]

885. paita: Indeterminada (wayuunaiki) [Key, 2000]

886. pan si noha: Aiphanes ulei (cofán) [Henderson, 1995]

887. papí: Bactris gasipaes (guayabero) [Tobar, 1993]

888. pắpố: Attalea sp. (wanano) [Hablante anónimo, Naná, Vaupés, com. pers., 2004]

889. pắrara büüri: Oenocarpus minor (embera) [Binder et al., 1995]

890. pắrara hua: Indeterminada (embera) [Binder et al., 1995]

891. parará: Oenocarpus minor (embera) [Bernal \& Galeano, 1993, como O. mapora]

892. pareka kinena: Mauritia flexuosa (uitoto) [Kronik et al., 1999]

893. patisakó: Ammandra decasperma (cofán) [Henderson, 1995]

894. patisako nume badishi: Ammandra decasperma (cofán) [Borchsenius et al., 1998]

895. patisako numemba: Ammandra decasperma (cofán) [Borchsenius et al., 1998]

896. pátiu: Phytelephas macrocarpa (yagua) [Chaumeil, 1998]

897. patówa: Indeterminada (guayabero) [Tobar, 1994]

898. patsatsa nihonchó: Oenocarpus minor (cofán) [Cerón, 1995, como O. mapora $]$

899. pattapan: Indeterminada (wayuunaiki) [Pérez van Leenden, 1996]

900. páutta: Copernicia tectorum (wayuunaiki) [Mugica, 1969, como indet.]

901. pawenaboto: Indeterminada (cuiba) [Merchán, 1993]

902. pawenaboto: Syagrus sancona (sikuani) [Sánchez, 1989]

903. pawénbot: Syagrus sancona (jitnu) [Buenaventura, 1993]

904. peédi: Oenocarpus bataua (piaroa) [Pedersen \& Balslev, 1990]

905. peep ${ }^{\mathrm{h}}$ : Attalea racemosa (tuyuca) [Avelino González, Taina, Vaupés, com. pers., 2004]

906. peko: Iriartella setigera (andoque) [Balcázar 683 (COL), 1998]

907. pekor: Pholidostachys synanthera (uitoto) [Henderson, 1995]

908. perõra: Synechanthus warscewiczianus (embera) [Bernal 1150 (COL), 1986

909. petoñi: Cocos nucifera (koreguaje) [Cook et al., 2001]

910. pewitsaboto: Oenocarpus bataua (sikuani) [Sánchez, 1989]

911. p pãpú: Attalea butyracea (wanano) [Bernal 3606 (COL), 2004]

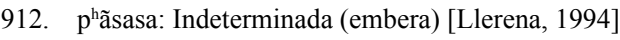

913. p pépunĩ: Attalea racemosa (tucano) [Avelino González, Taina, Vaupés, com. pers., 2004]

914. phiruñi: Astrocaryum cuatrecasanum (koreguaje) [Cook et al., 2001, como indet.]

915. $\mathrm{p}^{\mathrm{h}}$ irusava: Astrocaryum cuatrecasanum (koreguaje) [Cook et al., 2001, como indet.]

916. pie kuró: Oenocarpus minor (embera) [Balick, 1986a, como $O$ mapora]

917. piekuurhõ bä: Oenocarpus minor (waunana) [Binder et al., 1995]

918. píerkúur piu: Indeterminada (waunana) [Binder et al., 1995]

919. piherú: Desmoncus polyacanthos (yukuna) [Balcázar 656 (COL), 1998]

920. pikiño eerekwe: Bactris killipii (uitoto) [Kronik et al., 1999]

921. pimpiñu: Iriartella setigera (cubeo) [Borrero \& Pérez, 2004]

922. pio ü puori: Oenocarpus bacaba (piaroa) [Guánchez \& Romero, 1998]

923. piohoko: Socratea exorrhiza (cubeo) [Gutiérrez 581 (COL), 1944]

924. pioñi: Indeterminada (cubeo) [Valencia, 1994]

925. pìpiri: Bactris gasipaes (piapoco) [Reinoso, 1993]

926. pipirí: Bactris gasipaes (yukuna) [José Yepes Matapí \& Eli Yukuna, La Pedrera, Amazonas, com. pers., 1991]
927. pípirip $^{\mathrm{h}} \mathrm{i}$ : Bactris gasipaes (tariano) [Domingo Muniz y Jhon Batista, Piriquito, Brasil, com. pers., 2004]

928. pípirri: Bactris gasipaes (curripaco) [Eliana Garrido, Mitú, Vaupés, com. pers., 2004]

929. piseró: Desmoncus sp. (yukuna) [José Yepes Matapí \& Elí Yukuna, La Pedrera, Amazonas, com. pers., 1991]

930. poá: Socratea exorrhiza (piapoco) [Guánchez \& Romero, 1998]

931. poabä: Socratea exorrhiza (piaroa) [Guánchez \& Romero, 1998]

932. pohtáño: Bactris elegans(tucano) [Gallo, 1972, como indet.]

933. põ táño: Bactris corossilla (wanano) [Bernal 3617 (COL), 2004]

934. pol: Chamaedorea sp. (cuna) [Giraldo 74 GIP (COL), 1993]

935. pooko: Socratea exorrhiza (andoque) [Galeano, 1991]

936. pootá: Euterpe precatoria (andoque) [Galeano, 1991; La Rotta 133 (COL), 1982]

937. popere: Oenocarpus minor (nukak) [Cárdenas \& Politis, 2000, como O. mapora]

938. popui: Bactris sp. (cocama) [Patiño, 1960]

939. põrá kiríño: Bactris sp. (siriano) [Gaudencio Rodríguez, Ibacaba Vaupés, com. pers., 2004]

940. póre: Bactris sp. (yagua) [Patiño, 1960]

941. potamé: Lepidocaryum tenue (tucano) [Henderson, 1995]

942. pốtaño: Bactris elegans (tucano) [Avelino González \& Gustavo Trinidad, Taina, Vaupés, com. pers., 2004]

943. potáñó: Bactris hirta (wanano) [Cristóbal Texeira Barbosa, Ibacaba, Vaupés, com. pers., 2004]

944. pu'tëgn: Iriartea deltoidea (kakua) [Arbino Furia, Taina, Vaupés, com. pers., 2004]

945. púba: Indeterminda (piapoco) [Reinoso, 1993]

946. pubèeri: Oenocarpus bacaba (piapoco) [Benaissa, 1991]

947. puhurrupere: Oenocarpus sp. (yukuna) [José Yepes Matapí \& Elí Yukuna, La Pedrera, Amazonas, com. pers., 1991]

948. púi: Geonoma triglochin (siona) [Balslev et al., 1997]

949. puivochosí: Chamaedorea pinnatifrons (cofán) [Cerón, 1995]

950. pum: Mauritiella armata (puinave) [Hablante anónimo, Puerto Inírida, Guainía, 1994]

951. punáma: Oenocarpus bacaba (tariano) [Balick, 1986a]

952. púnama: Oenocarpus bataua (curripaco) [Eliana Garrido, Mitú, Vaupés, com. pers., 2004]

953. pùnama: Oenocarpus bataua (piapoco) [Reinoso, 1993]

954. punama: Oenocarpus bataua (yukuna) [José Yepes Matapí \& Elí Yukuna, La Pedrera, Amazonas, com. pers., 1991]

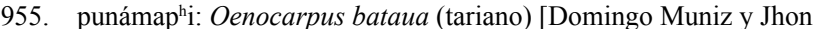
Batista, Piriquito, Brasil, com. pers., 2004]

956. púne: Mauritia carana (tariano) [Domingo Muniz y Jhon Batista, Piriquito, Brasil, com. pers., 2004]

957. pũõ: Iriartella setigera (wanano) [Emilia Gómez, Mitú, Vaupés, com. pers., 2004]

958. púpa: Iriartea deltoidea (curripaco) [Eliana Garrido, Mitú, Vaupés, com. pers., 2004]

959. púpa: Socratea exorrhiza (curripaco) [Hablante anónimo, Puerto Inírida, Guainía, com. pers., 1994]

960. pupa: Socratea exorrhiza (yukuna) [José Yepes Matapí \& Elí Yukuna, La Pedrera, Amazonas, com. pers., 1991]

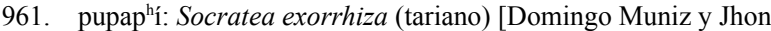
Batista, Piriquito, Brasil, com. pers., 2004]

962. pupé: Oenocarpus bacaba (yukuna) [José Yepes Matapí \& Elí Yukuna, La Pedrera, Amazonas, com. pers., 1991]

963. pupechi: Oenocarpus bacaba (tikuna) [Prado, 2008, como O. cf. makeru]

964. pupeirip ${ }^{\mathrm{h}}$ : Oenocarpus bacaba (tariano) [Domingo Muniz y Jhon Batista, Piriquito, Brasil, com. pers., 2004] 
965. púperre: Oenocarpus bacaba (curripaco) [Eliana Garrido, Mitú, Vaupés, com. pers., 2004]

966. pũrámañũ: Oenocarpus bataua (cubeo) [Hablante anónimo, Naná, Vaupés, 2004]

967. puramu: Indeterminada (curripaco) [Rojas, 1997]

968. purumaboto: Attalea butyracea (sikuani) [Sánchez, 1989]

969. pũtiñi: Attalea maripa (koreguaje) [Cook et al., 2001]

970. puzùi: Indeterminada (piapoco) [Reinoso, 1993]

971. reño: Mauritia flexuosa (barasana) [García \& Monguí, 1975]

972. riamuhiño: Indeterminada (barasana) [García \& Monguí, 1975]

973. ríño: Bactris gasipaes (desano) [Bernardita González, Naná, Vaupés, com. pers., 2004]

974. ropokire: Lepidocaryum tenue (uitoto) [Kronik et al., 1999, como Lepidocaryum sp.]

975. ruchi: Lepidocaryum tenue (cabiyarí) [Schultes 14736 (COL), 1951 como roochee]

976. ruiregó: Astrocaryum gynacanthum (uitoto) [Henderson, 1995]

977. ruirida: Astrocaryum gynacanthum (uitoto) [Galeano, 1991]

978. ruiridye: Astrocaryum gynacanthum (uitoto) [Kronik et al., 1999]

979. ruirui: Astrocaryum ciliatum (uitoto) [Galeano, 1991]

980. rukua: Indeterminada (tunebo) [Romayne, 1997]

981. rurkuicha: Indeterminada (tunebo) [Romayne, 1997]

982. sabáhtégn: Iriartella setigera (kakua) [Patricia Gómez, Taina, Vaupés, com. pers., 2004]

983. sagu: Phytelephas schottii (cuna) [Duke, 1972, como $P$. seemannii]

984. sãk ${ }^{\mathrm{h}}{ }^{\prime}$ da: Indeterminda (embera) [Llerena, 1994, como sãqhu'da en la fuente]

985. sakuá: Indeterminada (tunebo) [Romayne, 1997]

986. samake: Elaeis oleifera (cuna) [Duke, 1972]

987. sansagarra: Bactris pilosa (embera) [Henderson, 2000]

988. sapohe: Attalea butyracea (cofán) [Cerón, 1995]

989. sarayá: Indeterminda (tunebo) [Romayne, 1997]

990. sehua: Phytelephas tenuicaulis (siona) [Henderson, 1995

991. séina: Indeterminada (kogui) [Reichel-Dolmatoff 1985]

992. seitabaha: Elaeis oleifera (kogui) [Carbonó de la Hoz, 1987]

993. seitaboka: Indeterminada (kogui) [Ortiz, 1994]

994. sewa: Phytelephas sp.(secoya) [Vickers \& Plowman, 1984]

995. shakalaka: Indeterminada (kogui) [Ortiz, 1994]

996. shakána: Acrocomia aculeata (damana) [Reichel-Dolmatoff, 1989]

997. shimbu: Oenocarpus minor (siona) [Henderson, 1995, como $O$. mapora]

998. shishihe: Phytelephas macrocarpa (cofán) [Cerón, 1995]

999. shishihe: Phytelephas tenuicaulis (cofán) [Borchsenius et al., 1998]

1000. shishká: Indeterminada (kogui) [Reichel Dolmatoff, 1985]

1001. shúnu: Indeterminada (kogui) [Reichel Dolmatoff, 1985]

1002. siba: Indeterminda (tunebo) [Romayne, 1997]

1003. síbim: Oenocarpus bacaba (kakua) [Patricia Gómez, Taina, Vaupés, com. pers., 2004]

1004. sieñe: Astrocaryum ciliatum (andoque) [Galeano, 1991, como $A$. sciophilum]

1005. sieñe: Astrocaryum ciliatum (uitoto) [Sánchez, 1997, como $A$. sciophilum]

1006. sikisikiboto: Leopoldinia piassaba (sikuani) [Sánchez, 1989]

1007. siməse: Oenocarpus bataua (yagua) [Chaumeil, 1998]

1008. sin nuar: Bactris coloradonis (cuna) [Henderson, 2000]

1009. siná: Mauritiella armata (piaroa) [Guánchez \& Romero, 1998]

1010. sínkuacha: Indeterminda (tunebo) [Romayne, 1997]
1011. sirá: Astrocaryum urostachys (secoya) [Balslev et al., 1997]

1012. sirá: Astrocaryum urostachys (siona) [Balslev et al., 1997]

1013. siri: Indeterminada (ika) [Zalabata, 1995]

1014. sisi nehéame: Bactris killipii (muinane) [Kronik et al., 1999]

1015. sisimohomo: Bactris hirta (muinane) [Galeano, 1991]

1016. sisimúrr: Prestoea decurrens (embera) [Aguirre, inédito, como indet.]

1017. sitanó: Bactris fissifrons (andoque) [La Rotta 106 (COL), 1982]

1018. sítuma: Oenocarpus bataua (tunebo) [Romayne, 1997]

1019. sná: Euterpe precatoria (kogui) [Carbonó, 1987]

1020. soaira: Geonoma sp. (barí) [Stephen 1977]

1021. sodyabatú: Oenocarpus minor (andoque) [Galeano, 1991, como O. mapora; La Rotta 131 (COL), 1982]

1022. sokarrõ: Oenocarpus bataua (waunana) [Bernal \& Galeano, 1993]

1023. sokorrong: Oenocarpus bataua (embera) [Balick, 1986a]

1024. som: Indeterminada (puinave) [Hablante anónimo, com. pers., 1994]

1025. soso: Sabal mauritiiformis (cuna) [Duke, 1972]

1026. soto neé: Mauritia flexuosa (secoya) [Vickers \& Plowman, 1984]

1027. supi: Bactris gasipaes (embera) [Patiño, 1960]

1028. sute dédé: Geonoma deversa (siona) [Borchsenius et al., 1998]

1029. sute ëne: Bactris simplicifrons (siona) [Borchsenius et al., 1998]

1030. taaba móomoo: Bactris riparia (muinane) [Kronik et al., 1999]

1031. taaba néhe: Astrocaryum jauari (muinane) [Kronik et al., 1999]

1032. taagaho: Oenocarpus bacaba (muinane) [Galeano, 1991]

1033. taagaiho: Oenocarpus sp. (uitoto) [Kronik et al., 1999]

1034. taahiyie: Manicaria saccifera (miraña) [Galeano, 1991]

1035. taaudau: Phytelephas seemannii (waunana) [Binder et al., 1995]

1036. tabahiyui: Geonoma pycnostachys (muinane) [Urrego 1660 (COL), 1990]

1037. tado: Lepidocaryum tenue (andoque) [La Rotta 116 (COL), 1982]

1038. tagará: Indeterminada (cuna) [Victor Petrucci, com. pers., 2005]

1039. tai': Oenocarpus minor (nukak) [Cabrera et al., 1999, como $O$. mapora]

1040. táina: Indeterminada (piapoco) [Reinoso, 1993]

1041. takimiku: Socratea exorrhiza (muinane) [Kronik et al., 1999]

1042. takone: Astrocaryum chambira (andoque) [La Rotta 134 (COL), 1982; Henderson 1995]

1043. tananako: Mauritiella aculeata (cofán) [Cerón, 1995]

1044. tapú: Wettinia radiata (embera) [Bernal 2143 (COL), 1995]

1045. tapúrbü: Attalea allenii (waunana) [Hablante anónimo, Bajo San Juan, Chocó, 1998]

1046. tapuru: Attalea cuatrecasana (embera) [Bernal \& Galeano, 1993]

1047. tarábwa mĩhî́: Euterpe oleracea (desano) [Luz Mila Santa Cruz y Matilde Arango, Naná, Vaupés, com. pers., 2004]

1048. tarapắnẽ: Euterpe oleracea (desano) [Bernardita González, Naná, Vaupés, com. pers., 2004]

1049. tataba: Geonoma deversa (miraña) [Galeano, 1991]

1050. tátəchi: Astrocaryum chambira (yagua) [Chaumeil, 1998]

1051. tau né: Manicaria saccifera (tikuna) [Prado, 2008]

1052. tau ya: Dictyocaryum ptarianum (tikuna) [Prado, 2008]

1053. tayó: Iriartella setigera (puinave) [Schultes 13729 (COL), 1951]

1054. te hế: Astrocaryum gynacanthum (kakua) [Arbino Furia, Taina, Vaupés, com. pers., 2004]

1055. teevidá: Mauritia flexuosa (tariano) [Domingo Muniz y Jhon Batista, Piriquito, Brasil, com. pers., 2004]

1056. tegpayage: Lepidocaryum tenue (miraña) [Galeano, 1991]

1057. tema: Mauritia flexuosa (tikuna) [Prado, 2008]

1058. tema chikü: Mauritia flexuosa (tikuna) [Prado, 2008] 
1059. téma: Mauritia flexuosa (tikuna) [Prado \& Torres, 2004] 1060. tero beña: Bactris gasipaes (uitoto) [Kronik et al., 1999] 1061. tërukë: Oenocarpus bataua (nukak) [Cabrera et al., 1999] 1062. teuíra: Mauritia flexuosa (tariano) [Pedersen \& Balslev 1990] 1063. tewi: Mauritia flexuosa (baniva) [Guánchez \& Romero, 1998] 1064. tëwpëdë: Bactris maraja (nukak) [Gutiérrez 011 (COL), 1995] 1065. thếñó: Astrocaryum gynacanthum (wanano) [Avelino González \& Gustavo Trinidad, Taina, Vaupés, com. pers., 2004]

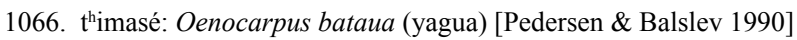

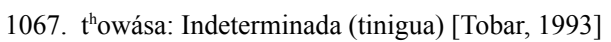

1068. ti aakaiba: Chamaedorea pauciflora (miraña) [Henderson, 1995] 1069. tidori: Astrocaryum gynacanthum (uitoto) [Bernal 2075 (COL)]

1070. ṫehakimox: Desmoncus polyacanthos (muinane) [Kronik et al., 1999]

1071. tiiyaña: Mauritiella aculeata (miraña) [Sánchez 1652 (COL), 1988]

1072. tíña: Mauritia carana (curripaco) [Eliana Garrido, Mitú, Vaupés, com. pers., 2004]

1073. tinuikore: Geonoma macrostachys (uitoto) [Kronik et al., 1999]

1074. tiraña: Desmoncus polyacanthos (uitoto) [Sánchez, 1997]

1075. tíyaña: Mauritiella aculeata (uitoto) [Kronik et al., 1999]

1076. tüù: Bactris gasipaes (yuhup) [Ospina, 1999]

1077. tóchi: Oenocarpus bacaba (yagua) [Chaumeil, 1998]

1078. tokët: Mauritia carana (kakua) [Arbino Furia, Taina, Vaupés, com. pers., 2004]

1079. tomohonase: Attalea butyracea (yagua) [Chaumeil, 1998]

1080. tonobá: Attalea allenii (embera) [Bernal 1149 (COL), 1986]

1081. tóókëI’'ìbà: Indeterminada (miraña) [Seifart, 2002]

1082. toókee: Syagrus smithii (miraña) [Henderson, 1995]

1083. tooyige: Euterpe precatoria (miraña) [Galeano, 1991]

1084. torko: Indeterminada (ika) [Zalabata, 1995]

1085. tosoremi: Indeterminada (carijona) [Robayo, 1993]

1086. tosu: Indeterminada (embera) [Aguirre, inédito]

1087. tótóse: Astrocaryum ferrugineum (yagua) [Chaumeil, 1998]

1088. totue: Euterpe catinga (miraña) [Sánchez, 1997]

1089. towihiboto: Attalea insignis (sikuani) [Sánchez, 1989]

1090. toxoloboto: Oenocarpus bataua (sikuani) [Sánchez, 1989]

1091. trupa: Oenocarpus bataua (embera) [Pedersen \& Balslev, 1990]

1092. tsa tsa ghasa: Indeterminada (embera) [Llerena, 1994]

1093. tsao he tsi: Geonoma polyandra (cofán) [Henderson, 1995]

1094. tsashá: Indeterminada (kamsá) [Howard, 1972]

1095. tseneboto: Mauritiella armata (sikuani) [Sánchez, 1989]

1096. tseneneboto: Indeterminada (cuiba) [Merchán, 1993]

1097. tsitsihu: Oenocarpus bataua (bora) [Pedersen \& Balslev, 1990]

1098. tsozüìsa: Euterpe precatoria (tinigua) [Tobar, 1993]

1099. tuchi: Bactris corossilla (tikuna) [Prado, 2008]

1100. tuchi: Bactris simplicifrons (tikuna) [Prado, 2008]

1101. tuchiwa: Euterpe precatoria, la var. más sabrosa (tikuna) [Prado, 2008]

1102. tuhe kumee: Oenocarpus bataua (muinane) [Kronik et al., 1999]

1103. tuí: Lepidocaryum tenue (puinave) [Schultes 14736 (COL), 1951]

1104. tuí: Mauritia carana (puinave) [Schultes 19216 (COL), 1953]

1105. tuinfa: Astrocaryum chambira (cofán) [Cerón, 1995]

1106. tukira: Manicaria saccifera (embera) [Bernal \& Galeano, 1993]

1107. tukomeku: Attalea microcarpa (muinane) [Sánchez, 1997]

1108. tứkür: Manicaria saccifera (waunana) [Binder et al., 1995]

1109. tumá pakurú: Geonoma divisa (embera) [La Rotta 619 (COL), 1985]
1110. tuntu: Desmoncus giganteus (siona) [Borchsenius et al., 1998]

1111. turuma huikorao: Desmoncus mitis (uitoto) [Kronik et al., 1999]

1112. tute dede: Geonoma pycnostachys (siona) [Balslev et al., 1997, como G. stricta]

1113. túte sewa: Ammandra decasperma (siona) [Henderson, 1995]

1114. tuugiku inóho: Mauritia flexuosa (muinane) [Kronik et al., 1999]

1115. tuugiku kinena: Mauritia flexuosa (uitoto) [Kronik et al., 1999]

1116. tuuguiye móomoo: Bactris gasipaes (muinane) [Kronik et al., 1999]

1117. tuuguiyi: Euterpe precatoria (muinane) [Sánchez 546 (COL), 1988]

1118. tuuko: Attalea racemosa (muinane) [Kronik et al., 1999]

1119. tuumo hahéku: Geonoma sp. (muinane) [Kronik et al., 1999]

1120. tuutuku: Bactris maraja (muinane) [Kronik et al., 1999]

1121. ú baká: Iriartella setigera (nukak) [Cárdenas \& Politis, 2000]

1122. ua kinena riaña: Mauritia sp.(uitoto) [Kronik et al., 1999]

1123. uaibi: Attalea maripa (puinave) [Guánchez \& Romero, 1998]

1124. udatiñore: Bactris acanthocarpa (uitoto) [Galeano \& Huitoto 1306 (COL), 1987]

1125. udkám: Astrocaryum acaule (puinave) [Bernal 2107 (COL), 1994]

1126. uehirí: Attalea maripa (yukuna) [José Yepes Matapí \& Elí Yukuna, La Pedrera, Amazonas, com. pers., 1991]

1127. uheeka: Chamaedorea pauciflora (muinane) [Kronik et al., 1999]

1128. $u^{\mathrm{h}}$ púño: Iriartella setigera (piratapuyo) [Carlos Acosta, Ibacaba, Vaupés, com. pers., 2004]

1129. uicheparo kinena: Mauritia flexuosa (uitoto) [Kronik et al., 1999]

1130. uigonokidye: Astrocaryum chambira (uitoto) [Kronik et al., 1999, como A. aculeatum]

1131. uihuiyo: Geonoma sp. (yukuna) [José Yepes Matapí \& Elí Yukuna, La Pedrera, Amazonas, com. pers., 1991]

1132. uitłnigi: Bactris maraja (uitoto) [Galeano, 1991]

1133. uiyodyi: Attalea racemosa (uitoto) [Kronik et al., 1999]

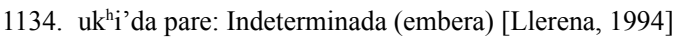

1135. umachúkusu: Bactris simplicifrons (cofán) [Henderson, 2000]

1136. ümeh: Attalea butyracea (bora) [Henderson, 1995]

1137. uná: Bactris gasipaes (siona) [Patiño, 1960]

1138. uné: Bactris gasipaes (yurutí) [María Montoya, Yavaraté, Vaupés, com. pers., 2004]

1139. ũnéño: Bactris gasipaes (tuyuca) [Avelino González, Taina, Vaupés, com. pers., 2004]

1140. ungurahua: Oenocarpus bataua (siona) [Balslev et al., 1997]

1141. upa: Socratea exorrhiza (baniva) [Guánchez \& Romero, 1998]

1142. upeli: Oenocarpus bacaba (baniva) [Guánchez \& Romero, 1998]

1143. ür: Bactris gasipaes (waunana) [Hablante anónimo, Bajo San Juan, Chocó, com. pers., 1998]

1144. urabá: Oenocarpus bataua (embera) [Jaidonesama Domicó, Alto río Sinú, Córdoba, com. pers., 1986]

1145. ure inóho: Mauritiella aculeata (muinane) [Galeano, 1991]

1146. ure maña: Oenocarpus bataua (uitoto) [Kronik et al., 1999]

1147. uréño: Bactris gasipaes (piratapuyo) [Carlos Acosta, Ibacaba, Vaupés, com. pers., 2004]

1148. ũréñu: Bactris gasipaes (tucano) [Norma Nelly Sabana, Naná, Vaupés, com. pers., 2004]

1149. uriá: Mauritiella aculeata (piaroa) [Guánchez \& Romero, 1998]

1150. uriep $^{\mathrm{h}}$ í: Mauritiella armata (tariano) [Domingo Muniz y Jhon Batista, Piriquito, Brasil, com. pers., 2004]

1151. urúkena: Oenocarpus bataua (embera) [Jaidonesama Domicó, Alto río Sinú, Córdoba, com. pers., 1986]

1152. urút ${ }^{\mathrm{h}} \mathrm{a}$ : Oenocarpus bataua (embera) [Key, 2000]

1153. usuk ${ }^{\mathrm{h}}$ ĩs: Indeterminada (embera) [Llerena, 1994] 
1154. ut: Astrocaryum chambira (nukak) [Gutiérrez 08 (COL), 1995]

1155. ut: Bactris hirta (puinave) [Hablante anónimo, Puerto Inírida, Guainía, 1994]

1156. ut agn: Astrocaryum jauari (kakua) [Patricia Gómez, Taina, Vaupés, com. pers., 2004]

1157. üthüberüxanaeboto: Indeterminada (sikuani) [Sánchez, 1989]

1158. uuheuté: Bactris balanophora (muinane) [Galeano, 1991]

1159. vávara: Geonoma deversa (sikuani) [Balick 1202 (COL), 1978]

1160. vea orañi: Indeterminada (koreguaje) [Cook et al., 2001]

1161. vesiriphí: Attalea maripa (tariano) [Domingo Muniz y Jhon Batista, Piriquito, Brasil, com. pers., 2004]

1162. vihiño: Indeterminada (barasana) [García \& Monguí, 1975]

1163. víikume: Geonoma pycnostachys (muinane) [Kronik et al., 1999, como G. stricta]

1164. viiñi: Indeterminada (koreguaje) [Cook et al., 2001]

1165. vuó: Oenocarpus bataua (puinave) [Hablante anónimo, Puerto Inírida, Guainía, com. pers., 1994]

1166. waa: Indeterminada (cuna) [Duke, 1972, como Roystonea sp.]

1167. wàakézi: Indeterminda (piapoco) [Reinoso, 1993]

1168. wãcha ikuti: Indeterminada (sáliba) [Benaissa, 1991]

1169. wächäì: Attalea maripa (piaroa) [Guánchez \& Romero, 1998]

1170. wachi: Manicaria saccifera (cubeo) [Borrero \& Pérez, 2004]

1171. wachó muhî́: Bactris corossilla (wanano) [Bernardo Rodríguez, Naná, Vaupés, com. pers., 2004]

1172. wachó muhî́: Geonoma pycnostachys (wanano) [Bernardo Rodríguez, Naná, Vaupés, com. pers., 2004]

1173. wagaei: Desmoncus cirrhifer (embera) [La Rotta 591 (COL), 1985]

1174. wagai hükára: Desmoncus cirrhifer (embera) [Binder et al., 1995]

1175. wagara: Indeterminada (embera) [Binder et al., 1995]

1176. wágara: Indeterminada (waunana) [Binder et al., 1995]

1177. wa $\mathrm{w}^{\mathrm{h}}$ tu darí: Desmoncus sp. (wanano) [Emilia Gómez, Mitú, Vaupés, com. pers., 2004]

1178. wàh: Oenocarpus bataua (yuhup) [Ospina, 1999]

1179. wáhe: Manicaria saccifera (yukuna) [Henderson, 2000]

1180. wahée: Manicaria saccifera (tanimuca) [Henderson, 2000]

1181. wa káriñu: Iriartea deltoidea (siriano) [María Noemí Uribe, Ibacaba, Vaupés, com. pers., 2004]

1182. waho: Attalea maripa (siona) [Borchsenius et al., 1998]

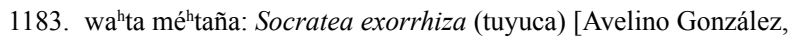
Taina, Vaupés, com. pers., 2004]

1184. wa $a^{\mathrm{h}}$ ta pá ${ }^{\mathrm{h} k a n ̃ o ̃}:$ Iriartea deltoidea (tuyuca) [Avelino González, Taina, Vaupés, com. pers., 2004]

1185. wa tát $^{\text {h }}$ saro: Socratea exorrhiza (tucano) [Hermana Clarisa, Iauarate, Brasil, com. pers., 2004]

1186. wa'táño: Socratea exorrhiza (tucano) [Avelino González, Taina, Vaupés, com. pers., 2004]

1187. wahu: Euterpe precatoria (carijona) [Robayo, 1993]

1188. wahtapahkeño: Iriartea deltoidea (tucano) [Graciliano Lima, Panuré, Guaviare, com. pers., 1999]

1189. waichara: Lepidocaryum tenue (tikuna) [Prado, 2008]

1190. waira: Euterpe precatoria (tikuna) [Victorino Bautista, Leticia, Amazonas, com. pers., 1999]

1191. waítudáh: Desmoncus sp. (tucano) [Avelino González, Taina, Vaupés, com. pers., 2004]

1192. wáketi: Astrocaryum chambira (curripaco) [Eliana Garrido, Mitú, Vaupés, com. pers., 2004]

1193. wakó: Geonoma sp.(secoya) [Guánchez \& Romero, 1998]

1194. walamaboto: Mauritiella aculeata (sikuani) [Luis García, Cumaribo, Vichada, com. pers., 1999]
1195. waltit: Wettinia kalbreyeri (awa pit) [Francisco Guanga, Ricaurte, Nariño, com. pers., 1999]

1196. wamni: Astrocaryum chambira (nukak) [Cárdenas \& Politis, 2000, como A. aculeatum]

1197. warí: Mauritia flexuosa (piaroa) [Guánchez \& Romero, 1998]

1198. wasekumu: Oenocarpus bacaba (carijona) [Robayo, 1993]

1199. wátếgn: Oenocarpus bataua (kakua) [Arbino Furia, Taina, Vaupés, com. pers., 2004]

1200. wati: Manicaria saccifera (curripaco) [Hablante anónimo, Puerto Inírida, Guainía, com. pers., 1994]

1201. watiboto: Manicaria saccifera (sikuani) [Sánchez, 1989]

1202. watipie: Indeterminada (curripaco) [Rojas, 1997]

1203. watosuné: Bactris simplicifrons (siona) [Henderson, 1995]

1204. wawarabotoo: Geonoma deversa (sikuani) [Sánchez, 1989]

1205. wàwó: Oenocarpus bacaba (yuhup) [Ospina, 1999]

1206. weí: Astrocaryum gynacanthum (nukak) [Cárdenas \& Politis, 2000]

1207. well $\mathrm{f}^{\mathrm{y} t u}$ : Indeterminada (páez) [Rojas, 1993]

1208. wepi: Bactris gasipaes (baniva) [Guánchez \& Romero, 1998]

1209. wéger: Astrocaryum standleyanum (waunana) [Bernal \& Galeano, 1993]

1210. werre: Astrocaryum standleyanum (embera) [Binder et al., 1995]

1211. wi: Bactris concinna (siona) [Borchsenius et al., 1998]

1212. wichítua: Synechanthus warscewiczianus (embera) [Bernal 1150 (COL), 1986]

1213. wigirbü: Astrocaryum standleyanum (waunana) [Hablante anónimo, Pichimá, Chocó, com. pers., 1998 ]

1214. withíño: Euterpe precatoria (piratapuyo) [Zeneida Acosta, Iauarate, Brasil, com. pers., 2004]

1215. wikungo: Astrocaryum urostachys (cofán) [Balslev et al., 1997]

1216. wikungo: Astrocaryum urostachys (secoya) [Balslev et al., 1997]

1217. winiko: Wettinia maynensis (siona) [Balslev et al., 1997]

1218. wisiri: Attalea maripa (piapoco) [Pharris de Klumpp, 1995]

1219. wiyapé́nẽ: Bactris gasipaes (secoya) [Vickers \& Plowman, 1984]

1220. wõ: Indeterminda (tuyuca) [Key, 2000]

1221. wo: Oenocarpus bataua (puinave) [Triana, 1985]

1222. wochachi chikü: Hyospathe elegans (tikuna) [Prado, 2008]

1223. woibúwa: Indeterminada (guayabero) [Tobar, 1994]

1224. woku: Attalea maripa (tikuna) [Prado, 2008]

1225. wookú: Attalea maripa (tikuna) [Montes, 1995, como indet.]

1226. wuiro ñoõmĩá: Oenocarpus sp. (tanimuca) [Zaleth Cordero, Bogotá, com. pers., 2004.]

1227. xanaeboto: Astrocaryum gynacanthum (sikuani) [Sánchez, 1989]

1228. xü: Oenocarpus bataua (guayabero) [Tobar, 1994]

1229. ya: Indeterminada (kogui) [Ortiz, 1994]

1230. ya'tếgn: Mauritia flexuosa (kakua) [Patricia Gómez, Taina, Vaupés, com. pers., 2004]

1231. yáab butu: Oenocarpus bacaba (nukak) [Cárdenas \& Politis, 2000]

1232. yab: Oenocarpus bataua (nukak) [Cabrera et al., 1999]

1233. yabapút: Indeterminada (jitnu) [Buenaventura, 1993]

1234. yaimu deku: Bactris hirta (muinane) [Sánchez, 1997, como llaimu deku]

1235. yak: Mauritia flexuosa (kakua) [Arbino Furia, Taina, Vaupés, com. pers., 2004]

1236. yakorchít: Indeterminada (jitnu) [Buenaventura, 1993]

1237. yakuere: Attalea plowmanii (yukuna) [José Yepes Matapí \& Elí Yukuna, La Pedrera, Amazonas, com. pers., 1991]

1238. yakwera: Attalea insignis (yukuna) [Sánchez, 1997]

1239. yaósa: Bactris gasipaes (tinigua) [Tobar, 1993] 
1240. yaṕ: Attalea sp. (secoya) [Vickers \& Plowman, 1984]

1241. yapó: Attalea sp. (cubeo) [Hablante anónimo, Naná, Vaupés, com. pers., 2004]

1242. yarí: Astrocaryum chambira (piaroa) [Guánchez \& Romero, 1998 , como Astrocaryum sp.]

1243. yarina: Attalea maripa (uitoto) [Galeano, 1991]

1244. yariyi: Attalea insignis (uitoto) [Galeano, 1991]

1245. yaro: Oenocarpus bataua (baniva) [Balick, 1986a]

1246. yäu: Oenocarpus bataua (baniva) [ Guánchez \& Romero, 1998]

1247. yaw kü: Attalea plowmanii (tikuna) [Prado, 2008, como yau kü]

1248. yavekohañu: Oenocarpus bataua (cubeo) [Zarucchi 1833 (COL), 1976]

1249. yawalaboto: Acrocomia aculeata (sikuani) [Sánchez, 1989]

1250. yayoer: Bactris balanophora (uitoto) [Galeano \& Huitoto 1280 (COL), 1987]

1251. yerena: Oenocarpus minor (uitoto) [Kronik et al., 1999, como $O$. mapora]

1252. yiha déré: Geonoma macrostachys (siona) [Borchsenius et al., 1998]

1253. yiiri: Hyospathe elegans (uitoto) [Galeano, 1991]

1254. yïsu: Euterpe catinga (muinane) [Galeano, 1991]

1255. yipirie: Astrocaryum jauari (miraña) [Galeano, 1991]

1256. yod pi: Euterpe precatoria (puinave) [Hablante anónimo, Puerto Inírida, Guainía, com. pers., 1994]

1257. yoíbot: Indeterminada (jitnu) [Buenaventura, 1993]

1258. yopiboto:Indeterminada (cuiba) [Merchán, 1993]

1259. yopihiboto: Astrocaryum jauari (sikuani) [Luis García, Cumaribo, Vichada, com. pers., 1999]
1260. yorod: Indeterminada (puinave) [Hablante anónimo, Puerto Inírida, Guainía, com. pers., 1994]

1261. yot: Euterpe precatoria (puinave) [Schultes 14865 (COL), 1951, como yawt]

1262. yot pigot: Euterpe catinga (puinave) [Triana, 1985]

1263. yot pigot: Euterpe precatoria (puinave) [Triana, 1985, como E. oleracea]

1264. yúbudi: Euterpe precatoria (nukak) [Cárdenas \& Politis, 2000]

1265. yuimiku: Geonoma pycnostachys (muinane) [Sánchez, 1997, como G. stricta var. piscicauda]

1266. yuipa: Leopoldinia pulchra (puinave) [Hablante anónimo, Puerto Inírida, Guainía, com. pers., 1994]

1267. yuitsára: Indeterminada (cocama) [Victor Petrucci, com. pers., 2005]

1268. yum: Oenocarpus bataua (puinave) [Triana, 1985]

1269. yurua: Iriartella setigera (piaroa) [Guánchez \& Romero, 1998]

1270. yúutëgn: Bactris gasipaes (kakua) [Patricia Gómez, Taina, Vaupés, com. pers., 2004]

1271. ziiyana: Mauritiella aculeata (uitoto) [Sánchez, 1997, como ziillana]

1272. zitoakai: Bactris fissifrons (uitoto) [Sánchez, 1997]

1273. zobina himena: Bactris gasipaes (uitoto) [Sánchez, 1997]

1274. zuhé: Geonoma maxima (cofán) [Cerón, 1995]

1275. zuteyecho: Prestoea schultzeana (cofán) [Cerón, 1995] 